


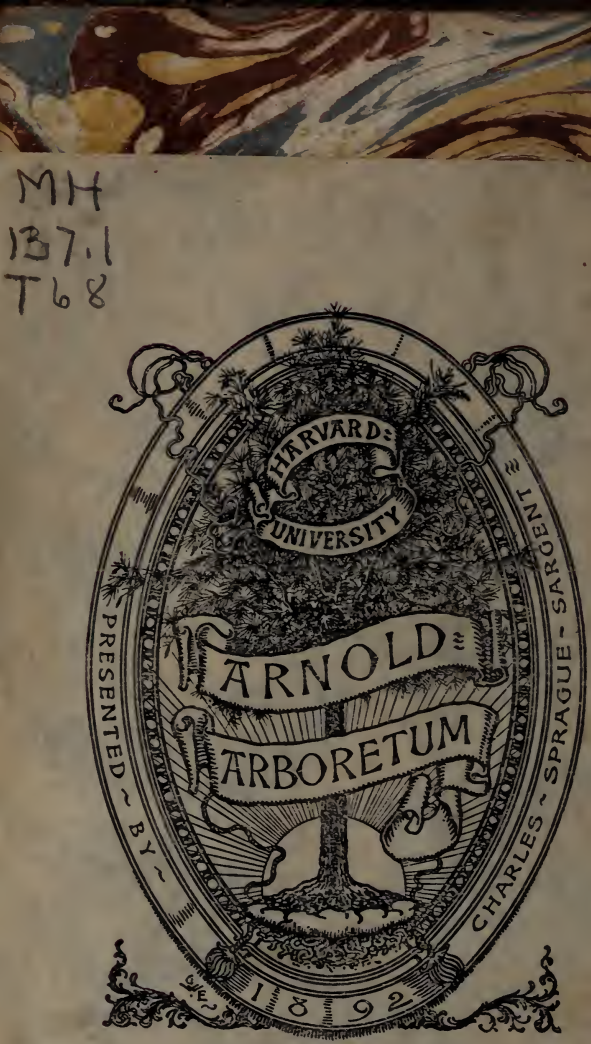





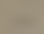




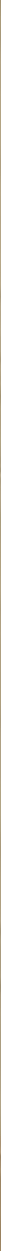



$\mathrm{T} R \mathrm{~A} I \mathrm{~T} E$

C O M P L E T

DE L A C U L T U R E

DES ORANGER S

E T

\section{DES CITRONNIERS,}

LA Manière de les élever, de les greffer, de les tranfplanter, de leur faire produire de belles Fleurs $\&$ de bons Fruits; avec la Defeription d'une bonne Serre, le temps où l'on doit $\mathrm{y}$ renfermer les Orangers, \& la Manière de les conferver:

\section{S U I V I}

D'Un Traité de la Culture des Grenadiers, Genets, Jafmins, Lauriers, Myrtes, \& $\boldsymbol{z}$ autres A rbuftes quî fervent d'ornemens aux Jardins, après les Urangers,

$$
\begin{aligned}
& \text { Prix, } 30 \text { fols relié. } \\
& \text { A P A R I S, }
\end{aligned}
$$

Chez L A M Y , Libraire, quai des Auguftins:

$$
\text { M. D C C. L XXXII. }
$$

Ayrc Approbation, et Privilzge du Rot, 


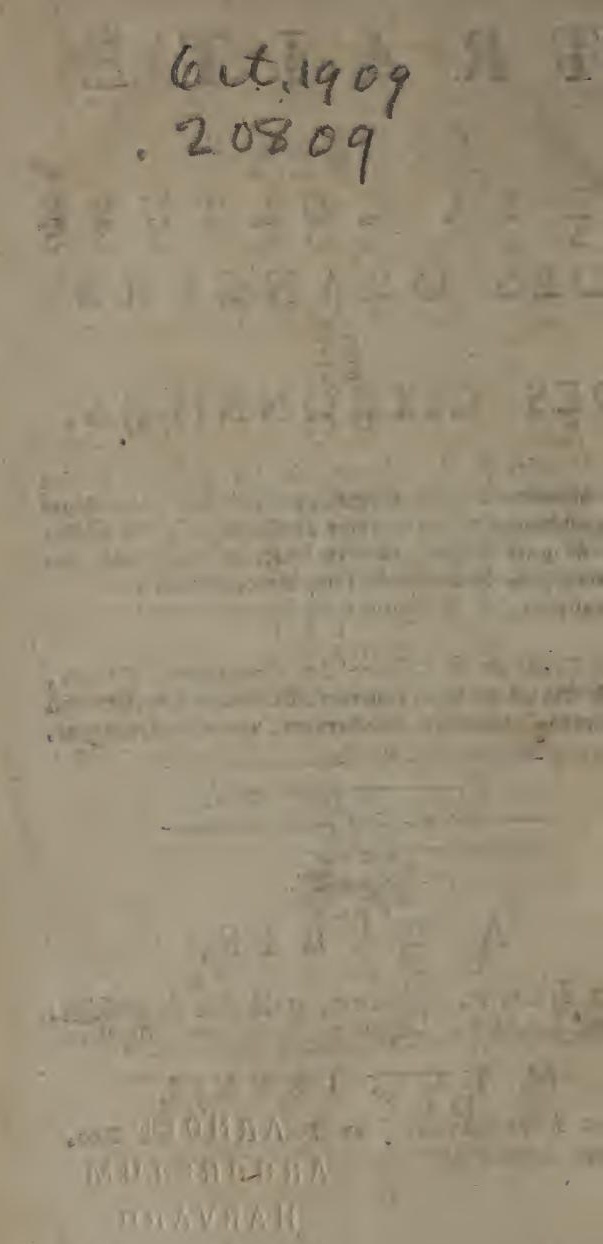




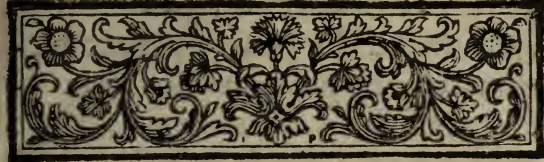

NOUVEA U

T R A I T E'

DES

ORANGERS E T

CITRONNIERS;

C O N T E A N T

La maniére de les connoître, les façons qu'il leur faur faire pour les bien cultiver, \& la vraie methode qu'on doit garder pour les conferver.

CHAPITRE PREMIER.

Deffein \& divifion de l'Auteur. UEL QUE fecond que Q $\mathrm{a}$ 能 foir ce fiécle en Livres, aresem d'autres matieres, je n'aunbitionne pas cependant de m"ériger 
2 Deffein of divifion

en Auteur. Je pourrois veritablement traiter de mon métier peutêtre auffi-bien qu'un autre, aiant toûjours pris foin de m'inftruire de tout ce qui le regarde. C'eft dans cette veuë qu'apres un long apprenriffage, j’ai crû devoir voiager, non feulement dans les Provinces de France les plus curieufes en fleurs $\&$ en fruits de toutes fortes, mais encore dans les païs voifins, comme l'Italie, où j’ai jugé qu'il y avoit quelque chofe à apprendre. A mon retour j'ai eu le bonheur d'être emploié à la culture \& à la conduite d'un des plus beaux Jardins qu'il y, ait dans ces quartiers. L'affiduité \& le fuccez avec lequel j’ai tâché de m'en acquiter, m'a attiré les bonnes graces \& les bienfaits du maître que j'ai eû l'honneur de fervir, \& en même-temps l'amitié d'une partie de ceux de ma profelfion, \& l'envie des aurres. Les premiers fe font fait un plaifir de me voir quelquefois travailler, \& n'ont pas dédaigné de me preffer de leur faire part des connoiflances que j'ai ac- 


\section{'de l'Auteur.}

quifes. Leurs follicitations réite rées m’y ont enfin engagé ; \& comme c'eft touchant les Orangers \& les Citronniers qu'ils m'ont paru plus empreflez, fous pretexte qu'aiant parcouru la Provence \& les autres païs où ils font communs, je pouvois mieux fçavoir ce que c'en étoit, \&z qu'effectivement je gouvernois affez heureufenent ceux que $j$ 'avois en charge; je me fuis déterminé à leur donner cette fatisfaction, \& à rediger par écrit dans les heures de mon loifir, la methode que je pratique là-delfus, \& mes remarques fur celles des aum tres qui s'y appliquent, ou qui en ont écrit.

Je ne puis auparavant m'etnpê_cher de témoigner de l'indignation contre ceux qui pour détourner le monde de la culture des Orangers, ou par d'autres veuës intereffées, éxagerent d'une maniere outrée, la peine \& la difficulté qu'il y a à y réufir, \& les frais immenfes aufquels on s'engage.

Les uns le font par averfion pour 
4. Deßein o divifion

des arbres dont on retire, difent-ils, fi peu d'utilité, tandis que des Poiriers, par éxemple, nous réjouiiffent \& nous charment fucceffivement toute l'année; tantôt la veuë par la beauté de leurs fleurs, \& enfuite par celle de leurs fruits; tantôt lodorat par le parfum agreable qu'ils exhalent ; \& tantôt le goût par les diverfes qualitez de la chair caffante \& fucrée des uns, beurrée \& fondante des autres, \&c. leur bois même tout mort \& inutile quil devient aprés avoir épuifé fa fecondité, fert à mille embelliffemens, ou befoins de la vie; au lieu que des Orangers chargez pour ainfi dire en tout temps des mêmes dépoïilles, he nous donnent que peu de fleurs, encore moins de fruir, \& ne peuvent être emploiez à rien, fi malgré nôtre vigilance, le froid, ou quelqu'autre accident fâcheux, vient à leur ravir le principe de vie qui les anime.

Ces raifons affez plaufibles peuvent frapper \& prévenir les amateurs des jardinages en faveur de ce 


\section{de l'Auteur.}

quii eft de plus commun \& de plus fructueux, mais non pas donner J'exclufion à des arbres qui outre la proprieté qu'ils ont de nous tracer par leur état toûjours verdoiant, tne idée de l'érernité de l'Erre fupréme qui les a créez, font encor dignes de nos foins \& de nôtre eftime par plufieurs autres ufages dont nous pourrons parler, \& même en ce qu'ils nous coutent davantage; de la mêne maniére que ce qui fair le plus grand prix des perles \& des pierres précieufes, n'eft autre à mon avis, que les dangers aufquels on s'expofe, \& les travaux qu'il faut effuier pour en faire la recherche.

Er en effer, s'il n'eft rien que l'on: ne fafle aujourd'hui pour fatisfaire certe fuperiorité que l'homme a reçûc fur les choles terreftres, ici applaniflant des montagnes, la forçant le courant des eaux, \& furmontant ailleurs en mille autres manieres les difficultez que la nature avoit oppofées à nos plaifirs; pourroit - on negliger des arbres $f i$

$$
\text { A iij }
$$




\section{Deffein o divifion}

prêts à y répondre en toute faifon, par la feule raifon que pour les accoûtumer à nôtre climat, il faut une dépenfe qui furpalfe celle qu'on eft obligé de. foûtenir pour les autres arbres fruitiers ? furtout quand on verra, comme on pourra le reconnoître par la pratique des inftructions que j'efpere donner, que cette dépenfe eft bien éloignée de l'excez qu'on avoit eu lieu de fe perfuader, à en croire ces autres, qui par un interêt mal conduit, ou pour tirer une fauffe gloire de leur Çavoir, ont tellement groffi les difficultez, qu'ils auroient pû rebuter les curieux touchez de cette belle inclination, fi elle n'avoit été fondée fur des charmes trop fenfibles pour ne pas l'emporter \& prevaloir fur tour le refte.

Ma penfée n'elt pas de prendre le contrepied de ces deux fortes de perfonnes, pour tâcher d'engager indifferemment un chacun dans la Culture des Orangers, en infpirant qu'il n'êt rien de plus aifé ni qui demande moins d'affiduité. Ce feroit 
à mon avis romber dans une extremiré contraire à une longue experience, \& dangereufe pour ceux qui fans des facultez convenables donneroient dans ce parti. Ce n'eft pas qu'on ne pût foûtenir qu'il n'y a pas plus de myltere \& de travail à élever \& entretenir un Oranger, que plufieurs arbres en Efpaliers qui font devenus affez communs. Mais comme l'utilité de ces derniers fait oublier rout ce qu'ils coutent de peine \& de fueurs ; je tronve fort jufte qu'on ne fonge a avoir des Orangers qu'aprés avoir premiérement pourvû à ce qui eft de plus de rapport, comme devant être le principal objer d'une prudenre œconomie; à moins qu'on ne foit en état de ne fe rien épargner, ainfi qu'il arrive aux Grands \& aux aifez; ou qu'on ne garde par rapport à eux, cette proportion du plus au moins, qui fans être à charge ne laiffe pas de faire trouver dans peu, les mêmes plaifirs \& les mêmes agrémens, que ceux là goutent dans une prodigue, mais chere abondance. 
8 Deffein o divifion

Je finirai ce préambule par un avertiffement, que ce qui fera dit des Orangers, fe doit entendre des Citronniers \& de toutes les efpeces qui $f_{e}$ rapportent à ces deux arbres; puis quils fe cultivent d'une égale maniere. Ces derniers ont même cela d'avantageux qu'ils viennent plus facilement \& rapportent plûtôt ; au lieu que les Orangers ne répondent que pluftard aux foins qu' on en prend, \& à la culture qu'on leur donne.

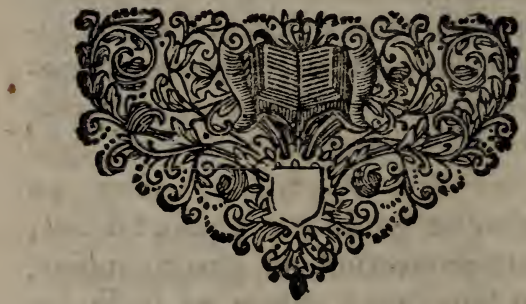




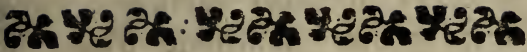

\section{HA P I T E II.}

Maniere d'élever des Orangexs \& Citronniers, foit de pepin, de bouture, ou de marcotze.

$N$ ne peut difconvenir que l'homme ne foit beaucoup mieux partagé en ce qui concerne les Oranges \& les Citrons, qu’à l'égard de beaucoup d'autres fruits deftinez à fon ufage. L'art \& l'induftrie ont tellement fuppléé au petit nombre qu'on en connoiffoit autrefois, qu'aujourd'hui l'on en conte de plus de quatre-vingts efpeces. On voit leur dénombrement dans l'inftruction fur les Orangens \& les Citronniers, imprimée en 1685. qui contient auffi-bien qu'un autre petic traité fur cette matiere, plufieurs bonnes remarques fort utiles que les curieux y peuvent voir.

Il eft yrai que nonobftant les dif 
ferences fenfibles qu'il y a entre cetre grande multitude d'efpéces, elles fe reduifent à ces feules qualitez, d'aigres, de douces, \& d'aigres-douces. Les meilleures des Oranges aigres font, comme tout le monde fçair, les Bigarades. Parmi les douces, les Oranges de Portugal, des Indes \& de la Chine font les plus renommées, mais celles des Indes \& de la Chine dégénerent beaucoup en ces quartiers. Celles qui font trop doucereufes font à rebuter. On en fair plus de cas, lorfque cette douceur eft relevée par une petite pointe aigrelette, comme l'ont celles de la troifiéme efpece. On juge de la quantité du jus des uns $\&$ des autres, à leur écorce fine \& deliée, même parmi les Bigarades \& leurs femblables, qui l'ont cornuë \& mal unie. Celles dont l'écorce eft plus épaiffe \& plus grofliere, en ont le moins, quelque pefantes qu'elles paroiflent à la main.

Quant aux Citrons, le fruit du Cedrat qu'on peut dire en être la 


\section{des Orangers, of c. IT}

principale, ou du moins la plus groffe efpece, eft le plus odoriferant; il eft doux \& d'une forme oblongue, auffi-bien que les Limons qui fone aigres \& moins gros : j'en ai vû cependant d'une groffeur prodigieufe à Nice. Les Citrons parmi lefquels il y en a d'aigres \& de doux, auffi-bien que des Poncires, font les plus petits \& abondent moins en jus ; auffi ont-ils l'écorce plus groffe \& plus raboteufe que les Fruits precedens.

Il feroit inutile de s'arrêter plus long-tems à ces differences d'efpéces d'Oranges \& de Citrons, puis qu'elles fe contentent d'une mêne culture ; celle qui eft entre les Arbres qui nous donnent ces fruits eft auffir affez facile a difcerner pour n'avoir pas befoin d'une longue difcufíon. On connoît les Citronniers à leur écorce jaunâtre, au lieu que les Orangers l'ont d'une couleur grife. Leurs feüilles font auffi differentes dans leur figure, celles des Citronniers n'aiant pas du côté de la queuë cette maniere de cœur 
12

que l'on voit dans les feüilles des Orangers.

Ces connoiffances préfuppofées, il faut venir aux moiens d'avoir de ces Arbres. L'ordre le plus naturel elt d'en élever de pepins. On choifit pour cet effet des Fruits cueillis dans leur parfaite maturité ; on prend les graines qui s'y trouvent, $\&$ aux mois de Mars \& d'Avril on plante ces graines dans des pots, ou dans des caifles pleines de terreau de mouton, \& vieille couche mêlée de terre franche, de marc de vigne \& feiilles pourries, aprés l'avoir premierement arrofé.

Comme l'on n'eft pas fûr com- bien il en levera, on les peur mertre par raions, out dans des trous feparez, à la diftance d'un ou deux pouces. On couvrira enfuite les graines, en forte qu'elles fe trouvent enfoncées dans le terreau, de deux ou trois doigts; on leur donnera de l'eau quand il fera neceffaire, les expofant au foleil chaque jour un peu de rems, jufqu'à ce qu'elles foient levées; \& alors il 


\section{des Orangers, toc.}

faudra les y laiffer tout à fait, \& les éloigner du vent du Nord qui leur eft fort contraire.

$S i$ les Graines réüfiffoient toutes; ou du moins en trop grande quantité, il ne faudroir pas manquer d'en ôter une partie, c'elt-ì-dire celles qui paroîtront les plus foibles; afin que les autres prenant davantage de nourriture, prennent auffi plus d'accroiffement, \&s que les nouveaux plants qui auront poufIé deviennent plûtôt affez forts pour pouvoir être replantez.

A mefure qu'ils croîtront, on leur mettra au pied de nouvelle terre femblable à celle dans laquelle on les aura femez. A deux ou trois ans de là on changera ces fauvageons avec leur petite mote dans des pots feparez, ou autres lieux où ils aient plus d'étenduë. On prendra foin de couper les brins qui poufferont du pied, \& d'arrachor les feüilles $\&$ les épines qui pourroient les relndre noiieux \& tortus; on ne leur épargnera pas les arrofemens ordinaires, ni de frequens petits labours 
convenables à leur delicateffe ; par cette application on trouvera dans cing ou fix ans que ces fauvageons feront en eftat de pouvoir être greffez.

La maniere d'arrofer durant ce tems qu'obfervent quelques-uns m'a paru fort bonne : c'elt de mettre le pot ou la caiffe où l'on éleve ces jeunes plants, dans une fontaine, ou une marre, ou autre vaiffeau, avec de l'eau jufqu’à la moitié du pot ou caiffe. La terre s'arrofe doucement de cette forte fans être lavée \& fans trop s'affailfer. On connoît qu'elle a de l'eau fuffifamment lorfque la fuperficie paroît mouiillée : ce qui arrive trois ou quatre heures aprés que le pot ou caiffe font plongez dans l'eau. Cet arrofement fe fait par attraction, élevant l'humidité du fond à la fuperficie.

Ceux qui trouveront cette maniere d'élever des Orangers \& des Citronniers un peu trop longue, peuvent tenter les moiens d'en faire yenir de bouture \& d'en provigner : 


\section{des Orangers, ofc.}

ce font des expediens qui abregeront chemin de beaucoup.

La bouture fe fait aux mois d'Avril \& de May. Dans le tems qu'on taille les Orangers \& les Citron- . niers au fortir de la Serre, on choifit quelques branches des plus droites \& des plus unies. On les reduit à environ un pied de hauteur; on ratiffe l'écorce par en bas l'efpace de deux ou trois travers de doigt : on coupe auffi le haut, \& on en ôte les fleurs qui peuvent s'y trouver : \& dans cet étar, on plante ces branches éloignées d'environ deux pieds, dans du terream tel qu'il a été dit ci-deffus.

On les enfonce jufqu'à quatre ou cinq travers de doigt, \& on les - laiffe pouffer racine fans y rien faire davantage. Quand on s'apperçoir qu'elles ont pris racine, on les cultive par de petits labours \& par les arrofemens necelfaires. Le fuccez de ce foin eft tel, que dans trois ou quatre ans on peut avoir des Ar. bres qui portent du fruit, principa. lement des Citronniers. 
- Cette maniere eft à la verité pluśs feure dans les Païs chauds, où regulierement les branches d'Orangers \& de Citronniers, \& principalement de Pommiers d'Adam ou de Balotin, reprennent "de bouture auffi facilement que font en ces quartiers les Figuiers, Grofeillers \& autres. On ne laiffe pas cependant d'en voir de fort bons effets en plufieurs Jardins, depuis quon a effaié \& mis en ufage cette experience; \& moi-mêne il eft peu d'années que je n'aie fauvé quelques-uns de ces Arbres avec beaucoup de fatisfaction.

A l'égard du provignement ou marcotte, on le peut mettre en ufage au mois de Mars \& de Septembre. Pour cet effet, aiant choifi la branche d'Oranger ou de Citronnier que l'on veut provigner, on envelope le bas avec une bande de cuir d'un travers de doigt. On coupe auparavant au deflous l'écorce qui occupe cet efpace ; on lie \& ferre la bande de cuir avec de la petite fiffelle poiflée ou cirée, afin qu'elle 


\section{des Orangers, otc.}

qu'elle tienne plus ferme \& ne fe lâche point. On entoure cet endroit de quelque petit vafe fendu \& percé par le fond, à travers du quel la branche forte ; on remplit ce vafe de terreau : on en fufpend au deffus un autre plein d'eau qui la laiffe tomber goute à goute dans celui de deffous, pour l'arrofer infenfiblement, finon on lai donne cette humectation de telle autre maniere que l'on juge à propos. Au bout de fix mois l'on trouve que la branche a affez pris de ra. cines pour la couper, \& la planter dans un lieu feparé plus facieux. $S i$ on ne les croioit pas affez fortes, comme il fe peut faire lorfqu'on ne provigne qu'en Septembre, on pourroit attendre toute une année. Pour n'être pas dans cette peine, on provigne ordinairement au mois de Mars : les beaux jours qui fui vent depuis ce mois-là jufquà l'automne, rendent le fuccez plus: promt \& prefqu'immanquable.

Ceux qui fçavent comment or marcotte les Oeillets, ou qu'on 
provigne les autres Arbres aufquels cette maniere de multiplier eft commune, comprendront aifément tout ce que nous avons dit pour cette operation, ou pourront s'en acquitrer par les voies qui leur feront plus connuës \& plus familieres. Mais ce à quoi l'on doit principalement prendre garde, c'eft lorfque le rems de planter à part la branche provignée eft venu, de la metrre dans une bonne terre telle qu'il fera dit ci-aprés, \& dans une fituation expolée au Soleil ; car par ce moien I'on a,du moins dans les Païs chauds, le plaifir dés l'année fuivante, d'avoir un Arbre pour ainfi dire parfait, puifqu'il commence à porter des fleurs \& du fruit.

L'on conçoit fans doute bien que ce n'eft que fur des Arbres forts que l'on peut provigner, à caufe de la pefanteur des vafes que l'on remplit de terre \& d'eau. Je ne determine point le tems de la Lune auquel il faut le faire; chacun peut te regler là-deffus fuivant fon caprice ou fa commodité, comme étant une 


\section{des Orangers, ofc.}

chofe indifferente. Les opinions partagées que j’ai vû là-delfius, m’ont donné lieu de m'en éclaircir; car les uns voulans que l'on plante, par éxemple,les Pepins au Decours, \& d'autres en pleine Lune, j'ai éprouvé les deux conjonctures, \& les Pepins font venus également bien.

Il en eft de-même de la bouture, quoiqu'on s'accordât mieux à ne la pratiquer qu'au Decours, en taillant, ainfi qu'on le fait ordinairement en ce tems-là ; mais avec trop de fcrupule, puifqu'on le peur auffi en toute autre quadrature. $\mathrm{Er}$ en effet, il eft bien jufte, que quand mềne la Lune auroit quelque afcendant fur les chofes terreftres, elle porte ce refpect à l'Aftre dont elle emprunte fa lumiere, de le laiffer agir feul dans la production des Oranges \& des Citrons, qui font proprement les emblémes du Soleil \& les fruits de fa chaleur.

J'ajoûte encore cette remarque, que les pepins des Citrons \& des Poncires profitent davantage que 
les pepins d'Orangers, parce qu'ils abondent plus en féve ; \& que pour être plus affeuré de ceux qui ont la maturité neceffaire pour réuiffir, on peut prendre les pepins des $\mathrm{O}$ ranges \& Citrons qui font atteints de pourriture, du moins quand on voit que cela ne provient pas de ce qu'ils aient été meurtris, ou autre. ment endommagez.

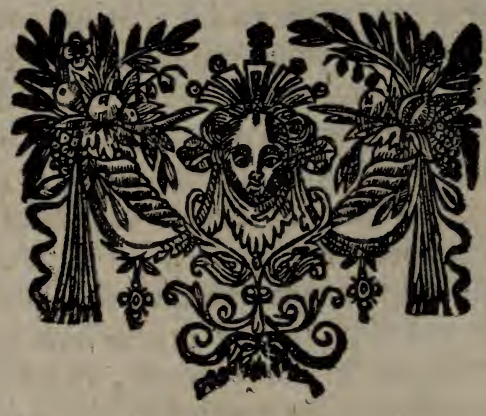




\section{'des Orangers, of. 2 .}

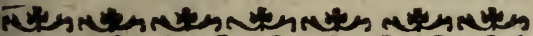
S S* $\leqslant * S * S * S * S * S * S * S *$ $* * 5 * 5 * 5 * 5 * 5 * 5 * 5 * 5 * 5$

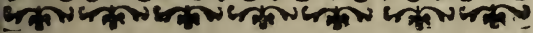

\section{CHAPITRE III.}

Quelles fortes de Greffes conviennent aux Orangers \& $\mathrm{C} i$ tronniers, \& comment on les fait.

Es diverfes fortes de Greffes que l'induftrie de l'homme a fçu mettre en ufage, il n'y en a que deux qui foient pour les Orangers $\&$ les Citronniers. L'une qui eft fort utile \& fort commode, eft de les greffer en approche : voici de quelle façon je m'y prens.

Je coupe en tête le fauvageon qui pour cela doir être raifonnablement gros. J'y fais enfuite une enraille, \& quelquefois une fente pour y pouvoir appliquer la branche, oa rameau de l'Oranger dont je veux avoir de l'efpece. Je coupe un peuz de l'écorce \& du bois des deux câ. 
tez; \& fans autre myftere, je fais entrer ce rameau dans le milieu de l'entaille, \& je couvre le tout avec de la cire ou de la terre glaife que j'envelope de linge, les liant enfemble avec de l'écorce d'arbre, ou de l'ofier, afin que rien ne s'ébranle \& que la greffe ne retourne en arriere comme elle pourroit faire, tenant toûjours à fon principe.

Le mois de Mai eft la veritable faifon pour cette maniere de greffe, qui reprend alors plus facilement par la recontre de la feve des deux Arbres qui eft plus abondante en ce tems - là. On attendra neanmoins jufqu'au mois d'Août à feparer le fauvageon greffé d'avec I'Oranger approché ; ce qu'on fera en coupant ou feiant la branche approchée, directement au deffous de l'endroit où elle entre dans l'entaille.

Une chofe à quoi 'on doit prendre garde, eft de ne pas aller juf qu'à la moëlle, foit en faifant l'entaille au fauvageon, foit en coupant des deux côtez la branche qu'on 
propres aux Orangers, ofc.

veut approcher, ce qui n'eft pas difficile. L'unique embarras que l'on regarde dans certe forte de greffes, eft de faire l'approche avec la branche d'un Arbre affez gros \& haut, fans laiffer encore plus de hauteur au fauvageon; mais cet inconvenient n'eft pas à craindre pour les Arbres qui font en des pots out caiffes, parce qu'on peut les élever autant qu'il faut par le moien de quelque billot ou treteau.

La Greffe à écuffon à ail dormant qui eft la feconde que l'on pratique, demande plus de fujetion. On la met en ufage dans les mois de Juillet, Août \& Septembre : comme l'on y obferve les mêmes chofes que pour les autres Arbres fruitiers, l'ordre que i'y fuis eft tel.

Je prens fur l'Oranger ou Citronnier dont je veux greffer, un rameau d'une branche qui ait deux ans, lequel foit garni de bons yeux. Afin qu'ils ne fe fanent pas facilement, je ne coupe avec les cifeaux les feiiilles entre lefquelles ils font 
$24 \quad$ Des Greffes

que jufqu'auprés de l'endroit ov̀ elles tiennent à leur queuë; c'elt-àdire, que j'en laiffe le bout $\&$ l'extremité, avec quoi je tiens l'écuffon entre mes lévres fans le moüiller de falive, aprés qu'il eft enlevé.

On appelle comme l'on fçait, écuffon, l'œil dont on lê fert pour la Greffe. Je l'enleve ordinairement par une incifion avec le taillant du Greffoir, que je commence un peu au deffus, \& que je pourfuis juf qu'en bas, en coupant delicatement, en forte que l'wil ne foit point offenfé. Sans finir de le détacher, je le remets en place, \& coupe en travers la partie fuperieure pour la faire carrée, \& les deux côtez d'en bas en pointe, ce qui fepare l'œil auquel il faut laiffer un pet de bois qui y tienne. On peut auffi l'enlever fans ces dernieres incifions, en preffant avec le pouce fur les côtez; ce que je n'approuverois pas fi bien pour d'autres Arbres qui auroient moins de féve que les. Orangers \& Citronniers. 
propres thx Orangers, of. 25 Ce quil y a d'important $\&$ de la derniere confequence, eft que le germe interne par où l'œil doit recevoir fa nourriture, \& qui lui répond, foit refté à l'écuffon enlevé. Il n'ett pas moins neceffaire que le fauvägeon qu'on veut greffer ne manque point de féve; ce qui n'arrive gueres autrement, quand le bois eft jemie: ón le connoit aifément dés qu'on applique le greffoir pour faire l'incifion necelfaire, par un perit bruit, caufe, je crois, par l'air qui fe trouvoit avecla féve entre l'écorce \& le bois. Cenx qui font cette incifion avarit que d'enlever l'éculfon, s'expofent à éventer ce fuc effentiel qui doit fervir à coler l'œil fur le fauvageon, parce qu'outre le temps quion met à l'enlever, on ne réuffit pas toûfours àl'avoir d'abord bien conditionné. Pour moi je ne fais jamais l'incifion que la derniere, craignant que quelque foin que je priffe de ne pas déprendre la peau, ou écorce dii fauvageon, la féve ne trouvât encor allez de jour pour $f e$ deflécher.

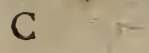




\section{Des Groffes}

La forme de cetre incifion, eft colle d'un grand $T$. Je choifis pour cela fur le corps du fauvageon que je veux greffer, un endroit bien uni, le plus prés de la fuperficie de la terre qu'il eft poffible, afin que le jet qui doit fortir de l'éculfon puiffe faire un arbre bien droit. Je coupe en travers la pelure, appuiant le tranchant du greffoir auffi doucement qu'il le faut pour ne pas offenfer la tige; puis avec la pointe prenant au milieu de cette ligne sranfverfale, $j$ en tire une paralelle en bas qui forme le $T$.

Aprés ces deux coups de tranchant je leve avec le bout applati du manche du greffoir la peau incifée des deux côtez longs, la renverfant à droit \& à gauche fans rien déchirer. Je prens enfuite l'écuffon que je tenois par le bour des feüilles entre mes levres, \& le place en l'endroit que j'ai preparé, en forte que la tête joigne fans aucun vuide à la traverfe incifée, \& que les côtez de l'écorce que j'ai détachez le couvrent entierement a la referve de l’œil. 
propres aux Orangers, of c. 2

Pour faire qu'ils s'uniffent mieux enfemble, je les lie avec un brin de chanvre ou filaffe, que je moüille. prenant garde de trop ferrer audeffous.de l'œil, de peur d'empêcher le cours de la féve qui le doit nourrir; \& que le plant greffé veitant à grofir, ne foit pas étranglé \& fcié. J'arrête cette ligature par un nœud que je fais en paffant le bout du chanvre dans le dernier tour. Au mois de Mars fuivant je coupe le chanvre par derriere a la referve de ce qui tient le haut de l'écullon pour donner liberté à la léve de s'élever; autrement elle ne produiroit au pied qu'une multitude de jets fauvages. Je racourcis à même-temps la tige greffée, à deux oul trois pouces prés del'écuifon; ; afin que la feve mon-tant plus haut, ne néglige pas ce qu'on fouhaite le plus, \& qu'elle foit par là toute emploiée à faire pouffer l'éculfon, L'année d'aprés je coupe l'argot refté tout proche la greffe, le plus proprement que je puis ; \& fi je la vois en état d'y couper quelque chofe \& de l'arrêter

$$
\text { C ij }
$$


$2 S$

\section{Des Greffes}

par le haut, je le fais, prenant foin de commencer à luy donner la difpofition qui felon toutes les apparences, peut faire une têre ronde \& pleine, telle que la doivent avoir les Orangers.

On trouve dans l'Inftruction fur les Orangers \& Citronniers dont nous avons parlé ci-devant, la maniere de rranfporter d'un lieu à d'autre bien éloignez des greffes de ceux qui font les plus beaux quand on n'en eft pas déja pourvû ; ainfi je n'en dirai rien ici, finon que je l'ai vû pratiquer dans plufieurs contrées d'Italie, avec beaucoup de fuccez. Si l'on peut en avoir fans qu'elles foient un auffi long-temps en chemin que cette maniere le fuppofe, on peut fe contenter des précautions que l'on prend ordinairement pour faire venir des Greffes d'autres arbres, \& les tenir le plus fraîchement qu'on peut. Ce qui eft à fouhaiter, c'eft de greffer dans la même lunaifon qu'on a cueillis les Greffes, foir au Decours, comme la plûpart veulent, foit en une autre 
propres aux Orangers, ofc. 29 quadrature, ainfi quisl a été dit au chapitre precédent : il fuffit que ce foit dans un temps qui ne foit $n$ i trop fec, ni trop pluvieux.

On peut greffer indifferenment des Orangers fur des Citronniers ou fur des fauvageons de leur efpece, \& les Citronniers de même. On ne gagne rien dans ce renverfement à l'égard des Orangers; ils poulfent, fi l'on veut, un peu plûtôt fiur des Sauvageons de Citronniers ou Bàlotins; mais auffi ils font plus fujets a fe dépoiiiller. Les Citronnicrs au contraire, outre qu'ils ne perdent rien de leur naturel promt $\&$ facile pour être greffez fir des fauvageons de;Pommiers d'Adam \& d'Orangers, ont cet atantage quilis en refiftent mieux au froid \& aux injures du temps. On raifonnera la-deffus comme on voudra, pour pratiquer, ou pour rejetter, ce que quelques-uns ont propofé, de greffer la moindre efpéce fur la meilleure \& la plus eftimée , par éxemple un Limonnier fur un $\mathrm{Ci}$ tronnier, au lieu qu' on fait com-

$$
\text { C iji }
$$


munément ' tout autrement.

La culture que l'on donnoit aux Orangers \& Citronniers avant que de les greffer, leur doit être conrintiée avec encor plus de foin aprés qu'ils le font. Il faur donc les arrofer à l'ordinaire, labourer \& rafraîchir la terre de temps en temps, ôrer tous les petirs jets \& les feuilles qui pourroient pouffer au pied, \& confumer l'humeur qui doit fervir de nourriture à l'arbre; \& cela jufqu'à ce qu'étant devenus forts comme ils peuvent faire dans deux ans, on les puiffe encaiffer ou planter autrement, de la maniere que je l'expliquerai ci-aprés.

Il y a une autre voie de peupler en peu de temps un jardin de Cirronniers \& d'Orangers, qui parmi nous fait negliger prefque a tout le monde, celles que nous avons décrites. C'êt la commodité qu'on a d'en trouver de tout élevez par le fecours des Marchands étrangers qui en apportent aux mois de Février, Mars, Avril \& May, \& quelquefois auffi 
propres anx Orangers, 0 c. 31 an mois d Octobre. Comme cette voie ne lailfe pas d'a oir fes inconveniens par le danger quil y. a d'être trompé, il eft bon de donner à ceuf́x qui s'en fervent, quelques avis pour pouvoir s'en garentitios \& pour ne pas perdre. le fruit de leur argent, faure de fçavoir planter ces arbres, comme il faut; \& celt à quoy je vai m’apliquer dans le chapirte qui fuit.
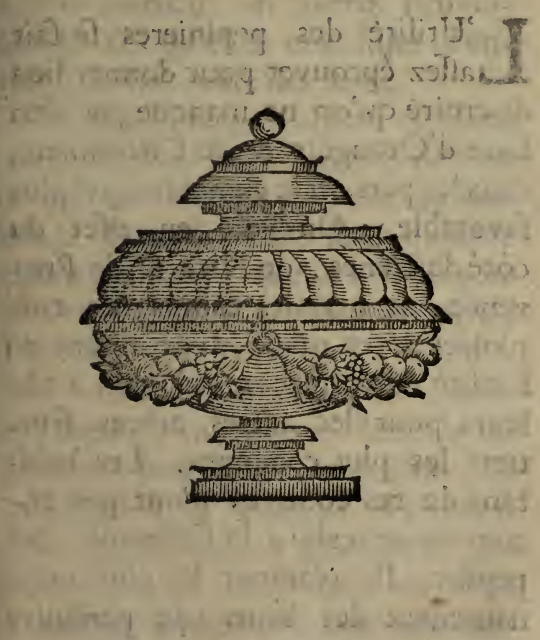

C iiij 
32 Remarques pourtien choifir

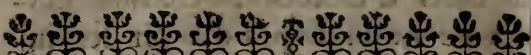

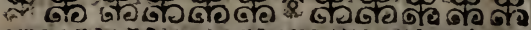

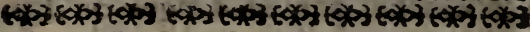

C HAPITRE IV.

Remarques pour bien choifre \& - tranfplanter les Orangers \& Citronniers quion apporte tout élevez, \& greffez.

T Utilité des pepinieres fe fait Laffez éprouver pour donner lieu de croire qu'on ne manque pas d'en faire d'Orangers \& de Citronniers, dans les païs où le climat leur eft plus favorable. On voit en effet du côté de Genes, de Nice \&r de Provence, de grandes campagnes emploiées à cet ufage, avec autant de fucilité '\& de fuccez, qu'on en a ailleurs pour les autres arbres fruitiers, les plus communs. Les habitans de ces contrées riont pas recours pour cela à la feule voie des pepins. Ils plantent le plus ordinairement des brins de pommier 
otransplanter les Orangers, ofc. 35 d'Adam pour les faire venir de bouture, de la maniere que nous avons dic, n'éloignant mêmé les brins les uns des autres que d'un, pied. Ils greffent dans la fuite ces jeunes plants lorfque par le foin quils en ont pris, joint à la bonté du terroir, ils font parvenus à la grolfeur d'environ un doigt : \& c'eft de ces pepinieres dont ils tirent tous les ans a leur avantage \& profir, dequoi enrichir les autres Provinces de ce qu'elles ont fujet d'envier à la fecondité des leurs.

On tranfporte ces arbres de deux manieres; ou avec la mote de terre qui tient à leurs racines, ou fans mote. Potri le faire fans qu'ils fe gâtent, aûfi-tôt que les Orangers $\&$ Citronniers font hors de terre, if on les veut fans mote, on courvre les racines avec de la moulfe \& fougere ; on racourcit leurs branches \& leur tige, reduifant les moindres à la hauteur d'environ deux pieds; on les empaquete enfuite dans de la fougere ou de la moufte, \& on les met dans des caif 
34 Remarques pour bien choifir

fes faires exprés, enforte qu'ils foient à couvere du froid.

On prend les mêmes précautions pour les tranfporter avec leurs motes; en quoi l'on ufe quelquefois d'une fineffe qu'il eft bon d'obferver: car ces motes ne font pas toûtjours naturelles; ; on en contrefaie avec de la glaife ou de terre forte qu'on applique fur les racines; ce qui a deux effers tout à la fois, l'un de conferver ces racines, \& l'autre de tromper ceux qui prévenus de cette maniere, ne remarquent pas que la terre ainfi appliquée, ne s'attache pas fi bien aux racines qu'une mote naturelle.

On lailfe aux Orangers qu'on apd porte en mote des branches \& des feuilles qu'ils confervent, iv c'eft une facilité pour connoître s'ils fe portent bien, la vigueur des unes $\&$ des autres en étant un bon figne. Les antres marques anfquelles on en juge, font que l'écorce foit- d'un verd jaunâtre; qu'elle foit ferme \& non molaffe, \& que par le moien de la féve qui s'y fera confervée, 
or transplanter les Orangers, o. 3 elle quitte te bois facilement, aus lieu d'être dure \& deffechée, telle qu'elle devient lorfque ce fuc alimentaire lui manque. Le bois en doir auffi paroître imbu \& penetré; mais mediocrement, car fi l'on y remarquoit trop d'humidité, elle ne proviendroir tans doute, que de ce que ces arbres auroient été trop arrofez en chemin, \& alors l'écorce en feroit comme pourrie, \& le bois au-deffous auroit une couleur livide \& noirâtre, à laquelle on ne connoîtroir que trop que ce feroir un arbre mort.

Pour s'affurer de toutes ces circonftances, on n'a qu'à couper ou écorcher un peu de la tige auffi-bien que des branches \& des racines, en d's endroits qui ne leur nuifent point, \& qu'on puilfe couper aprés cela : Par ce moien on voit aifement fi un arbre eft tel qu'il faut, quelque peu d'experience qu'on ait d'ailleurs en matiére de jardinages.

Les Orangers \& Cirronniers qu'on veut acheter aiant été choifis fuivant les conditions que nous venons 
36 Remarques pour bien choifir de dire, \& les plus fains \& droits qu'il fe peut, voici ce que l'on doit pratiquer avant que de les planter.

Si ce font de ceux qu'on a apportez fans mote, on lave bien tout le pied avec de l'eau nette pour en oter la terre qu'on y pourra trou-. ver. On taille les racines comme on feroit celles d'un autre arbre fruitier, en coupant toutes les mor-. tes ou meurtries jufqu'au vif, \& retranchant le chevelu qui eft ordinairement fec. On racourcit aufir les branches autant qu'elles le peuvent fouffrir ; ordinairement on les coupe à deux on trois ponces de: la tige.

Il eft bon de faire enfuite tremper le pied de ces arbres dans de l'ea! pour cinq, oti fix heures, \& même davantage, fi l'on ne juge pas quil foit fuffifamment imbu d'humidité. Pendant ce temps - lil, on prefare, fi on ne l'a fait plûtôt, les pots, cailfes, ou mannequins où l'on veut les metrre; on les remplit du même rerreau que nous avons 
- tran/planter les Orangers, \&c. 37 dit ci-devant, ou de quelqu'une des bonnes Terres dont il fera parlé. On laiffe au milieu un trou proportionnè à la profondeur ou hauteur des racines ; \& quand on vient à planter, ce qu'on fait le plus prés du bord de la caiffe qu'il fe peur, on étend \& on arrange foigneufement les racines, afin qu'elles prennent toute la nourrirure qui leur eft neceffaire.

Aprés qu'on les a recouvertes, on leur donne de l'eau qui fait que la terre dont elles la doivent tirer, s'attachent plus facilement à elles. On place les pots ou caiffes en des endroits à l'abri , \& qui foient peu en vûë du. Soleil. Il y en a qui les mettent dans des couches: mais outre qu'elles ne contribuent en rien à l'avancement de ces Arbres à travers les vaiffeaux où ils font, je les crois trop chaudes l'été, quelque part qu'eiles foient fizuées, à moins qu'outre les grandes hamectations, on ne s'aflujettiffe à les couvrir dans les grandes chaleurs, avec des nattes ou paillafions, \& 
38 Remarques pour bien choifir

à les découvrir feulement lorfqu'il fait un tems fombre \& pluvieux. Ces Arbres ont en effer dans ces commencemens plus befoin de fraîcheur \& d'humidité que de beaucoup de chaleur; ainfi je ne voudrois me fervir de couches, qu'au cas qu'on mît les Orangers dans des mannequins, ou pour l'hiver, fi j'étois obligé de lailfer en plein air ces jeunes plants, aufquels je. ferois de plus de bonnes couvertu. res. Ils courront moins de rifque dans la Serre, principalement fi l'on n'avoit eu des Orangers qu'en Octobre, étant alors plus furceptibles de froid, parce que leurs racines ne font pas encore reprifes quand il fe fait fentir. On les laiffe paffer l'année en cet étar ; \& au mois de Mai ou d'Octobre, fuivant qu'on a planté en l'un ou l'autre tems, on les tire des cailfes ou pots oul ils-étoient avec la mote qui s'y eft formée, pour les mettre dans d'autres plus grandes, \& les cultiver enfuite de la maniere qu'il fera dit. 


\section{\% tran/planter les Orangers, o c. 39}

Pour s'exemter d'un changement fi promt, il y en a qui plantent d'abord les Orangers comme l'on feroit au bout de lan ; \& il eft cerrain que cette métode eft tresbonne fi ces Arbres font un peu forts, puifque les tranfplantations \& les remuëmens font autant de crifes dangereufes pour eux.

Ce que l'on doir obferver en ce cas, eft que la Terre foit affairfée quand on plante, finon qu'on la preffe fortement. On prendra garde auffi de placer le pied de l'Oranger le plus haut vers la fuperficie qu'il fera poffible; tant à caufe qu'il jouira mieux de l'afpect du Soleil qu'un plus grand enfoncement lui cacheroit, que parce qu'étant ainfi tenu au deffus, il lui refte davantage de terre dans la profondeur de la caifle ou di vafe, pour étendre fes racines \& pour fe noturir.

Il faut donc pour bien faire que la caiffe foit, par éxemple, fi pleine, \& l'Arbre planté fi haut, qu'on lui voie le gros de fes pre- 
40 Remarques pour bi en $\mathrm{cli} \mathrm{i}$ mieres racines; in forte qu'on ne le puiffe arroler qu'eni mettant autour quatre petits bardeaux ou bouts d'ais, pour retenir l'eau \& la terre, \& que l'Arbre s'abaiffant comme il fait petit à petit par l'arrofement \& par fon propre poids, Se trouve toûjours au haut de la caiffe.

Ceux qui ces dernieres années, fe font dit les Auteurs de cette maniere, n'avoient apparemment pas lû ( non plus que ceux qu'ils ajoûtent s'être récriez contre eux làdelfus) le petit Traité fur la Culxure des Orangers, imprimé il y a fort long-tems, dont nous avons déja parlé. Ils auroient vû que cette métode y eft décrite chapitre cinquiéme. Elle m’a paru fi utile \& fi jufte, quil y a plus de quinze ans que je m'en fers publiquement, \& j'y rétiffis avec fuccez ; c'eft à peu prés ce qu'on fuir à l'égard des Arbres fruitiers de toute efpece. Yoiez le Curé d'Enonville, page 109.

Il y a encore d'autres précautions 
or tranfplanterles Orängers, ofc. 4x à prendre, lorfqu'on n'a point envie de changer fi-tôt, que nous remarquerons dans la fuire; ainfi nous $n^{2}$ en dirons rien ici. Il nous refte feulement à voir ce qu'on fait aux Orangers \& Cirronniers qu'on apporte emmotez. La premiere chofe eft que fi cetre mote eft naturelle, il la faut ôter ainfi que fi elle avoit été appliquée, à l'exception qu'on en laiffe un peu au pied de la tige entre les grolfes racines, $\&$ l'on ne coupe qu'un peu de l'extremité des racines. On la mer enfuite tremper, jufqu'à ce qu'on voie qu'elle eft bien imbibée ; \& on ne l'empote ou encaille qu'aprés qu'on l'a bien laiffé égouter, \& qu'on a retranché de la tête les. petites branches qui la rendent: trop confufe \& d'une forme défagreable. 


\section{\&2 Des Terres}

19 से सु में से मे० से से० से से से

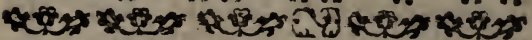

- CHAPITRE V.

Des Terres qui font propres pour les Orangers \& les Citranniers.

Dins la fuppofition que par les degrez que nous avons marquez, les Orangers \& Citronniers qu'on a élevez ou achetez font devenus des Arbres parfaits qui demandent une culture plus forte, nous ne devons pas paffer outre fans parler des Terres qui leur font propres en cet état, comme érant la premiere condition neceffaire à cette culture. C'eft ici qu'on reconnoîtra principalement la facilité qu'il y a d'élever de ces $\mathrm{Ar}$ bres, par les diverfes manieres dont ils fouffient d'être gonvernez; car quoique le terroir où l'on peut être foit bien different de selui des 
propres pour les Orangers, ofc. 43 Païs chauds, où ils croiffent naturellement \& en pleine Terre; il eft certain qu'il y en a de plufieurs fortes où l'on vient égalemént à bout de les faire réûfirir.

L'une de ces Terres eft feche \& legere, compofée de fumier de mouton reduit en terreau \& terre franche, de reftes de vieille couche, de fumier de feüilles pourries, de crotin de mouton reduit en poudre, de marc de vin \& autres femblables ingrediens, Quelquesuns en veulent exclure le marc, par la crainte que contenant quelque refte d'humeur vineufe, l'eau des arrofemens qui le laveroit n'en demeurât impregnée, au préjudice du plant à qui cetre qualité eft eneore plus contraire quaux autres efpeces.

Mais cette apprehenfion paroit affez mal fondée, puifque par l'effai qu'ils en ont apparemment fait, ils ont trouvé, difent-ils, que l'eau où dı mare de vin a trempé pendant plufieurs heures n'en contracte aucun goût, ce marc's'étant 
44

\section{Des Terres}

entierement déchargé de fon fuc à force d'être preffuré.

Que fi l'on objecte qu'il ne peut. par cette raifon fervir d'engrais, n'aiant plus de vertu; quand cela feroit, ce n'eft pas un grand inconvenient. Les autres matieres aufquelles on le joint y fuppléent affez ; \& le marc les rendant legeres, fait qu'elles font aufi plus fufcepribles de l'eau qu'on. leur donne par les arrofemens.

Au défaut de marc dont je ne prétens pas pour cela établir la neceffité, avoiiant au contraire qu'on s'en paffe fort bien dans les. Païs où il n'y a pas de vignobles; on peut metre un ou deux doigts'de crotin de cheval au-deffus de la caiffe où. font les Orangers : ce crotin fait le même effet ; \& outre qu'il ameliore davantage la Terre, il conferve long-tems fa fraîcheur durant les chaleurs de l'Eté.

La feconde efpece de Terre emploiée à la culture des Orangers \&. Citronniers eft d'une qualité oppofée à celle dont nous venoņs de 
propres pour les Orangers, of $c^{*}$ parler, c'elt à dire gralte \& humide. Ceux qui font pour cette Terre, trouvent que les Orangers ne jetrent pas d'allez grofles racines, \& font trop peu de mote dans d'autres plus legeres; ce qui fait qu'ils font difficiles à changer de caiffe, \& plus fujets à deperir \& à fe dépoiiiller.

Dans le purti contraire, on ne fait pas grand cas de ces raifons. On eftime peu important que les Orangers falfent une fi grolfe mote, puifquil en fut retrancher la plus grande partie, auffi-bien qus des vieilles racines quand on viene à rencaiffer ; \& dans l'experience qu'on a que ces Arbres ne manquent jamais de bien pouffer dans le terreau, ou dans la poudrette tout purs, on croit n'avoir rien à craindre de leur déperiffement, eir continuant de les metrre dans de femblables Terres, préferablement à d'autres fpongieufes, graffes \& humides.

On compofe celles-ci de vieilles Terres d'égoût, de vieilles bouës 


\section{6 \\ Des Terres}

feches confommées, de curures de mares bien confommées auffi pendant plufieurs hivers, de funjier de pigeon, de poule, \&c. le tout mêlé enfemble pendant une année s'il fe peut. Ceux qui en petvent avoir commodément, ne rifquent rien de $s^{3}$ en fervir. Les Orangers $n^{3} y$ profitent pas moins que dans les Terres precedentes; auffi tels ingrediens font-ils chargez de fels particuliers fort propres pour le fecours de la vegetation.

Que fi l'on n'en peut recouvrer qu'avec peine, ou qu'on n'ait pas prevû d'en preparer de longue main, quand on fe refout à avoir des $\mathrm{O} \rightarrow$ rangers, voici ce que l'on peut: faire: C'eft un troifiéme mélange dont on fe trouve encore fort bien. Telle forte de bonne Terre \& de bon fonds que ce foir y peut être emploiée ; comme de champ à bor1 bled, de chenevieres, de prez \& autres femblables, ou l'on voit que ce qui y croît foir. naturellement

- ou par culture, y vient beau, vigoureux \& en abondance. 
propres pour les Orangèrs, toc. 47 Ceux qui dans le choix des Ter"res preferent celles de deffus, en 4hetirent affez d'utilité pour fe croire fondez en raifon, D'autses cependant eftiment mieux celle de deffous quand elle ne degenere point; \& alleguent qu'étant plus neuve elle renferme non feulement tout fon premier fel, mais encore une grande partie de celui qui lui eft venu des Terres d'en haut aufquelles elle a fervi d'égoût.

On pourroit oppofer à cette opinion une cxperience facile; car $f$ par la colature on fait paffer du fel ou du falpêtre diffout à travers du fable ou de la cendre, on trouve que ce qui eft au deffus s'en charge le plus, \& qu'il ne s'en échape prefque point dans les parties inferieures; ce qui doit bien moins arriver à l'égard de la Terre, que les pluies. ne penetrent gueres jamais au delà d'un pied. Auffi eft-ce le jugernent des meilleurs Auteurs \& Jardiniers, que la Terre de deffus eft roûjours la plus excellente, non feulement darzs les lieux où le Tuf \& las 
Glaife font fort proches, mais auffi dans les meilleurs fonds, parce que, difent-ils, la Terre du fond n'aiant jamais reffenti la chaleur du Soleil, ni reçû la douce humeur que les pluies portent avec elles, elle eft comme morte \& incapable de produire.

Ce qu'on doit particulierement éviter, c'eft tout ce qui approche de la Glaife ou Argille, \& les Terres graveleufes. Il faut auffi s'atiacher autant qu'on peut à celles qui font d'un gris noirâtre ; non pas neanmoins à caufe que cette couleur eft plus agréable à la vûëe car ce feroir là une pauvre' raifon : mais parce que c'eft la marque certaine de la bonté d'une Terre, au lieu que la rougeâtre eft rarement bien conditionnée, \& que la blanche ne l'eft jamais.

Les principaux avantages de la Terre que nous venons de dire, font qu'elle dure long - tems fans s'alterer, fe défendant mieux de la chaleur du Soleil que les Terres le_ geres; \& quand par une longue 
propres pour les Orangers, of c. 49 fuite les Orangers ont befoin d'être renouvellez, on le fair avec moins de danger qu'ils ne fe dépouiillent ; parce que $s^{3} y$ étant formé une bonne \&. folide mote, on travaille aux racines en feureté fans qu'elles fe découvrent.

Mais auffi elle ne fuffit pas toute feule, quoiqu’à peu prés conforme à celle où les Orangers viennent naturellement. Elle feroit fujette à s'endurcir, ne communiquant dans les caiffes out on la mettroit, avec rien dont elle pût tirer quelque fecours : Et le Soleil ne pouvant penetrer une Terre fi forte, elle n'auroit qu'une humear groffiere \& froide peu propre pour des Arbres qui demandent plus de chaleur; au lieu que dans les Terres legeres \& graffes, le Soleil qui les penetre \& les échaufe facilement, leur prepare un fuc plus fubtil \& plus doax, même fans le diffiper, pourveu qu'on arrofe fuivant les regles que nous marquerons en fon lieu.

Il faut donc y remedier par l'induftrie, \& mêler cette Terre d'au- 
so

\section{Des Terres}

tres compofitions de la nature de ces dernieres, par le moien defquelles elle foit renduë meuble \& capable de recevoir les impreffions du Soleil, \& l'eáu des arrofemens qui font necelfaires à ces Arbres. Pour cet effet, on peut prendre: du terreau ou du crotin de mouton qu'on reduit en poudre, ou bien du terreau de vieilles couches, ou enfin du fumier de feüil. les d'arbres. On mêlera autant: des uns \& des autres de ces ingrediens, qu'on aura amaffé de bonne: Terre naturelle, fuivant les Orangers qu'on voudra planter ; \& cela fuffira pour donner à cette Terre ou compofition la qualité qu'il lui faut, foit que le mélange ait été fair long - tems avant que de s'en fervir, ou feulement quelques jours auparavant. Si l'on jugeoit la Terre naturelle trop froide \& trop humide, il n'en faudroit mettre que le tiers, \& les deux autres des ingrediens qu'on a dit.

Il y a encore une autre forte de Terre pour les Orangers \& les 
propres pour les Orangers, of c. Citronniers que nous ne devons pas oublier : elle eft même bonne pour tout ce qu'il y a d'autres plantes qu'on veut élever, foit en pot, foit en caiffe. On creufe une folfe de fix pieds de large, de quatre pieds de profondeur, \& d'une longueur proportionnée à la quantité de terreau dont on peut avoir affaire. On la remplit d'une coun. che de fumier menu bien pourri, d'environ deux ponces d'épaiffeur. On en met all delfus une autre de pareille hauteur de bonne terre, une de marc de vin, une de fumier de mouton, une autre de fumier de pigeon, \& une autre de vache. On y mêle les tiges \& les feüilles de Citrouilles, Concombres \& Melons, même leurs fruits gâtez \& pourris, continuant à mettre alternativement une couche fur l'autre, jufqu'à ce que la folfe foit remplie. On jette enfuite quantité d'eau deffus ; on acheve de la couvrir de terre, \& on la laifie deux ans fe confommer \& pourrit, aiant foin d'ôter les 


\section{\{2 Des Terres}

herbes qui croîtront deffus affez a: bondamment, \& del'arrofer de tems en tems.

Cetre humectation des fumiers ne plaît pas à quelques-uns. Ils pretrendent que les chofes ainfi lavées perdent leur fel, \& par confequent leur fecondité \& leur vertu \& voudroient qu'étant une fois mifes en tas, elles fuffent à couvert même des pluies, de peur que les eaux parfant à travers n'en tirent le fuc, \& le répandent inutilement fur les côtez \& au deffous de la malfe.

Mais c'eft encore un inconvenient qa'on peut appeller chimerique dans la maniere dont nous venons de parler. Car fi les terres d'égoût \& autres femblables font tres - bonnes, fans doute parce qu'étant dans une fituation baffe, elles ont reçû par le moien des eaux qui s'y fónt écoulées, les fels des terres voifines; que ne doivent pas être des matieres affemblées dans un creux, où par la difpofition qu'elles ont à s'imbiber, elles s'entre-cómuniquent leurs qualitez, fans qu'on puiffe dire qu'il en 
propres pour les Orangers, ofc. $s$ paffe ailleurs; puifque les côtez \& le fond de la folfe fe trouvent d'une conftitution à n'être pas fi aifénrent penetrez, quand même il y auroit de l'eau de refte aprés avoir abreuvé ces matieres. On fçair de plus, que le furmier entaffé fe brûle au lieu de fe confumer \& de s'abonnir, fi on ne le moüille pour en temperer l'ar: deur.

De tout ce que je viens de dire, il paroît, que de laquelle de ces quatre fortes de terres qu'on fe ferve, elles font toutes propres pour les Orangers \& les Citronniers; ainfi je ne déterminerai point celle que l'on doit choifir, laiffant à chacun à fe fatisfaire là-deffus, fuivant qu'il fe trouvera prévenu. Je ne dirai rien nom plus de quelques autres manieres de faire qui font en ufage; parce qu'elles fe rapportent aux precedentes, \& qu'elles n'en different que par des circonftances peu confiderables. Les uns, par éxemple, pratiquent feulement de frequens remuëmens des terres preparées; ce qu'il n'y a point de mal d'imiter 


\section{Des Terres}

quand elles ne font pas entaffées de longue main, \& auffi difpofées à fe bien mélanger que les dernieres dont il a été parle. Les autres s'attachent à l'ancienneté de la compofition, comme à une chofe effentielle; \&e je ne voudrois malfijettir à la methode de ces derniers, que pour des ingrediens trop chauds, \& capables de deffécher le plant plûtôt que de le nourrir, comme eft entre autres le fumier de Pigeon, qu'il eft bon par cette raifon de n'emploier, non plus que la plus part des matieres de la premiere \& feconde claffe, qu'aprés avoir palfé plus d'un $\mathrm{Hy}$ ver à fe confommer \& à perdre fon feu.

Il s'agit maintenant de voir, dans quoi placer cette terre deftinée pour les Orangers \& Citronniers, \& de quelle maniere on les y plante. C'eft un point qui femble ne devoir pas renfermer de grandes difficultez, aprés ce que nous avons tonché au Chapitre quatriéme; \& cependant on verra qu'il y a fur cela auffi-bien que fur le refte, des opi- 
s6 Cominent on encaiffe

certain que des Arbres ainfi placez font dans la meilleure difpofition à bien profiter. Leurs racines n'y font point génées ny étouffées par un air renfermé ; \& la nourriture abondante qu'ils tirent de tous côtez, ne peut du moins que de les faire pourfer avec une vigueur $\&$ une durée qu'on ne voit point autrement.

Pour pratiquer cette maniere, il n'y a gueres d'autres chofes à faire que ce qui a déja été remarqué cydevant. C'eft pourquoi aiant choifi \& aligné dans un terroir bon \& fertile, tel que nous fuppofons être le jardin que l'on a, les endroits où l'on veut planter des Orangers, foit en allée, ou feulement aux coins, ou au milieu de quelque quarré; on y. creufe des foffes ou trous de deux ou trois pieds de profondeur, dont on remplir les deux tiers de la terre preparée, \& davantage s'il le faut. On laiffe affaiffer cette terre pendant quelque temps; finon on la preffe \& trepigne à mefure qu'on la met dans la foife à la referve des derwiers lits. On tire enfuite les Orane. 
la premiere fois les Orangers, $6 \mathrm{c} .57$ at gers \& Citronniers des pots, caiffes ou mannequins où ils ont été élevez depuis qu'on les a greffez, ou achetez : Et parce qu'il faut en conferver la mote, de peur que ce chan. gement ne recule ces arbres; on leur donne le jour d'auparavant un bon arrofement, pour faire mieux tenir cette terre enfemble ; ce qu'autrement elle auroit de la peine à faire, étant legere comme elle eft.

Les Mannequins ont en ce point quelque chofe de fort commode; Car comme il faut qu'ils foient à claire voie, \& qu’aiant été tenus. dans des couches, ils fe trouvene plus d'à moitié pourris, on peut les enterrer avec le plant fans rien ôter, \& par là on ne court point de rifque d'éventer les nouvelles racines. Que s'il s'en trouvoit qui fe fuffent déja étenduës au dehors, on les doit conferver avec foin pour les bien ranger \& foûtenir de terre; \& dans cette incertitude avant que d'enlever les Mannequins, ce qu'il faut faire auffi-bien que le refte un jour que: le temps eft doux, on commence. 
58

Comment on encaisfe

toûjours par un bon arrofement, \& l'on détourne la terre qui eft autour le plus doucement qu'on peut, afin de ne rien rompre ou ébranler.

Qu'on ait, ou non, cette facilité, il faut placer les Orangers dans le milieu de la foffe le plus droit qu'il eft poffible; en forte que la fuperficie de la mote excede celle de la terre voiline, parce qu'elle s'abaiffera affez. On remplira enfuite les côtez qui font vuides jurfqu'a ce qu'ils foient de niveau ; \& l'on preffera alfez la terre pour qu'elle joigne ibien par tout, \& que l'arbre ne puiffe être agité par les fecouffes du vent. Pour tenir ce qui s'éleve au deffus dans un quarré toûjours uniforme, on mettra des hauffes, c'eftì-dire, des tringles de bois, aux quatre côtez; \& cela fervira auffi à conferver l'eau des arrofemens, par où il faut finir, les faifant à diverfes reprifes, afin que l'eau penetrant mieux par tout , facilite plûtôt l'action des racines.

Il n'eft pas befoin de grandes re. 
la premiere fois les Orangers, ofc. sg flexions pour juger des avantages d'une telle maniere de planter. On voir facilement qu'clle doit être éxemte de tous les dangers attachez aux autres. Et en effet la quantité de terre menble \& preparée qu’on emploie, fert pour fi long-reinps, ainli qu'il a été dit, d'une grande \&c bonne nourriture aux Orangers \& Citronniers que l'on y met, principalement aiant les fecours qu'elle peut tirer de la bonne terre qui eft dans le voifinage, qu'on n'eft point dans l'embarras, où les caiffes \& les vafes nous expofent, de renouveller ces Arbres lorfque par la langueur où ils tombent, ils font connoître un peu trop-tôt, que la terre dans laquelle ils font eft ufée.

On n’a pas non plus à craindre de fe voir dans cette peine, foit du côté de l'affailfement ou de la petiteffe du lieu, qui dans les mêmes Vaifseaux caufe encore afsez fouvent cetre langueur, \& la neceffité du changement; parce que l'Arbre par le premier de ces inconveniens ne trouve plus de fubftance au fond, \&z 


\section{to Comment on encaiße}

que l'autre, refserrant trop les racines, les force à s'entortiller, \& à fe furmonter les unes les autres, \& à s'élever même jufquau defsus de la terre, aprés avoir rempli tout ce qu'il y avoit d'efpace; aul lieu qu'ici les terres affaiffées ou trepignées qui font au fond du trou, \& la hauteur où l'on place les Orangers, font qu'ils ne defcendent gueres jamais : Et quand d'ailleurs cela arriveroit ; outre qu'à la place des terres abaiffées, on en peut mettre de nouvelles fort utilement, les racines ne laifferoient pas malgré l'enfoncement, de porter leur pointe plus avant, comme elles le peuvent faire de tous côtez, aiant la liberté qu’elles ont.

Il y a encore d'autres accidens dont on eft heureufement à couvert; comme de l'incommodité du tranfport, de la fragilité des vafes, du peu de durée des caiffes, \& du gachis que fait l'épanchement de l'eau fuperfluë des arrofemens, ce qui n'arrive pas quand les Orangers font en pleine terre. $\mathrm{La}$ raifon en eft 
la premierefois les Orangers, of $c .6 \mathrm{I}$ fenfible. C'eft que cette eau s'imbibe doucement fans qu'on ait lieu de craindre, que s'arrêtant au fond elle puiffe pourrir ou alterer les racines, puifque la terre qui s'y trouve reçoir avec plaifir cetre humectation quoique preffée, \& que même celle qui eft plus forte, \& qui n'eft point preparée la fouffre aifément, fur tout fi on l'a adoucie \& labourée legerement comme je le confeille.

Il feroit à fouhaiter que pour profiter de tous ces avantages, on ne plantât des Orangers qư en pleine terre. C'eft cependant ce qui ne fe pratique gueres hors des $P$ aiis chauds, où l'on n'y prend même pas tant de peine. La feule chofe qui en détourne, c'eft ladifficulté qu'il y a à garantir ces Arbres du froid : Car comme il leur faudroit pour cela des couvertures auffi chaudes qu'épaiffes \& élevées, \& qui fuffent difpofées de telle forte qu'on pût les beaux jours d'Hyver, faire joüir ces Arbres de l'afpect du Soleil, dans les heures que fa chaleur eft plus 


\section{G2 Comment on encaiffe}

grande; on fe forme là-deffus une idée de dépenfe ou d'embarras, qui fait qu'on renonce volontiers à tour ce qu'il y a d'ailleurs de commode. \& d'agreable.

Pour engager à en ufer autrement il faudroit propofer ici quelque expedient affez fimple \& également pratiquable. Mais nous le refervons pour l'endroit où nous parleront des Serres, \& des autres manieres de conferver les Orangers \& Citronniers pendant les rigueurs de l'Hyver. Venons donc à l'ufage des Vafes. Comme il n'eft pas encore affez bien établi, il y auroit beaucoup de chofes à dire là-deffus. Nous avons remarqué quels en font les principaux inconveniens, fçavoir leur petiteffe, \& leur fragilité. Examinons s'ils font en cela de pire condition' que les caiffes, \& fi ce qu'ils ont d'utile, peut, finon l'emporter, du moins égaler la commodité de ces dernieres.

Il faur convenir qu'on ne voir point de Vafes de la grandeur qu'on peut donner à des caiffes, quand des 
la premiere fois les $\mathrm{Orangers,} \sigma^{\circ} \mathrm{C} . \mathrm{G}_{3}$ Orangers font devenus extrémement forts \& grands. Peut-être s'en pourroit-il faire; mais il y auroit trop de danger $\&$ de peine a les tranfporter \& manier; au lieu qu'on peut s'aider par plufieurs moiens à l'égard des caiffes, qui font de plus d'une matiere à n'être pas fi fort épargnée.

Cer avantage n'eft pourtant rien, fi l'on peut montrer que fe fervant de Vafes, il n'elt pas necelfaire qu'ils foient fi grands, par la raifon que les Orangers trouvent dans leur capacité ordinaire, autant de nourriture que dans des caiffes beaucoup plus grandes.

On co te pour quelque chofe làdeffis la déduction quil faut faire de l'efpace qu'occupent les platrâs dont on garnit le fond des cailfes pour faciliter l'eau fuperfluë des arrofemens, ce qu'on ne fait point à l'ćgard des Vafes : Ainfi il ne refte dans les premieres gueres plus de terre qu'en contiennent les derniers.

Mais fuppofant ou admettant 


\section{Comment on encaißs}

même le contraire, voici une coñfequence plus forte. Elle eft fondée fur ce que les caiffes étant en l'air, la chaleur du Soleil les frappe \& penetre de toutes parts, avec dautant plus de facilité que leur matiére \& leur conftruction en font trés fufceptibles. Il eft vrai que cela eft neceffaire dans nos Climats, furtout quand on emploie beaucoup de terres fortes, telles que font celles de la troifiéme claffe ; autrement ces fortes de terres ne pourroient recevoir les impreffions de cette chaleur, les raions du Soleil qui ne nous regardent qu'obliquement étant trop foibles; au lieu que portant directement dans les Pais chauds, il fuffit que la terre foit vûe du côté de la fuperficie. Mais auffi qu'arrive-t-il de cette difpofition des caiffes? C'eft que la chaleur qui s'y infinuë avec tant de facilité, met la terre qu'elles contiennent en un tel mouvement, $\&$ dans une fi grande fermentation, que les fucs ou efprits vegetatifs qui y font contenus, $s^{\prime}$ exhalent \& fe diffipent pour la plus grande partie, plû- 
la premiere fois les Orangers, \& $c .6 \mathrm{~s}$ tôt que de fervir à la nourriture de l'Arbre. On le voit par les deux inconveniens qui naiffent de là : L'un, qu'on eft reduit à faire de grands \& $\&$ frequens arrofemens; \& l'autre, la neceffité de changer \& rencaiffer fouvent les Orangers, la tetre fe trouvant confumée.

Il n'en eft pas de même à l'égard des Vafes. Comme ils font d'une matiere moins poreufe, \& qu'on les place à terre, la chaleur du Soleil agit fur eux beaucoup plus lentement, \& cette chaleur rencontrant une fraicheur oppofée qui vient d'en bas, elle détache infenfiblement les fels, $\&$ les prepare pour la nourriture des Orangers d'une maniere fi temperée; que rien ne s'en perd, \& ne s'en diffipe, mais tout eft employé à les. faire vivre \& pouffer avec vigueur.

Ce bon effet éxemte d'arrofer que rarement \& mediocrement ; \& par là la terre n’eft pas encore dépoüillée de fes fels, puifque l'on pretend que plus elle eft lavée, plus elle s'ap. pauvrit; ce qui eft affez certain 


\section{Comment on encaiffe}

quand l'eau palfe à travers auffi facilement que dans les cailles. Car pour les Vares, comme elle n'y trouve pas une même iflü̈, le féjour qu'elle y fait idonne tout le tems qu'il faut aux racines d'attirer les fels qu'elle a détrempez; de forte que s'il y avort enfuite de l'eau fuperflue, ce qu'on n'a pas lieu de croire, étant verfée fort fobrement, elle feroit toûjours dénuée de coute vertu, ou acheveroit avant que de fortir au dehors, de.s'en decharger fur les terres qu'elle abreuveroit.

On voit par la même railon, que dans les vafes la terre ne peut que fe conferver long-tems meuble \& feconde; auffi elt-on peu fujer à la renouveller : ce qui eft un autre avantage affez grand, fi on le compare aux perils que courent les $\mathrm{O}$ rangers dans les rencaifferens.

L'on objecte qu'ils y font plus oppofez par un autre endroit, en ce que les vafes aiant le pied mediocrement large, \& trop peu d'affiette pour des Arbres qui ont la tête fort chargée, ils ne fçaus- 
la premierefois les Orangers, of c. 67 roient par confequent refifter à la violence des vents, \& courent rifque d'être renverfez \& brifez, au hazard perpetuel des Orangers dont il peut fe rompre quelque branche, ou qui même fans cela, dans la neceffité qu'il y aura de les changer, fouffriront toûjours affez de ce contre-tems.

Mais quand les Ouragans impetueux tel qu'il en faut un pour avoir fujet de craindre un pareil accident, ne feroient pas auffi rares qu'ils le font; la pefanteur des vafes \& leur fituation prés de terre donne lieu de foûtenir qu'ils font auffi fermes \& ftables que les caiffes, lefquelles étant plus élevées, femblent pour le moins autant expofées aux prifes \& aux tourbillons du vent. Que fi elles tiennent bon, on ne répondra fans doute pas que dans cette refiftance un Arbre ne puiffe être ébranlé \& deraciné , puifque le vent en arrache de bien plus forts en pleine campagne.

C'elt done un danger commun 


\section{Comment on encaiße}

que celui que l'on regarde du côté des orages qui peuvent furvenir : mais ce qu'on ne fçauroit nier, c'elt que fi les vafes en peuvent fouffrir plûtôt, quand on y a des Orangers, qui par la groffeur ex-. ceffive de leur tête font fujets à une agitation qui peut emporter le pied: ils ont du moins autant de folidité qu'il en faut pour ceux qui font mediocres; ainfil'on peut s'en fervir fort long-tems : avec d'autant plus de farisfaction, qu'outre les 2vantages que nous avons dit, ils. font, \& plus agréables à la vûë que les cailfes, , tant par leur figure que par la diverfité de leur coloris, $\&$ auffi plus, commodés pour pouvoir tenir avec propreté des Orangers dans les: appartemens, \& profiter par ce moien à toute heure: du: doux: parfum \& des autres de. lices. que l'on trouve dans ces Arbres.

Dans l'abregé pour les Arbres: nains par le Notaire de Laon, on fait la defcription d'une maniere de pots ou: vales pour éle- 
Ta premiere fois les $\mathrm{O}$ rangers, $\sigma c .6 \%$ ver les Orangers \& autres $\mathrm{Ar}$ buftes dans les Païs froids, qui peut être fort utile: j'y renvoie le Lecteur, qui verra en mêmetems dans cet Ouvrage plufieurs: bonnes remarques fur: les matieres dont il traite.

On plante les Orangers plis gros: dans les vafes dont nous avons. parlé, de la même maniere que nous l'avons: déja dit ci - devant, foit au chapitre quatriéme, foit au commencement de celui-ci, pour les Orangers en pleine terre ; c'eft-à-dire, qu'on met au fond du vafe autant de terre affaiffée ou preffée avec quelque bois fi l'on n'a pas le poing affez-ferme; qu'il en faut pour ne laiffer de place que pour la hauteur de la mote, laquelle étant placée au milieu, \& d'une maniere un peu éminente, on garnit le refte de terre, \& l'on. arrofe.

On doir obferver lá même chofe pour encaiffer utilement les Orangers, qui eft le parti ordinaire que lon prend. La feule difference eft- 


\section{$70 \quad$ Commest on encaiffe}

que l'on met comme il a éré dit, au fond de la caiffe, un lit de platrâs ćpais de trois à quatre pouces, afin que l'eau des arrolemens s'écoule par là, \& qu'elle ne pourriffe ni les racines, ni la caiffe, qui pour la même facilité doir avoir le fond inégalement applani, percé de plufieurs trous, ou compofé de diverfes douves ou ais, entre lefquelles il y ait du vuide.

A l'imitation de ces platrâs dont on garnit le fond des caiffes, quel. ques-uns ont jugé à propos de mettre dans le fond des trous que l'on fait pour les Orangers \& autres Arbres qu'on plante en pleine terre, un lit de menu gravois, avant que les terres preparées $\&$ amendées. Ils eftiment que les racines n'en font que plus en fureté du côté de l'eau qui pourroit les pourrir, \& que ceffant là de trouver de la nourriture, elles en cherchent plus haut \& plus prés de la furface où la terre eft plus feconde, parce qu'elle reçoit les influences du Soleil \& les effers des 
la premierefois les Orangers, pluies \& des rofées. C'eft entre aultres le fentiment du Curé d'Enonville, page irr. \&c. de l'Auteur du Theatre des Jardinages, affez contu pour un Livre tres-utile, auffi-bien que le premier. Il en apporte diverfes raifons que j'approuve fort, bien-loin d'entreprendre de les combattre.

Pour une plus grande durée des Caifies, il y en a qui fe font avifé d'ajoûter à ce que nous avons dit, un expedient nouveau. Comme ils ont vû que les bois expofez à la pluie \& aux injures du tems, y refintent davantage lors qu'on leur donne quelques couches de verni, ou autre peinture à huile, ils ont crû que les caiffes refifteroient auffi. beaucoup mieux à la pourriture s'ils obfervoient la même chofe à leur égard. L'éprouvera qui voudra : ceft une precaution qui ne peut nuire aux Orangers par l'odeur ou qualité de la peinture, \& qui leur fera au contraire avantageufe, en ce qu'on n'aura pas befoin de changer fi fouvent ces Arbres; ainfi its 
72. Comment on encaifle

s'en porteront mieux, fans parler de l'épargne qu'il y aura dans la durée des caiffes au delà de ce qu'elleś ont accoûtumé. Ce qu'on ne doit pas negliger fi on le fait, c'eft que les coins \& les jointures foient bien remplis de cette peinture, en forte que l'eau ne puiffe s'y donner le moindre paffage pour aller aux. extremitez des ais, de peur que venant à manquer par le bout, le refte ne fe conferve inutilement.

Les autres qualitez que doivent avoir les Caiffes pour être le mieux conditionnées qu'il eft poffible, font que fi elles furpaffent deux pieds, elles foient faites de bons ais de chêne bien fec, qui aient un bon: pouce d'épaiffeur, avec de bonnes membrures de trois pouces en carré pour les quatre pilliers. Les moindres peuvent fe faire de vieilles douves, ou de merrein neuf; parce que contenant moins de terre., \& étant par confequent moins pefantes, elles peuvent être tranfportées facilement fans crainte de fe gâter. \& brifer. Le fond doit être fort \& materiel, 
la premierefois les Orangers, foc. 73 materiel, à proportion du fardeau dont il fera chargé. On ne doit pas manquer de lo foûtenir de bonnes traverfes de bois, \& mêtne de barres ou bandes de fer, fi c'eft une cailfe un peu grande \& lourde, afin que les leviers dont on fe fervira pour la remuër ne rompent rien. Il eft bon pour la même raifon de ferrer la caiffe dans toutes fes encoignures, rien n'étant plus fàcheux que d'être reduit à en changer fouvent, faute de telles précautions.

Quant à la grandeur qu'elles doivent avoir, on la regle fur celle des Arbres qu'on veut encaiffer. Les plus grandes que l'on voie ne paffent gueres quatre pieds. Quoi-que de mettre un petit Oranger dans une grande caiffe, cela choquiât la vûe, ce ne feroit pas néanmoins une faute fi confiderable que d'en mettre un grand dans une caiffe trop petite, où il manqueroit de nourriture, au lieu que le premier feroit pour ainfi dire, comme en pleine terre. $\mathrm{La}$ hauteur des cailfes doit répondre à leur largeur pour être plus agréa- 
74 Comment on encaiffe, toc.

ble. Le pied eft ordinairement de cinq ou fix pouces d'élevation plus ou moins, fuivant que les caiffes paffent, ou font au deffous d'un pied \& demi jufqu'à trois \& quatre. Quelques-uns les font à guichets; en forte que deux côtez fe puiflent ouvrir \& fermer avec des barres de fer, \& des crochets qui les foûtiennent. L'urilité qu'on en retire, eft qu'on peut par ce moien donner des demi rencaiffemens, \& faciliter ceux des grands Orangers, en fortant par ces guichets la plus grande partie de la terre qui compofe leur mote.

Comme ces rencaiffemens font un mal inévitable, principalement dans l'ufage des caiffes, on peur prendre cette précaution, finon s'en tenir à ce que nous allons voir qu'on doit obferver quand on eft réduit à cette fâcheufe extremité. 


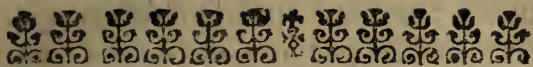
(2)

CHAPITRE VII.

A quoi lon connoit le befoin quiont les Orangers \& Citron. niers d'être changez \& renouvellez; of la maniere de lo faire.

A neceffité de changer un OranLger n'arrive pas feulement par le méchant état de la caiffe, ou du vafe où il étoit ; fçavoir quand ce dérnier vient à ćtre brifé par quelqu'accident imprevû, ou que la caiffe fe trouve ufee \& rompuë devieilleffe ou autrement. On a vû ci-devant qu'il y a d'autres cas où l'on eft obligé d'en venir là, qui ne fe font gueres moins connoitre; com. me lorfque les Orangers \& Cirron. niers font defcendus fi bas, faute. d'avoir preflé ou laiffé affaiffer la

$$
\text { G ij }
$$


76 A quoil'on connoit le befoin

terre, avant que de les planter, qu'ils touchent vrai-femblablement au fond des pots ou des cailfes; ou que les racines fe font tellement multipliées qu'elles rempliffent \& excedent même la capacité du lieu où ils font; ou qu'enfin de quelque maniere que ce foit, la terre fe trouve ufée \& confumée.

Dans ces divers cas les Orangers donnent des marques fenfibles de leur indigence \& de leur befoin. On voit leurs feuiilles fe faner \& quitrer leur verd, leurs fleurs toutes petites \& chifonnes, \& leurs jets s'ils en pouffent encore quelquesuns , être jaunes, foibles \& languiffans.

Il feroit à fouhaitter qu'on n'attendît pas à les fecourir qu'ils fuffent tombez dans ce trifte état. Il ne leur arriveroit pas de fe dépouiiller comme ils font, l'année d'aprés, \& fouvent l'année même de leur rencaiffement. Ils poufferoient au contraire prefqu'autant de nouveaux ets que s'ils n'avoient poin $t$ foufert de changement, \& ne donne= 


\section{qu'ont les Orangers, ofc.}

roient que de belles \& grolfes fleurs; au lieu que tardant trop, elles font fi chetives, qu'elles tombent prefque toutes fans s'épanoiiir.

Mais le plus grand mal eft . qu'on eft ordinairement forcé de leur ôter la plûpart de leurs vieilles branches, afin que les autres profitent mieux. On peut juger combien cela recule \& défigure un Arbre, \& quel temps il faut pour le rétablir.

Le peu de fatisfaction, pour ne pas dire le déplaifrr, qu'on en reçoit durant ce deperiffement, doit fans doute porter ceux qui ont des Orangers, a les changer \& renouveller dés qu'il y a la moindre apparence qu'ils en ont befoin. Il fuffit par éxemple, que nonotant le foin que l'on a continué d'en prendre, ils ceffent un printems de pouffer beaucoup de nouveaux jets fort vigoureux comme ils avoient accoûtumé. Cette défaillance eft dun mauvais augure, quoique les feiiilles confervent peut-être encore le vert qu'elles avoient les années precedentes.

G iij 
Is A quoil'on connoit le befoin

Ce n'eft pas qu'on ne voie quelquefois de ces Arbres palfer des deux \& trois ans fans rien faire, aprés avoir été nouvellement encaiffez ou changez de caiffe. Pour ceuxlà, on ne doir pas d'abord fe dégoûter de les cultiver, ni prendre le parti de les rencaiffer derechef. Tant que la tige \& les branches demeurent bien vertes, il y a lieu de croire que ce n'eft qu'une efpece d'affoupiffement dont on vient prefque toûjours à bout avec un peu de perfeverance.

Mais à l'égard des Orangers en-. caifez depuis plus long-temps, il n'en eft pas ainfi. Dés qu'ils manquent une année de répondre comme auparavant à la culture qu'on leur donne, on doit conter que ce n'eft pas une fimple fufpenfion de leurs fonctions ordinaires, mais un figne qu'ils manquent de nourriture, \& quils font menacez de langueur \& de maladie fi l'on n'y remedie auffi-tôt, foit en renouvellant la terre, \& retranchant une partie des racines de tels Orangers, foit en les 


\section{qu'ont les Orangers, ofc. 72} mettant dans un lieu plus Spacieux.

La prevoiance peut aller plus loin; car puifqu'on fçair par experience, que les Orangers tombent en ce beloin dans cinq ou fix ans, il n'y a qua regler la-deffus les rencailfemens, \& les faire fans autre indice, ou tous les quatre ans, fi ces Arbres font encaiffez \& dans des terres legeres ; ou plus tard, $s^{s}$ ils font dans des vafes \& dans des compofitions plus graffes \& plus fortes.

Pour bien faire certe operation qui tient lieu de ce qu'on fait aux autres Arbres quand on les rechauffe, il faut confiderer les diverfes circonftances où l'on peut être. Premierement fi les Orangers font mediocres, \& la caiffe fi petite que la béche n'y puiffe entrer, on en tire autour la vieille terre, avec une houlette de fer, ou autre petit inftrument. On prend enfuite l'Oranger par le tronc que l'on enleve avec fa mote hors de la caiffe; puis prenant d'une main la ferpetre, \& tenant l'Arbre de l'autre, on en retranche environ les deux tiers de la mote,

$$
G \text { iiij }
$$


so A quoi l'on connoit le befoin coupant tout le chevel u, \& les moin: dres racines jufqu'à ce que l'on commence de trouver les groffes. Ce retranchement fe fait autant en la partie de deffous qu'aux quatre cốtez. On doit prendre foin de ne pas laiffer le moindre brin de ce que l'on coupe. On peur grater ce qui refte de la mote pour découvrir le bout des racines qu'on aura taillées, afin qu'elles foient plûtôt revêtuës de la nouvelle terre dans laquelle on les met; en quoi il n'y a à obferver que ce que nous avons remarqué au chapitre precedent.

Que fi la cailfe eft grande, \& que l'Arbre ne fe manie plus facilement, voici ce que l'on doit faire, quand on n'a pas la commodité des caiffes à guichet, ou qu'elles petvent encore fervir ; car fi ce font des caiffes ufées \& rompuës, en achevant de les brifer, on a la mote entiere \& difpofée à fouffrir tour ce qu'on veut. Il faut donc hors delà coucher la cailfe fur quelque billot de bois, qui empêche la tête 
qu'ont les Orangers, ofc. Ir de l'Oranger de porrer à terre;l'on vuide enfuite avec la béche, le côté de la cailfe qui eft au-deffius jufquau fond \& aux platrâs, confervant feulement environ un demipied de terre autour de l'Arbre, fuivant la groffeur ou periteffe de fon pied \& de fes racines, aufquelles on fait en même-tems le retranchement que nous avons dit pour les autres.

Aiant ainfi tire la vieille terre, on en met d'autre nouvelle à la place que l'on preffe \& foule, garniffant foignieufement les racines qui ont pû être découvertes. On tourne aprés la caiffe des trois autres côtez pour y faire la même chofe, \& de chaque côté l'on creufe at:àeffous de l'Arbre environ un demipied ; \& par ce moien le fond fe trouve renouvellé auffi-bien que le refte fans avoir déplacé l'Oranger. S'il s'étoit enfoncé durant les dernicres années, il faudroit y remedier, en le tirant par le tronc au haut de la caiffe, lorfqu'on en feroir au dernier côté. 
\$2. A quoil on connoit le befoin

Cela paroît encore plus facile à ceux qui fortent l'Oranger entierement hors de la caiffe, foic à force de bras, aprés avoir premie. rement vuidé la terre \& coupé les vieilles \& longues racines, qui ne font point de tort à la mote que l'on doir conferver ; foit en fe fervant d'une gruë', d'une poulie \& de cordes, qui tiennent l'Arbre fufpendu, randis qu'on taille fes racines \& qu'on remet de nouvelle terte dans la caiffe. Ce dernier expedient feroit fur-tout fort propre pour les Orangers en pleine terre s'ils pouvoient avoir befoin de cetre operation, ce qui ne peut guéres arriver: que quand le côté qui a davantage d'ombre eft moins fourni, \& femble par confequent demander qu'on le tourne du côté dir Soleil, pour le rendre de tontes parts égal dans la forme \& la force de les branches, aufli-bien que dans la production de fes fruits.

II faut remarquer tant pour les gros que pour les petits Orangers, que s'il fe rompoit de la mote de 
qu'ont les Orangers, of c. 83 quelque côté, en forte qu'il y eut: des racines découvertes de terre, il ne faudroit pas manquer de railler, celles qui feroient découvertes rour proche ce qui refteroit de la more, de peur que l'arbre ne fe dépoüille, ou ne foir au moins la premiere année fans rien faire. L'apprehenfion de tel accident fait qu'on peut beau. coup arrofer le jour auparavant le mencaiffement, fi la terre eft legere; car fi elle eft forte, \& qu'on prévoie que la mote foit affez folide, cela ent abfolument inutile.

Le vrai temps de faire cetre operation eft fur la fin de Septembre, ou au commencement d'Octobre; parce qualors les Orangers, aiant eû la chaleur du Soleil pendant tout l'Eté font dans la perfection de leur force, \& dans toute la vigueur qui leur eft neceffaire pour tenir bon contre ce changement. Quelquesuns cependant aiment mieux rencaiffer au Printems; \& fe reglent fur ce que l'on ne replante les arbres que lors qu'ils font hors de feve; \& c'eft veritablement au for 
$S_{4}$ A quoil'on connoît le befoin tir del'Hyver que les Orangers en ont le moins.

Si l'on ne rencaiffe que quand les Orangers font déja atteints d'infirmité \& de langueur, on doit comme il a été dir, couper celles de leirs branches qui gâteront le moins la figure pleine \& ronde de leur tête; autrement aprés le retranchement qu'on a fait à leurs racines, ils ne pourroient attirer alfez de nourriture pour fe fuffire \& pour fe rétablir. On peut fe conduire en cela, comme je le marquerai ci-aprés en parlant de la taitle de ces arbres.

Quand on déplace les gros Orangers, I'on peut avant que-de les rencaiffer, pratiquer ce que nous avons dit pour ceux qui font nouvellement venurs des Païs chauds ; je veux dire mettre tremper la mote aprés y avoir fait tout ce qu'il faut, jufqu'à ce qu'elle foit entierement pénetrće d'eau, \& qu'on ne voie plus de ces boüillons que forme l'ait qui s'échape, \& la laiffer enfuite égoûter fur quelque chofe d'élevée avant que de la rencaiffer. On fupplée aifé 
qu'ont les Orangers, ơc: 85 ment à cela fi la mote eft trop groffe pour la pouvoir plonger, ou qu'on ne forte pas l'arbre hors de la caiffe: Car alors le rencaiffement étant fait, il n'y a qu'à percer la mote en plufieurs endroits, avec une cheville de fer, ou un bâton pointu affez dur \& gros, \& verfer de l'eau dans ces trous petit à petit, \& à diverfes fois, jufqu'à ce qu'oln vo:e que l'eau ne s'imbibe plus, \& que toute la terre eft bien humectée. On peut pra:iquer la même chofe pour les petits Orangers, de quelque maniere qu'on les plante, finon faire un cerne entre la vieille mote $\&$ la nouvelle terre, enfoncée d'environ trois doigts, \& y verfer enfuire l'eau à plufieurs reprifes, afin que la terre s'uniffe à l'extremité des racines coupées, \& qu'en étant bien garnies, elles en produifent plûtôt de nouvelles qui foient bonnes \& vigoureufes.

Les demi-rencaiffemens fe peuvent faire quand un Oranger ne profite pas également d'un côté comıne de l'autre, \& qu'on ne peut reparer ce 


\section{Aquoilon connoit le befoin}

idefaut par la taille, l'ébourgeonnement \& les autres foins que l'on verra dans la fuite. Quelques-uns s'en contentent, les faifant alternarivement tous les trois ans. On fau. ve en effet ces arbres par ces demirencaiffemens, de plufieurs des dangers qu'ils courent quand on décaiffe tout-à-fait, quelque facilité qu'ils ayent à reprendre.

Je n'eftime pas neanmoins qu'ils fuffifent que pour des Orangers encaiffez feulement d'un ou deux ans, $\&$ mis dans des terres ou trop legeres ou trop fortes, \& nullement pour ceux quii fe trouveroient déja dans un commencement d'infirmité. Or doit auffi en ce cas prendre un extréme foin de ne pas ébranler l'Arbre, ni découvrir les racines; mais fe contenter de fubltituër des terres mieux conditionnées \& preparées à celles quion ôtera, tant au deffus quau deffous de la mote, fi on le peut par le moien d'une caiffe à guicher, ou quion puifse ôter des dou. ves inferieures pour faire ce renous. vellement. 
Les Vafes qui ont prés du pied une ouverture dans laquelle on peut pafser la main, tels que font ceux que nous avons indiquez, peuvent auffi donner cette facilité de rafrầchir jufques dans le fond la rerre d'un Oranger où l'on voit qu'il ne profite pas, \& de couper en mêmetems comme l'on doit faire, une parcie des racines, fi le Vafe en eft trop plein. Mais auffi ces Vafes doivent être enfoüis jufqu’à la moirié de leur hauteur, afin de recevoir par ce trou, \& par les autres qui fervent à l'ćcoulement de l'eau, l'humeur \& la fraîcheur de la terre.

Qu'on ne fe hâte pas cependant d'en venir toûjours à des demi-rencaifsemens quand un Oranger encaif fé d'un ou deux ans ne donne pas des marques qu'il fe trouve bien; mais quon le fouvienne de ce qui a éré obfervé au commencement de ce Chapitre, qu'ils font quelquefois fluets \& de peu d'apparence jufqu’à trois \& quatre ans. Cela arrive principalement à ceux qui étoient déja en langueur quand on les a rencaif 


\section{8s Aquoilon connoît le befoin}

fez; \& l'on pourroit dire que c'elt parce qu'ils fe font endurcis \& tellement pervertis par la méchante nourriture qu'ils fucçoient, que la nouvelle ne peut reparer cer affoiblifsement quavec peine; la chaleur de la bonne terre qu'on leur a donnée n'étant pas fí tôt afsez forte pour rarefier l'ancienne féve \& la diffiper.

$C^{\prime} e f t$ de cette méchante féve que fe forment les jets malades \& jaunes qui poufsent les premiers aprés le rencailfement d'un Oranger atteint d'infirmité. Pour en pouvoir produire de bons \& vigoureux, il faut qu'il fe foit fait de nouvelles racines. qui agiffans dans la terre neuve, fe rempliffent d'une bonne féve qu'elles font enfuire paffer dains le gros de l'Arbre \& dans les branches. Alors on voit de nouveaux jets qui pouffent au deffous des premiers ; \& fi quelques-uns meurent aprés avoir ainfi commencé à pouffer, c'eft un figne que les nouvelles racines ont peri, ce qui n'arrive gueres, quand on ajoûte une bome \& foigneufe culture 
quiont les Orangers, occ. 89 culture aux autres foins qu'on a apportez dans le retranchement des vieilles racines, \& dans la preparation des teries, dont on les a regarnies.

Cette culture confifte en plufieurs chofes dont il nous faut traiter féparément. Commençons par ce qui regarde le labour que l'on doir donner à ces Arbres, puifque c'eft proprement la premiere operation du Jardinage.

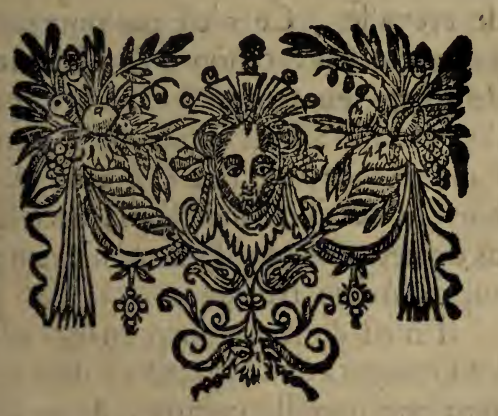




\section{go De la Culture o Labour}

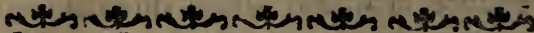
S.

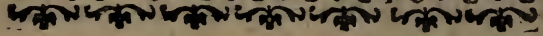

\section{CHAPITRE VIII.}

De la Cultute \& Labour que. demandent les Orangers

\& Citronniers.

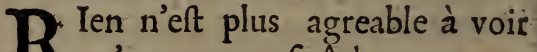
Rqu'une terre fraîchement remuée, \& non point feche \& pleine de crevaffes. Ce n'eft pas pourtant par cette feule raifon qu'on laboure de temps en temps les plants que l'on cultive : Le Labour étant conftamment ce qui fait les bons Arbres, on établit là-deffus la neceffité de cette façon, dont on n'éxemte aucun Arbre fruitier.

Il n'eft donc pas furprenant que les Orangers \& Citronniers demandent une pareille culture, $\&$ un labour qui foit même encore plus frequent; puis qu"étant parmi notss; comme dans une terre étrangere; 
que demandent les Orangers, ofc. or on ne fçauroit trop faire pour les dédommager des avantages qu'ils on perdus. Un des plus grands eft la chaleur du Soleil, qu'ils ont dans les Paìs qui leur font naturels, d'une maniere bien plus forte, que dans nos Climats. Pour y fuppléer, \& pour faciliter l'effer \& l'impreffion de cette chaleur, on doit labourer fouvent les Orangers. Les terres fortes le veulent être plus queles autres, qui par leur legereté, ou par la qualité des matieres graffes, \& chaudes qui entrent dans leur compofition, font plus difpofées à être échauffées. Le labour facilite auffi la penetration de l'eau des arrofemens; \& par un effet contraire à celui qu'il produit dans les terres precedentes, il maintient fraîches celles qui fontlegeres \& fablonneufes, procurant l'evalion de l'air qui les deffechoitinterieurement.

On peut regler ce labour à une: fois tour au moins chaque mois, depuis le mois d'Avril ou Mai jufques à la fin d'Octobre. I e refte du temps il elt inutile de remuër la terre, qui: 


\section{De la Culture \& Labour}

même fe morfondroit, fi on le faifoit, \& perdroir par là cette vigueur que les chaleurs de l'Eté lui ont donnée pour fe maintenir contre le froid.

La raifon pourquoi durant la belle raifon, on laboure fi fouvent les $\mathrm{O}$ rangers, eft parce que la chaleur \& les arrofemens frequens qu'on leur donne, affaiffent tellement la terre, qu'elle s'endurcit prefque fur les racines, \& leur ôrele moien de la penetrer $\&$ de s'étendre. Le labour les décharge de cette pefanteur ; \& par le moien de l'eau qu'on leur donne enfuite, elles, reçoivent avec plus de facilité \& de promtitude l'humeur qui les doir nourrir.

Deux fois l'année en donnant ce labour aux Orangers, il eft bon de mêler à la vieille terre, de nouveaux fents ou ingrediens qui reparent infenfiblement fes pertes, \& qui corrigent ce qu'elle peut avoir de trop froid ou de trop fec.

Quoique ces fients ne puiffent être: enfoncez au-deffous des racines, ils ne laiffent pas de leur être 
que demandent les Orangers, toc. 93 utiles. Les Orangers n'en pouffent pas de fi profondes, fur tout quand on les plante auffi prés de la furface que nous l'avons dit : Ainfi fe trouvant alfez au deffus, ce petit fecours. qu'on leur donne, les fortifie toûjours de plus en plus, \& fait qu'on n'eft de long-temps expofé aux rencaiffemens, ni même dans le befoin des demi rencaifsemens, qu'on peur ne faire en ce cas que tous les quatre ans.

Il me refte à avertir que dans les Labours qu'on donne aux Crangers, on doit prendre garde de découvrir les racines, \& d'infulter à leur mote. Par cette raifon ces Labours doivent être afsez legers, auffi-bien que tous ceux qu'on fait autour des pieds des autres Arbres, \& pour les menus legumes. Dans les grandes caifses or peut les faire avec une petite houlette à la main; \& avec la main.

On Laboure en des temps pluvieux les Orangers qui font dans des terres chaudes \& feches; comme celles de la deuxiéme clafse; \& par ce Labour l'eau des pluies \& des arro-

$\mathrm{H}$ iij 


\section{De la Culture of Labour}

femens penetre jufques aux racines qui en ont befoin : Au lieu que fans cela elles demeureroient fur la fuperficie où elles feroient inutiles \& infructueufes par le defsechement \& l'évaporation qui s'en feroir bien-tôt aprés. Les terres froides, humides, \& fortes comme les troifiémes, veulent au contraire être labourées dans un temps chaud, afin qu'étant amollies, la chaleur s'y infinuë facilement, \& détruife par fon accez, le froid des racines, qui fair jaunir ces Arbres.

Dans l'intervale des Labours qu'on fera tous les mois, on doit par d'autres plus petits, empêcher les méchantes herbes de poufser \& de prendre racines, ce qu'elles ne feroient qu'aux dépens des Orangers, confumant une partie de leur nourriture. Des Labours fi frequens ne font pas fort laborieux \& pénibles; $\&$ quand ils le feroient, lavantage qui en revient: meriteroit bien qu'on $s^{\prime} y$ appliquât ; puis qu'il ne s'agit pas feulement du plaifir qu'il y. a pour la veuë à voir toûjours 
que demandent les Orangers, forc. os des terres fraichement remuées, mais encore du bien de ces terres, \& de la confervation des Orangers; qui ne manqueroient pas de languir, fi par ces Labours on ne donnoit palsage à l'eau des arrofemens, que nous allons voir leur. être necelsaires.-

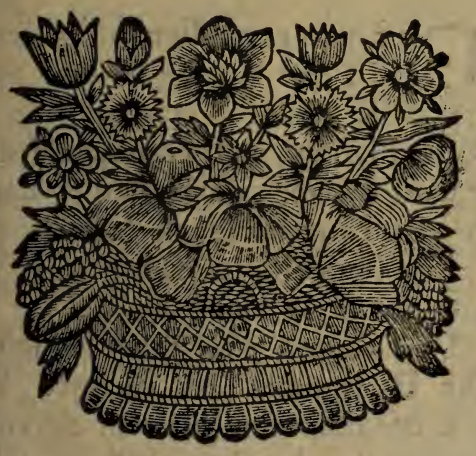


96 Quand o avec quelle proportion

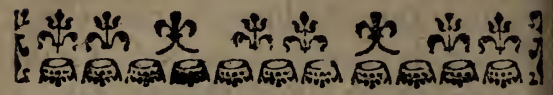

\section{CHAPITRE IX.}

2uand \& avec quelle propor. tion il faut arrofer les Orangers \& Citronniers.

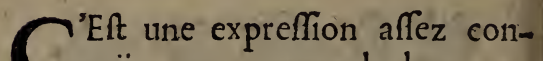
Cnuë, que comme le bon terroir eft le veritable pere des Arbres $\&$ des Plantes, auffi l'eau quand elle leur eft donnée avec mefure $\&$ dans un tems convenable, eft la mere qui par fa fecondité les fait germer \& leur donne la vie.

L'on voit en effet tous les jours que les legumes, par éxemple, les plus communs, ne peuvent devenir parfaits \& abondans, sils ne font humectez dans le befoin ; qu'ils ne profitent \& n'acquierent qu'a force d'eat, la grandeur, groffeur \& les autres qualitez qui les font eftimer; en un mot, quils courent rifque d'être 
il faut arroferles $\mathrm{O}$-angers, $00 \mathrm{C} .97$ d'être durs, amers \& infipides, quand ils n'ont pas le fecours des groffes \& longues pluies, ou celui des grands \& frequens arrofemens.

Auffi n'eft-ce pas de la fubftance materielle de la Terre que fe forme la féve qui fert de nourriture aux plantes; ce n'eft que de l'eau qui en paflant au travers de cette Terre s'eft impregnée de fon fel. I és que les racines manquent de cette eau, elles font connoître leur foif par des feüilles \& des jets fanez. Les Jardiniers foigneux de leur profic, n'attendent pas ce fignal. Outre les pluies qui tombent, ils arrofent reglément en Eté tout ce qu'ils cultivent deux ou trois fois la femaine. Ils n'en exemtent pas les Arbres nouvellement plantez; \& quelquefois même ils arrofent ceux qui aiant retenu une grande quantité de fruir, paroiffent mediocrement vigoureux, \& peu en érat de conduire à une heureufe marurité la recolte dont ils flatent leur efp ir.

Pour nous borner à ceux dont nous traitons, les arrofemens ne. 


\section{Quand o avec quelleproportion}

leur font pas moins neceffaires qu'à toute autre plante. Ils en ont principalement un extréme befoin durant les chaleurs exceffives des mois de May, Juin, Juillet \& Aouft, aufquels, les racines des Orangers devenuës plus vigoureufes qu'aux mois precedens, doivent fournir aux branches le fuc \& la matiere des fleurs \& des jets nouveaux qu'elles pouffent en cette faifon.

Alors on doit arrofer de deux ou trois jours l'un, fuivant que les Orangers font dans des terres legeres ou plus fortes. Les premie. res demandent de l'eau en plus grande abondance, auffi-bien que plus frequemment ; parce qu'aiant moins de corps \& de folidité, l'humidité y refte moins, \& veut par confequent être réiterée fouvent, ̀̀ moins que d'expofer les Orangers à fe faner. Les Terres fortes au contraire, fe contentent d'un arrofement moins abondant \& plus rare, parce qu'elles fone naturelle rent fraiches \& humides, \& qu'elles fe confervent telles plus 
il faut arrofer les Orangers, ơcc. long - tems pour peu qu'on les arrofe.

De-même on doit dans les caiffes arrofer plus amplement que dans les vafes, quelle qu'en foir la Ter-re; non pas neanmoins que l'eau dégorge avec tant de profufion que quelques-uns le pratiquent; il fuffit qu'elle forte fi peu que rien da fond de la caiffe. Que fi l'on jugeoit que les Orangers euffent befoin d'eau plus fouvent que deux ou trois fois la femaine, il faudroir les arrofer mediocrement, c'eft-àdire d'une maniere qu'on renouvellât feulement dans la partie fuperieure l'humidité qui s'eft confommée par la chaleur \& le hale du jour, \& par l'action des racines. Ce befoin fe connoît comme il a été touché, par des feiiilles fanées. \& qui fe ferment. On les trouve mollaffes au toucher, auffi-bien que leurs fruits, fi elles en ont. Il n'y a donc qu'a manier quelques feiiilles entre les doits \& le pouce, de bord en bord par le côté : fi elles fe caflent \& fe rompent fans nean- 


\section{Quand of avec quelle proportion}

moins fe feparer, c'eft un figne que l'Oranger eft plein de féve \& $\mathrm{re}$ porte bien; on fent alors un petit bruit que fait la feiille en $\mathrm{fe}$ caffant, qui marque fa fermeté. Si au contraire elles fe plient \& obéiffent, on peut conter que l'Arbre $\&$ fes racines fouffient quelque difette. Il elt vrai que ce n'eft pas toûjours d'eau; la fechereffe ne met pas regulierement les Orangers en cet étar. Ils fe fanent quelquefois lorfquion eft menacé d'un orage, ou quand n'érant pas encore bien établis en racines \& bien repris, on les expofe avec trop peu de ménagement à toute la chaleur du Soleil.

Pour juger donc fi les feuilles \& les jets fanez demandent de l'eau, il faut par un petir labour foüiller la terre, \& voir fi par fa fecherefle elle peut donner lieu à cette langueur. Si elle paroî feche on peut arrofer; mais fi elle elt encore un peu humide, on ne doit point fe preffer de le faire. L'on fçait en effet, qu'il y a des Orangers qui 
il faut arrofer les Orangers, $60 \mathrm{c}, 10 \mathrm{r}$ paroiffent toûjours fanez, quelque quantité d'eau qu'on leur donne.

Le temps auquel les Orangers veulent ordinairement être le plus arrofez, eft depuis Mai jufqu'à la fin dı mois d'Août, ainfi qu'il a été dit, parce que c'eft alors le tems de la fleur \& de la grande poufle, qui confument toûjours beaucoup d'humeur \& de fuc. Hors de.là, il faut diminuer les arrofemens; je veux dire, qu'au lieu de deux ou trois grands, \& quelques mediocres entre deux, qu'on a fait chaque femaine durant ces tems chaurds, on n'en fait plus qu'un tous les huir jours jufqu'à ce qu'on les ferre, afin de fevrer petit ì petit les Orangers d'une humectation qu'ils ne peuvent fouffrir en hiver fans qu'il leur en coûte beaucoup.

Faute de cette précaution, plufieurs ont le chagrin de voir leurs Arbres fe dépoiiiller, \& quelquefois mourir ; parce que s'étant habituez à boire, quelque temperans \& refervez qu'ils foient là-deflus, on n'a pû fe difpenfer de leur don- 
1022 uand os avec quelle proportion ner de l'eau trop prés de la gelée, dont ils fe font trouvez par la plus fufceptibles.

Pour moi, je n'arrofe plus aprés le grand arrofement que je tais aux Orangers quand ils ont été mis dans la Serre, \& placez aux lieux où ils doivent refter tout Yhiver. La prudence l'enfeigne demême à tout autre Jardinier un peu avifé.

L'utilité de cet arrofement ample \& grand, eft qu'il réünit les Terres aux racines, qui par l'agitation du tranfport ont pû fe feparer, fans quoi elies ne pourroient agir, \& attirer cette continuation de féve qui fait que les feüilles $\&$ les fruits fe nourriffent toûjours \& fe maintiennent en état : \& ce qui me fait croire qu'il eft fuffifant, c'elt que n'y aiant depuis, ni hale, ni grande chaleur capable de deffecher fi-tôt l'humidité qu'il a portée dans le corps \& dans le fond de la mote; il ne peut aufi arriver allcune alteration dans les racines qui puiffe notablement en troubler l'ac- 
ilfaut arrofer les $\mathrm{O}$ rangers, $0 \mathrm{c} .103$ rion, étant beaucoup moindre en hiver que lorfqu'elles font échauffées des raions du Soleil, \& des autres fecours de la belle faifon.

Je dis notablement, parce qu'il peut fe trouver des racines dans la fuperficie qu'il eft bon de rafraichir, lorfqu'on voit dans les feuilles une difpofition à fe faner : mais cette humectation doit être fort legere \& fort fobre, \& jamais on ne doit en venir là dans un tems de gelée; autrement ce remede feroit mortel, \& pire mille fois que le mal auquel on l'appliqueroir.

Qie fil l'on oppofe quil y a quelquefois des Orangers qui poulfent des jets en hiver, \& qui par certe raifon femblent avoir befoin du fecours des arrofemens; je répons hardiment que le peu de cas qu'on doir faire de ces jets, ne merite pas que pour les conferver on mette au hazard un Oranger, comme il le feroit par un arrofement hors de faifon. Je fuis d'avis au contraire, qu'on arrache ces jets nouveaux qui confument la féve qui 
$10{ }_{4}$ Qund ond aves quellepropertion doit fervir à groffir \& fortifier les anciens ; d'autant plus qu'aprés avoir fait cetre diffipation, on voit ordinairement qu'ils periffent \& qu'ils fe dépoüillent.

Au mois d'Avril que le froid eft pallé , \& que la féve commence à s'énouvoir, on reprend les arrofemens qu'on avoit celfez durant l'hiver. Comme alors on ouvre alfez fouvent les portes \& les fenêtres de la Serre pour faire joüir les Orangers de l'afpect \& de la chaleur dir Soleil, leurs Terres demandent abfolument ce rafraîchiffement, étant tout à la fois échaufées , \& par cette chaleur exterieu. re, \&z par l'action des racines qui devient alors plus forte. Il faut neanmoins le leur donner d'abord mediocrement \& en petite quantité. On pourroit fe contenter de les arrofer avec cette moderation, une ou deux fois feulement au commencement d'Avril, \& autant fur la fin ; \& celfant enfuite de le faire jufqu'à ce qu'on eût forti les Orangers pour ne pas appefantir les 
il faut arrofer les Orangers, ofc. 105 caiffes, on attendroit a les arrofer amplement que ce tranfport eût été fait.

Voilà à peu prés les regles que l'on doit fuivre dans l'arrofement des Orangers, qui eft un point qui demande, comme l'on voit, beallcoup de circonfpection ; car fill'on arrofe trop peu, il eft à craindre que les racines ne s'alterent \& ne fe defféchent faute d'humidité, fur tout dans les caiffes \& les Terres legeres où il s'en fait une plus grande confomption : \& f l'on arrofe au ccntraire exceffivement, quoique les Orangers ne s'en trouvent pas mal d'abord, on eft expofé à les voir dépoüiller quand on leur retranchera cette furabondance d'eau ; ontre que c'eft elle qui dénuë plûtôt la Terre de fes fels, \& qui fait qu'on eft plûtôt obligé de rencaiffer, à moins qu'on n'y fupplée en faifant les labours, ou par les demi-rencaiffemens. On peut rappeller là - deffus plufieurs obfervations que $j$ ai faites au chapitre fixiéme, \& dans les fuivans. 
106 Quand of avec quelle proportion

- Il me refteroit à remarquer de quelle maniere fe doivent faire les arrofemens pour être plus à propos, fi je n'en avois déja donné l'idée en parlant de ceux qu'on fait aux petits Orangers par attraction, $\&$ aux grands ou mediocres quand on les a encaiffez la premiere fois, ou changez de caiffe; fçavoir, en percant leur terre \& leur mote de plufieurs trous avec une cheville, \& y verfant enfuire de l'eau à plufieurs reprifes. On doit entre autres, ufer de cette derniere voie comme de la meilleure, quand on arrofe au fortir de la Serre ; \& prendre garde en quelque temps qu'on la pratique, d'écorcher les racines en perçant la terre.

On ne doit pas oublier auffi les hauffes, foit de bardeaux de paille, foit de douves, lorfque la terre s'éleve au deflus de la furface, afin qu'elle ne foit pas entraînée par l'eau que l'on donnera aux Orangers qui font ainfi plantez; \& que cette eau ne s'épanche pas fur les côtez, au - lieu d'aller humecter les racines qui 
il faut arrofer les $O$ rangers, 0 c. 107 en ont befoin. C'eft ce qu'elle fair facilement $f i$ on a foin de tenir la terre bien labourée $\&$ remuée, ou couverte d'un doigt d'épais de crotin de cheval, recouvert de fort pets de terre pour l'agrément de la veuë.

Pour bien ménager l'eau, \& ne pas perdredu temps, on peut partager un plein arrofoir à deux ou trois caiffes, \& recommencer quand cette premiere eau s'eft inibibée, fuivant que l'arrofement doit être grand ou mediocre. L'eau do it on fé veut fervir pour cet ufage doit être tenuë expofée au Solcil dans des cuviers, ou autres baffins. On y peut jetter des fients convenables à l'état des Orangers, afin qu'étant par ces fients, \& par la chaleur du Soleil, corrigée \& réchaufée, eile domne plus de force \& de vigueur anx Arbres, dont elle doit humecter les racines.

On doit éviter de moüiller le trone, ou la tige.

Quelques-uns arrofent fur le midi, \& d'autres fur le foir. Les premiers fe reglent au temps àuquel 
ios Quand of avec quelle proportion

les Orangers ont plus de befoin de ce fecours, ce qui ne peut être plûtôt que vers le milieu du jour ; parce que les rofées de la nuit les ont fuffifamment rafraîchis pour refifter $a$ la chaleur qui fe fait fentir la matinée. La penfée des autres eft, qu'arrofant dans un fi grand hale, l'eau eft d'abord évaporée, \& deffechée, \& n'eft par ce moien que de fort peu de foulagement; au lieu que le foir cetre eau fait merveille, fe mittonnant pour ainfi dire, avec la chaleur qui eft reftée dans les terres. Je prefere ordinairement cette derniere methode, à l'autre, à moins qu'on ne foit dans un temps doux \& fombre; car alors on peut arrofer fur le midi auffi-bien qu'a toute autre heure, fi les Orangers montrent par les indices, que nous avons dit, la neceffité de cetre humectation.

Tout le monde fçair la maniere des Arrofoirs, qui percez comme ils font, de plufieurs petits trous, donnent l'eau d'une façon qui imite une douce pluie. On fait quelque chofe de fanblable dans les Païs chauds, 
it faut arrolerles Orangers, of c. 109 pour arrofer les Orangers en pleine terre, qui parmi nous font ceux qui ont le moins befoin d'arrofemens.

On a des pots de terre cuite de la hauteur d'un pied, \& auffi larges du fond que de l'entrée, en forme de tuiaux. Ces pots riennent environ quatre pintes d'eau. Ils font percez d'un côté de cinq ou fix trous, les uns fur les autres; On enterre deux ou trois de ces pors au pied des Orangers, les pofant au deffus des racines, à un bon pied de diftance du tronc de l'Arbre. On tourne de ce côté les trous, qui doivent tous être enfouis dans la terre, ne devant y avoir qu'environ un travers de doigt des pots qui forte au dehors. Quelquefois on les couvre d'une tuile, \& de terre par-deflus, pour plus de propreté.

Quand il faut arrofer, on remplit ces pots d'eau, qui s'écoulant par les trous, humecte infenfiblement les racines fans qu'il s'en perde la moindre goure. Ce qu'il 
110 Quand of avec quelle proport. of $c$ : faut pour cela obferver, eft que les trous ne fe bouchent point, \& que la terre qui eft autour des pots la plus proche de la furface, foit preflée, \& battuë ; autrement l'eau pourroit regorger par. deffus la terre, \& n'iroit pas abreuver le plant pour lequel elle eft deftinée. On pourroit imiter cette maniere d'arrofer, dans les grandes caiffes.

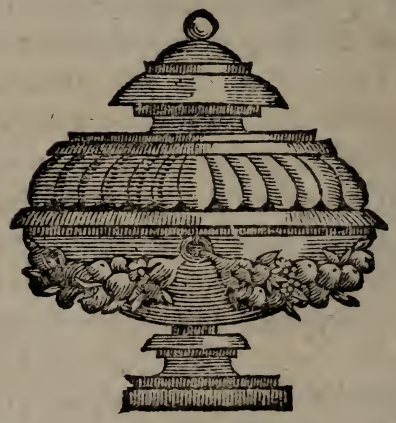




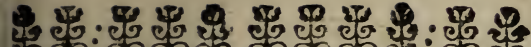 tक} "थ

\section{CHAPITRE X.}

De la Taille on Ebourgeonne: ment des Orangers \& Citronniers, fuivant la figure qui leur convient, \& les autres regles de cette operation.

T A Taille des Arbres eft comme Ll'on fçair, le chef-d'œuture de tout le Jardinage. Elle eft affujettie à diverfes regles, fuivant que les Arbres font, ou nains, ou à haute tige; en Buiffon ou en Efpaliers ; \& fuivant auffi les differentes efpéces \& qualitez de chacun. Plufieurs Auteurs ont écrit fur cette matiere avec beaucoup de connoiffance. Le Curé d'Enonville, le Jardinier Roial, \& les autres qui ont traité de la $\mathrm{Cul}$ ture des Arbres, ont tous montré fur cela leur experience, \& leur $\mathrm{Ca}$ - 
1 i2 Dela Taille of ébourgeonnement pacité; \& nous avons de plus un perit Livre intitulé , l'Art de tailler les Arbres Fruitiers, qui elt tres-bon \& tres-utile.

On n'ignore pas qu'il y a deux raifons principales pour lefquelles on taille. L'une eft pour rendre les Arbres plus agreables à la vûe ; \& l'autre pour les difpofer à porter davantage de fruit, \& à le donner plus beau. On fait le premier en fe propofant dans la taille, la figure qui convient à chaque Arbre. Un Ärbre en Buifion par exemple, veut être bas de tige, ouvert dans le milieu, rond dans fa circonference \& également garni fur les côter. Un Efpalier veut avoir d'autres qualitez pour être dans la perfection qui lui eft propre; \& il en eft de même des Orangers \& des Cirronniers, foit quils foient en Buiffon, à haute tige, ou autrement.

Les Orangers en Buiflon font ceux dont les branches commencent dés le bas. Tels font ces Orangers nains de la Chine, qui ont la feüille perice érroite, \& leur fruit gueres plus 


\section{des Orangers, foc.}

plus gros qu'une cerife: Ce font de ceux-là qu' on peut le mieux cultiver dans des pots ou vafes, à caufe de leur gentilleffe, \& de la facilité qu'il y a à les porter aux lieux où l'on mange, pour profiter de la fenteur agreable de leurs fleurs. Les autres efpeces d'Orangers auffi - bien que les Citronniers s'élevent plus haut. Il y en a depuis deux pieds \& demi de tige, jufqu'a trois, quatre \& cinq, \& c'eft à quoi fe bornent ordinairement ceux que l'on met dans des cailfes. En pleine terre on en voit qui ont au delà de dix pieds. Cette hauteur eft noble \& majeftuetife, mais ne fe peut gueres imiter dans nos Climats. On fait encore des Efpaliers d'Orangers le long des murailles, comme auffi des Berceaux, des Cabinets \& des Ailées couvertes, telles qu'on en à vû̀ à Trianon, \& plus communément dus côté de Genes \& de Nice.

Je ne m'arrêterai pas à ces dernieres difpofitions, non fenlement parce qu'elles font extraordinaires, \& peu ufitées ; mais encore parce 


\section{II4 Dela Taille st éborirgeonnement}

que ceux qui en auroient la curiofité n'ont qu'a fuivre en cela ce qui fe pratique à l'égard des autres efpéces d'Arbres que l'on reduit à de femblables formes. Il ne refte donc à parler que des Orangers à haute tige, pour voir quelle figure leur eft particuliere, \& établir là-deffus la maniere de les tailler.

Nous avons déja touché ailleurs que la tête en doit être pleine \& ronde. Par le premier de ces deux mots, on entend qu' un Oranger foit garni dans le milieu, à la difference des Arbres en Buiffon, qui doivent être ouverts \& vuides, ainfi qu'il a été dit ci-deffus. Il ne faut pas cependant qu'il y ait de la confufion, \& c'eft neanmoins contre ce point que l'on peche communément : car comme les Orangers viennent naturellement pleins par la quantité de bois qu'ils pouffent, auffi-bien que la plûpart des autres Arbres fruitiers; il arrive plûtôt qu'on les laiffe trop épais \& touffus, que vuides $\&$ dépourvûs de branches dans le milieu. 
des Orangers, of $c$. its

Que fi cela fe rencontroit, de quelque maniere que ce fât; pour $y$ remedier il n'y auroit qu'a conferver les branches qui ne manqueroient pas de pouffer à la place de celles qu'on auroit retranchées malà-propos, ou qui peut-être fe feroient rompuës: $\&$ au cas que l'Oranger fût caduque, \& dans un étar à ne pas efperer qu'il fecondât en cela nôtre attente, il faudroit prendre le parti de ravaler une ou deux des grolfes branches qui feroient les plus proches du milieu, afin que la féve qui les entretenoit naiant plus à les nourrir, pût faire pouffer des jets nouveatix aux lieux où l'on fourhaiteroit.

Quant aux Orangers qui fone geunes \& nouvellement encaiffez, il n'y a qu'à lailfer agir la nature : elle pouffera comme je l'ai dit, affez de branches pourr faire une tête pleine. Il n'y aura qu'à prendre foin qu'elles fe nourriffent \& groffifent également, en arrêtant ou pinçant celles qui paroîtroient trop vigoureufes. En quoi neanmoins l'on doir -

$\mathrm{K}$ ij 


\section{De la Taille óbourgeonnement}

prendre garde, que tels Arbres veulent être traitez avec plus de liberté, que les autres; parce que ne leur laiffant ordinairement aucunes vieilles branches, ils ont befoin d'en pouffer promtement d'affez grandes $\&$ d'affez dégagées pour former une tête qui réponde à la hauteur \& groffeur de leur tige.

La rondeur depend d'un peu plis de precautions. Elle fuppofe qu'un Oranger ne foir trop allongé, ni plat par l'un des côtez; que fes branches ne baiffent point vers la terre, ni ne fe terminent en pointe comme un Cyprés; mais qu'à la maniere des Maronniers d'Inde, \& de quelques autres Arbres, elles forment comme un ceintre d'une mediocre élevation, \& d'une circonference égale, fans avoir rien de trop affecté, ni de forcé, comme ces Arbuftes que l'on rend à defsein d'une figure ronde, mais feulement à force de coups de cifeaux.

A prés s’être propofé cette idée de rondeur quand on encaifse un Oranger, \& qu'on racourcit fes branches, 


\section{des Oraigers, occ.}

voici comment on doit le gouverner dans la fuite pour y parvenir. Les jets vigoureux qu'on lui aura laifsé poufser les premieres années, lui aiant formé une tête à peu prés proportionnée à fon pied; fi l'on voir qu'il y ait des branches qui s'élevent ou s'étendent plus que d'alitres, parce que la féve y prend fans doute plus de cours; il les faut pincer \& arrêter à une hauteur ou longueur raifonnable au temps de la poufse ; ce qu'on peut fixer à environ un demi pied par an, finon les tailler kannée d’aprés au Printemps.

Pour empêcher qu'elles ne panchent contre terre, ce qui ne provient que de leur foiblefse; il faut en regler la charge fuivant la vigueur \& grofseur du pied, diminiiant le nombre des jets qui poufsent conjointement, afin que ceux que l'on confervera, lefquels doivent toûjours être les mieux placez, \& les plus propres à la figure qu'on a en vûe, étant fortifiez du furcroit dé féve qui fe partageoit aux autres, 
118 De la Tuilleơ ébourgeonmement deviennent plus capables de fe foû. tenir droits, ainfi que font natu- ? rellement les branches bien nourries de tout Arbre qui eft en bonne ter. re, comme nous fuppofons que foit un Oranger.

Cet ébourgeonnement fe doit auffi faire au temps de la poufse, \& toûjours le plûtôt qu'il eft poffible; étant inutile, \& même préjudicia. ble de laifser confumer une partie de la féve à des branches qu'on doit ôter.

Que fi faute de ces foins ou par un autre accident, un Oranger excede, ou n'a pas la rondeur que nous avons marquée, il faut y remedier par la Taille. C'eft pourquoi, s'il eft par éxemple trop en pointe, on retranchera toute cette furéminence, pour la reduire à une rondeur plus applatie , \& qui approche en quelque façon de la figure d'un Champignon. S'il y a des branches qui fe foient trop alongées, on les ravalera jufqu'à celles qui font plus foibles. L'on en ufera de même fi l'un des côtez elt plus plat que l'au: 
tre, foit que cela provienne de ce que quelque branche fe fera rompuë, ou du peu d'habileté de celuí qui aura cultivél'oranger. Et fi les branches en font panchées, aprés avoir examinè fi ce n'elt point par le defaut d'une bonne nourriture ; on retranchera toutes celles qui feront les plus foibles, à moins qu'elles ne contribuent necefsairement à la perfection de la forme que l'on fouhaite.

Voilà les trois operations que l'ors doit regulierement pratiquer tous les ans à l'égard des Orangers; c'eltà-dire, le pincement, l'ébourgeonnement, \& la taille. Par le premier qui confilte à rompre avec l'ongle l'extremité des gros jets trop vigoureux, on fait un Arbre d'une égale fimetrie. L'ébourgeonnement empêche qu'il ne devienne trop confus \& trop chargé : Et la taille re. forme avec fuccez tous les défauts où peut tomber un Oranger, faute d'avoir pratiqué dans le temps deux operations fi importantes.

La poufse que nous avons dit être 
120 De la T aille ébourgeonnement. ce temps-là, arrive dans le mois de Juin. Durant cette premiere $\&$ grande action, les jets font fi - tendres qu'on les carse comme du verre. Elle recommence vers la fin de Juillet, \& au commencement du mois d'Aouft. L'on pince \& l'on ébourgeonne encore urilement dans cette feconde poufse, quoique moins que dans la premiere. Mais fi ce redoublement ne vient que fur la fin d'Aoul, ou en Seprembre: il eft plus à propos de negliger \& d'arracher les jets qui poufferont alors, afin que la féve qui les commencoir demeurant dans les branches où fe faifoit cette pouffe, les rende plus fortes \& plus vigoureufes; que de conferver tels jets au prejudice de ces branches, \& les voir infuite perir comme ils feront dans la ferre, pour n'avoir pas eû le remps de s'aoufter \& de s'endurcir.

A l'égard de la Taille on la pratique fil l'on veut, an Printemps quand on met dehors les Orangers, ou à la fin de l'Eté avant que de les ferrer. En taillant dans certe der- 


\section{'des Orangers, ofc.}

I2E

niere faifon, on ménage les forces d'un Arbre qui n'en doit gueres recevoir de tout l'Hyver : Et le faifant au Printemps avant que la féve foit en mouvement, on le difpole à emploier toute la nourriture dont il doit profiter, à fe bien rétablir, \& à acquerir la perfection \& la beauté qui lui manque.

Et en effer, il n'en eft pas de la taille des Orangers, comme de cels les de beauccup d'autres Arbres; fouvent dans ceux-ci une branche tallée ne repouffe rien, à caufe de la trop grande abondance de gomme. Mais dans les Orangers la taille eft plus heureufe. Elle pro. duit immancablement, auffi-bien que le pincer, beaucoup d'autres branches au lieu de celles que l'on coupe; ainfi il ne peut pas fe faire qu' il n'en revienne un grand avant ge, fans parler de celui que l'on trouve dans les branches, que l'on ch ifit alors pour les planter dans des caiffes ou pors où elles puiffent reprendre de bouture, comme nous l'avons dit au commencement. 
122 De la Taille e ébourgeonnement Venons maintenant à la fecon: de raifon pour laquelle on taille. Nous avons remarqué que c'eft pour difpofer un Arbre a donner davanrage du fruir, \& qui foit plus beau. A l'égard des Orangers, on doir auffi fe propofer d'avoir de plus belles fleurs, \& même des feüilles plus vertes \& plus grandes, puifque leur beauté confifte en tout cela.

Or c'eft à quoi l'on parvient par les mêmes regles que nous avons établies. Car pour commencer par les feuilles, il eft certain que plus les jets font beaux \& vigoureux, tels quion les a quand on pince \& qu'on ébourgeonne à propos, plus belles auffi font les feuiilles dont ils fe chargent; au lieu que les jets foibles ne fçauroient en avoir que de fort petites, contre le naturel de ces Arbres, qui eft de les avoir grandes, larges, épaifles \& hien vertes. Il arrive de plus que les feuilles des branches vigoureufes font de plus de durée: Elles vivent quelquefois des trois \& quatre ans; ou fi elles $t$ mbent plûtôt, celles des jets nouveaux 


\section{des Orangers, ofc.}

qui repouffent à l'extremité des branches pincées, prennent leur place, \& forment une nouvelle décoration. Au contraire quand les feüilles font petites, \& que l'on ne prévoie pas de bonne heure à leur en fubltituer d'autres par ces voies, on doit s'attendre à voir un trés-méchant effet; car venant à tomber, elles privent l'Oranger d'un ornement qui doit toûjours l'accompagner, \& qu'on ne peut lui rendre qu'en retranchant abfolument tout ce qui s'elt dépoïillé.

Pour ce qui eft des fleurs, les $\mathrm{O}_{-}$ rangers en portent de deux fortes. Les premieres paroiffent au Printemps. Elles viennent en grand nombre fur les jets de l'année precedente, mais font ordinairement petites \& rondes, \& font fujettes à tomber fans achever de fleurir.

Les autres ne commencent à paroître que fur la fin de Juin, \& qu’à la my-Juiliet : Elles viennent à l'cxtremité des jets nouveaux de l'année même ; elles font grandes, longues \& bien nourries, mais moins abondantes. 
124 De lat aille óbourgeonnement C'eft cependant certe abondance de fleurs que plufieurs perfonnes recherchent. Dans cetre vûë ils n’ébourgeonnent jamais leurs Orangers à la premiere pouffe : ils attendent toûjours que les fleurs foient paffées; \& c'elt veritablement le moien d'en avoir davantage, mais de fort perites, \& même des Arbres moins beaux.

Pour moi je pratique le contraire ; parce que je prefere une quanrité raifonnable de fleurs qui foient belles, grandes, longues, \& lourdes, à une plus grande confufion qui les donne plus chetives : Et bien loin de procurer par l'abondance une beauté de fi peu de durée, j'eftime qu'il faut toûjours éclaircir \& décharger un Arbre d'une parcie des fleurs qu' il produit, principalement de celles qui pouffent les premieres, puifqu'il y en a beaucoup au delà de ce quil en peut nourrir ; la nature l'aiant ainfi difpofé, afin que de ce fuperflu l'homme en fit ces parfums $\&$ ces eaux de fenteurs, qui font $\mathrm{ft}$ utiles \& fi agreables. 


\section{des Orangers, ooc.}

Je remarquerai en paffant que les fleurs des Limonniers doux, \& des Orangers, font entierement femblables, \& mal-aifées à diftinguer. Il n'en eft pas de même des autres $\mathrm{Ci}$ tronniers, qui ont la fleur plus grof$\mathrm{re}, \&$ moins blanche; ainfi on n'a pas de peine à en faire la difference.

Enfin à l'égard du troifiéme poine; il n'eft pas difficile de juger, qu'on ne fçauroit manquer d'cvoir fuffifamment de beaux fruits, aiant des fleurs aufi-bien conditionnées que nous avons dit, \& qu'on les a effectivenent quand on obferve le temps \& la maniere de pincer \& d'ébourgeonner, \& les autres foins qui ont été marquez; Mais on ne convient pas de celles qui font plus propres a laiffer noiier pour donner ces fruits. Les uns choififfent celles qui pouffent \& fleuriffent les premieres, pretendant que le fruit qui en vient, eft plus gros \& plus fort que celui que les dernieres fleurs produifent, \& par confequent avancé d'autant pour l'année fuivante. Les autres 
126 Dela Taille é ébourgeonnement au contraire font pour les fleurs qui viennenr fur les jets de l'année, comme aiant toutes les belles \& bonnes qualitez requifes. On peut à mon avis, en laiffer notier des unes. $\&$ des autres, mais beaucoup moins des premieres; \& ce qu'on doir éviter en cela, c'eft de n'en gueres laiffer deux enfemble à une même extremité; de peur qu'elles ne s'empêchent mutuellement de groffir, \& que le jet qui les porte ne foit pas au hazard de fe rompre par le poids de leur pefanteur.

Pour obvier à un pareil accident, dans les Païs où les Orangers $\& \mathrm{Ci}$ rronniers font capables de nourrir un plus grand nombre de fruits, it eft affez ordinaire de les voir foûterenir \& étaier avec des bâtons fourchus. C'eft un bon expedient pour relever les branches qui pendent au lieu de fe foûtenir ; nais il n'auroit pas un grand agrément parmi nous \& dans nos Climats, où l'on ne cultive gueres ces Arbres, pour le profir qu'on retire de leurs fruits.

Ceux qui auroient ces vûës, doi $=$ 


\section{des Orangers, of.}

vent particulierement obferver de ne pas ôter autant de bois aux Citronniers \& Limonniers, qu'aux Orangers. La raifon eft qu'ils s'en fourniffent beaucoup moins, quoique naturellement mieux faits : De forte que ce feroit leur ôter le moien de porter beaucoup de fruit, que de les ébourgeonner \& tailler autant qu'on peur faire les Orangers.

Cette difference de naturel entre ces Arbres fait qu'on les entre-mêle, plaçant un Oranger entre deux $\mathrm{Ci}$ tronniers, ou un Citronnier entre deux Orangers. Par ce mêlange qui plaît aux yeux, le Citronnier qui ne s'écarte pas tant, laiffe affoz d'efpace pour l'Oranger qui s'étend das vantage.

Je crois inutile d'avertir ici, qu'en taillant on doit couper jufqu'au vif tout le bois mort, retrancher les brins qui font rompus, \& arracher toutes les épines, \& les petites queuës aufquelles il y a eu du fruir attaché. C'elt un foin commun à tous les autres Arbres qu'on eftime un peu, \& qui tombe aifément dans

L iiij. 
${ }_{2} S \mathrm{De}^{\prime}$ T Tille of ébourgeonnement la penfée ; puifque toutes ces chofes ne feroient que défigurer la beauté \& la netteté a laquelle on doit tendre.

J'ajoûterai feulement, que les $\mathrm{O}$ ranges noiiées en Juin ou Juillet ne font d'ordinaire bonnes a cueillir qu'environ quinze mois aprés ; \& c'elt alors qu'elles commencent à jaunir.

Ce feroit là, ce me femble, tout ce qu'il y auroit à dire, fi la Taille des Orangers \& des Citronniers, n'avoit que les mêmes motifs que celle des autres Arbres: Mail il y a d'autres cas où il en faut venir à cette operation. C'eft quand il s'agit de rétablir un Oranger malade que l'on rencaiffe. Comme alors on retranche beaucoup aux racines, ainfi que nous l'avons vû en fon lieu, il eft jufte de diminuer auffi la charge de la tête, pour la proportionner a la vigueur du pied, \& à la nourriture qu'elle en peut recevoir. Or voici ce qu'on y peut obferver.

Les extremitez des branches étant ce quil y a de plus infirme \& 
des Orangers, of $c$.

de plus foible, à caufe que la féve étoit ou trop diminuée, ou trop partagée; il faur les ravaler \& rogner confiderablement, fe reglant la-deffus fuivant le long-temps qu'il y a que l'Arbre eft malade. On doir auffi fe propofer toûjours les conditions que nous avons marquées cidevant, taillant autant que l'on pourra, de telle Yorte, que les nouveaux jets qui poufferont aux extremitez des vieilles branches qu'on aura racourcies, forment vrai-femblablement cette tête pleine, ronde, \& dégagée qui eft à fouhairer. Conftamment il vaut mieux couper beaucoup, que d'être obligé d'y revenir ; parce qu'outre le temps perdu, tant de differentes incifions ne font que produire une tête pleine de confufion, \& peu agréable.

C'eft principalement aux menuës branches que l'on doir s'en prendre, quoique les feüilles qu'elles ont paroifent les devoir faire épargner; puis qu'auffi-bien elles s'en dépoiiillent peu de jours aprés le rencaiffement, \& font enfin voir par là la 
$130 \mathrm{DelaT}$ aille é ébourgeonnement neceffité indifpenfable qu'il y a de les retrancher. Pour les grolfes it les faut conferver avec plus de foin; $\mathrm{Ce}$ font elles feules qui font propres à former un Arbre de belle figure, en pouffant des jets vigoureux, \& gros comme elles. Ceux qui pourroient fortir des branches foibles, \& qu'on voit affez beaux, ne doivene pas pour cela être d'une grande con. fideration. Un jet pour être reputé tel, doit naîrre de quelque bon endroit de l'Arbre, foit des branches fortes, ou de la tige : puis qu'il n'y a que ceux-là qui puiffent donner de grandes feuilles, \& de belles fleurs, qui font les deux grands ornemens des Orangers.

Il arrive quelquefois que quoiqu'on ait coupé beaucoup, il y a des extremitez racourcies qui meurent fans rien poulfer : c'eft entre autres le fort des Arbres qu'on a laiffé languir rrop long-remps fans leur donner du fecours. Alors il ne faut pas differer de les couper encore plus bas, c'eft-à-dire, jufqu'au vif. On comnoit quand il le faut faire, à voir 


\section{des Orangers, ofc.}

le bois fe fecher, noircir, \& fe fendre. Hors de la il faut avoir patience quand un Oranger ne profite pas felon nôtre fouhait, pourvû qu'on n'ait rien à fe reprocher d'ailleurs; \& fe fouvenir que, comme nous l'avons déja dit plus d'une fois, tels Arbres font fouvent deux ou trois ans, fans rien faire qui vaille, pour avoir été trop negligez.

Si fur les vieilles branches des Orangers rencaiffez que l'on aura racourcies, il en fort de nouvelles en plufieurs endroits, \& que les plus belles d'entre ces nouvelles branches fe trourvent les plus proches du corps. de l'Arbre; il eft plus à propos de raprocher fur ces plus belles, \& d'abandonner le refte, que de continuer la figure \& l'érenduë de l'Arbre fur l'idée qu'on avoit, fous pretexte qu'elle eft plus avancée; parce que la grande vigueur de ces nouvelles branches les fera bien.tôt atteindre à la perfection des autres, \& rendra l'Oranger plus égal \& plus plein: Et $f$ les jets qui poufferont dans toute l'étenduë d'une branche qu'on 
132 Dela Taille \& ébourgeonnement aura laiffée affez longue, ne font que tous petits, foibles \& jaunâtres, au lieu d'être forts \& vigoureux,comme on fe l'éroit attendu pour la beatté de la figure ; il la faut abfolument tailler dans le fort de la féve, afin que ce que l'on confervera s'en porte mieux, ainfi qu'on aura le plaifir de le voir arriver.

On doit gouverner les nouveaux jets qui poufferont aux branches d'un Oranger rencaiffé, avec les mêmes foins que les aurres; c'eft-à-dire, que s'il y en a trop il faut les ébourgeonner, \& ne laiffer que les plus forts \& les mieux placez: \& fi ceuxlà aiant ê̂. par ce moien plus de nourriture, deviennent fi longs, comme ils font en peu de jours, qu'ils excedent les autres branches; on les pincera pour ne leur domer qu'environ la longueur d'un demipied, à guoi nous avons dit que peut fe borner le progrez d'un Oranger de chaque côté ; puifque cela produit un pied de diametre de plus par an, qui fait en peu d'années une érenduë fort confiderable. Il n'et pas 
des Orangers, \&cc. $\quad i_{33}$ neceffaire qu'il en acquiere autant pour la haureur : il fuffit qu'elle foit d'un demi-pied chaque année ; tant parce que plus les Orangers \& les Citronniers s'élevent, moins ils produifent de fruits, qu'à caufe que cela fortiroit de cette rondeur un peta plateque l'on doit chercher, afin de mieux joüir de tout ce qu'il y a d'agreable dans ces Arbres.

Les branches pincées veulent encore être ébourgeonnées, fi elles ne repouffent également, de forte que l'on ne conferve aucun de to'is ces nouveaux jets, à moins qu'il ne foir neceffaire pour la perfection de la tête; \& fi l'on avoit manqué de pincer, on reparera cette negligence par la Taille conformément à ce qui a été touché ci-deffus.

Aprés qu’on a taillé, il faut recouvrir la plaie, pour la défendre contre la pluie, le froid \& l'ardeur du Soleil. On fe fert pour celad'une cire preparée, fans beancoup de façon, fçavoir de la cire jaune neuve, $\&$ de fort peu d'huile, fondus $\&$ niệlez enfemble. J'y ajoûte de la 
$\$ 24$ Dela Taille Ǽ ébourgeannement poix-refine, aiant remarqué que cette cire feule ne demeure pas long. temps fur la coupure; parce que les Abeilles qui viennent ramaffer leur miel fur les feüilles des Orangers, la détruifent \& la tranfportent dans leurs ruches. Si l'on a été obligé de fe fervir de la fcie pour des branches rop grofles, il faut parer la fcieure avec la ferpette avant que d'y metrre la gomme ou cire. On taillera, fi l'on m'en croit, au Decours, comme la plûpart le veulent, ou bien en tout autre temps, pourvû qu'il ne foit ni trop chand, ni froid, ni humide, c'eft-à-dire pluvieux ; ces differentes conjonctures étant feules dangereufes \& dommageables. Nous avons vû jufqu'ici les moiens les plus reurs d'avoir des Orangers en bon état, \& de rétablir ceux qui font défectueux, loir faute de vigueur, ou du côté de la figure. On fait le dernier par les rencaiffemens, par la taille, $\&$ les autres operations dont nous venons de parler; \& l'on parvient au premier par la bonne nourriture qui 
des Oranvers, of c. dépend de la bonne terre, par les encaiffemens bien faits, par les bons labours \& \& par les arrofemens bien ménagez. Il nous refte encore quelques ennemis à détruire; mais ils font la plûpart peu confiderables; \& l'on ne manque pas d'expediens pour garantir de leur maligniré les Arbres qu'ils attaquent. 'Voions quels font les uns \& les autres.

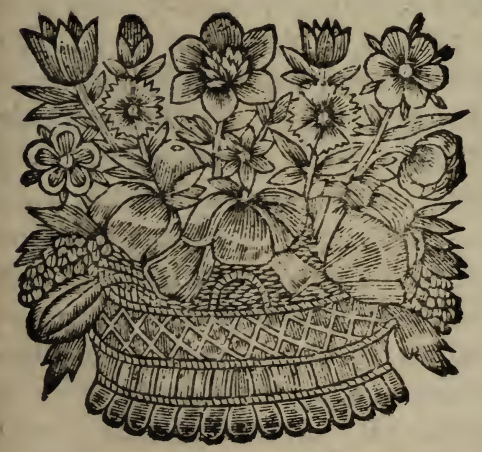




\section{x;6 Des Infectes}

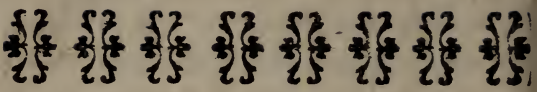

\section{CHAPITRE XI.}

Des Infectes \& autres ennemis. des Orangers of des

\section{Citronniers.}

L n'eft point d'Arbre, ni de plan-' Ite qui ne foit fujette à être alterée par certains infectes. Ceux qui attaquent particulierement les Orangers, font les fourmis, les punaifes \& les perce-oreilles. Les fourmis rongent les feüilles, \& re font guéres d'autre mal à $\mathrm{l}^{\prime} \mathrm{Ar}$ bre: mais parce que leur frequentation y engendre les punaifes, comme reciproquement elles y font attirées par le couvain de ces dernieres, il faut avoir foin de les exterminer dés qu'on voit qu'elles fe jettent fur un Ärbre.

On a pour cela plufieurs remedes. Quelques - uns prennent du 
to autres ennemis des Orang. \& c. 137 blanc d'Efpagne ou de la craie blanche, \& l'aiant pilée \& mife en poudre, ils en frotent legerement le tronc de l'Oranger, y en appliquant à la largeur de deux pouces; \& quand la pluie a emporté ce blanc, ils en remettent d'autre.

Les autres fe fervent de laine cardée dont ils envelopentl'Oranger au premier fourché, à la même largeur que ci-deffus, lailfant cette laine plus ferrée au haut qu'au bas, afin que les fourmis s'y embarraffent.

On a encore l'expedient des canaux ou vafes de fer blanc, de plomb, de cuivre, ou même de bois \& de terre pour ceux qui ne peuvent en avoir d'autres. On en fait de deux fortes; les uns pour y mettre les pieds des caiffes, \& les autres pour mettre autour du-trone de l'Oranger. Ceux-ci font de deux pieces,que l'on rejoint \& reffoude aifément quand ils font placez, de maniere qu'ils embraffent le bas de a tige fans laiffer aucun vuide. Quand. ils font de terre cuite, les 
extremitez que l'on affemble doivent être moins épailles de quelques lignes que le refte, afin qu'elles puiffent mieux fe joindre, en y mettant un peu de terre glaife. On remplit ces vafes d'eau qui regne ainfi tout autour de l'Arbre fans le moüiller; car s'ils perdoient l'eau, cela pourroit lui être nuifible : \& c'eft un obftacle aux fourmis pour monter à l'Oranger; auffi-bien que les vafes que l'on met aux quatre pieds des cailfes, lefquels font tout d'une piece, ces perits animaux ne hazardant pas de faire le trajet de l'eau qu'il contiennent fans $y$ perir.

Un remede encore plus feur, eft de prendre une phiole de verre que l"on frote de miel par le dedans: aú bord de l'embouchure, \& qu'on attache au premier fourché de l'O. ranger, en forte qu'elle touche le ronc. Cette liqueur atrire les fourmis, \& quand elle en eft couver$r e$, on vuide la phiole pour y en mettre d'autre. Les phioles carrées cont plus propres pour cet 
of autres ennernis des Orang. of c. $1: 9$ cffet que les autres

Tous ces remedes fuppofent qu'on ait auparavant challé les fourmis de l'Arbre, foit en fecoiiant doucement chaque branche, foit en les tuant dans l'Arbre, les preffant avec les doigts contre l'écorce, ou enfin les abbatant de quelqu'autre maniere. On s'en fert auffi pour faire la guerre aux perce-oreilles qui font de petits infectes rouffâtres \& fort vifs dans leur marche, lefquels fe jertans quelquefois fur les Orangers, rongene leurs feiiilles \& leurs fleurs. Comme c'elt pendant la nuit qu'ils font ce petit dégât, on s'elt avifé d'un expedient encore fort bon pour les, furprendre. Ce font des cornets de papier \& des ongles d'animaux à pied fourchu dont on met plufieurs en differens endroits de $\mathrm{l}^{\prime} \mathrm{Ar}$ bre. Les perce-oreilles s'y cachent dés que le jour paroîr; \& la on les. prend \& on les écrafe, quand on: vient à en faire la vifite.

Les punaifes \& leur couvain ne rendent pas feulement un Oranger 
hideux \& défagréable, mais elles alterent auffi la féve. Elles font plates $\&$ affez ailées à connoître, quoiqu'elles foient d'une couleur qui approche du verd du bois de ces Arbres. Les premieres qui infectent uu Oranger font des meres punaifes qui volent ; elles font leur couvain en automne, s'attachant principalement aux feüilles fales \& aux roupillons ; c'elt-à-dire, à ces menuës branches qui viennent en confufion tout auprés les unes des au-. tres, qu'on n'aura pas eu foin d'éclaircir \& d'ébourgeonner. Ce couvain n'eft pas plus gros d'abord. que la tête d'une épingle; on diroit que ce ne font que de petites taches de rouffeur. Mais on en voit. bien l'effer l'année fuivante, fi. l'on n'y remedie de bonne heure ; car la chaleur de l'Eté le fair groffir \& enfler confiderablement'; \& venant enfin à éclore, il produit. un grand nombre de punaifes qui l'Automne font d'autres couvains, \& infectent l'Arbre de plus. en plus. 
- antres ennemis des Orang. TC. 14

Ce qu'il y a à y faire, c'eft d'a. voir une petite broffe pour les ôtes: auffi-tôt que l'on s'en apperçoit, ou bien de les arracher avec les ongles, \& de les écrafer auffi-bien que les punaifes qui exhalent alors une extréme puanteur. Et enfuite on peut décharger l'Arbre de quelquesunes de fes branches, afin qu'il 'n'en ait pas tant à nourrir, puifque cette vermine en a diminué \& corrompu la féve.

Il n'y a comme l'on voit, aucun de ces infectes qui s'en prenne aux racines des Orangers, comme ceux qui defolent beaucoup d'autres plantes; \& c'elt fans doute un grand avantage pour enx, purfque de cette maniere le mal qu'ils en peuvent recevoir n'eft point incurable, mais au contraire tres-facile à reparer fi l'on veut y prendre un peu de foin. Il y a d'autrés ennemis dont il n'eft pas fi bien en nôtre pouvoir de les défendre, quoiqu'ils n'attaquent point non plis les racines. C'elt par exemple, une grêle fâcheure qui en déconpe \& déchire les feuiilles, 


\section{Des Infectes}

\& qui rompt mêtne quelquiefois des jets fort neceflaires pour la beauté de l'Arbre.

Lorfque ce malheur arrive, il faut ĉter ces feuiilles ainfi hachées, \& couper les jets rompus au-deffous de l'endroit out ils le fent. S'il y en avoir beaucoup de rompus, \& qu'en les retranchais comme on le doit, l'Oranger fe trouvât entierement défiguré, il faut autant retrancher aux côtez qui n'ont pas été endommagez, que fur ceux qui le font, afin de rendre l'Arbre égal. Pourveu qu'il foit vigoureux, il fe fera bientôt remis de cet accident; que s'il étoit infurme \& en: langueur, il faudroit fonger au rencaiffement, \& le fuire außfi-tôt fi la grêle eft tombée fur la fin de Mai, ou au commencement de Juin, comme c'eft la faifon qui y eft la plus. fujette; ou fi elle a donné plus tard, fe contenter de retrancher ce qu'il y a de gâté, foit aux branches, foit aux feiiilles, jufqu'ì ce qu'on: faffe le rencaiffement en un tems plus convenable. 


\section{0 autres enriemis des Orang. foc. 143}

Les grands vents font encore fort contraires aux Orangers \& Citronniers ; ceux entre autres qu'ils craignent particulierement, font les vents du Nord qui regnent entre le Couchant \& le Midi. Comme ils. ne fouflent gueres avant l'Automne, on peut en garantir ces $\mathrm{Ar}$ bres en les plaçant au commencement de cette faifon, à l'abri de quelque mur ou de quelque bois: oppofé, où ils ne laiffent pas deprofiter des raions \& de la chaleur du Soleil.

Mais le grand \& mortel ennemi des Orangers eft le froid. C'ift: par lui que l'on perd fouvent en une heure, le fruit d'une culture foigneufe de plufieurs années. Les Eitronniers y font encore plus fenfibles que les Orangers, parce: que ceux-ci ont le bois plus dur. Heureux font ceux qui habitent des climats affez doux malgré la rigveur ordinaire d'une telle faifon ${ }_{2-}$ pour navoir befoin que d'envesloper le tronc de ces Arbres avec de la paille ou fougere. Pour 


\section{$7_{44}$ Des Infectes}

nous, il nous faur de plus grandes précautions. La principale eft une bonne Serre pour les Orangers qui font dans des pors \& dans des caiffes. Faifons donc connoître quelles en doivent être les conditions; $\&$ nous parlerons enfuite des autres moiens de garantir du froid ceux de ces Arbres qui font en pleine Terre, foit en Efpalier, ou autrement.

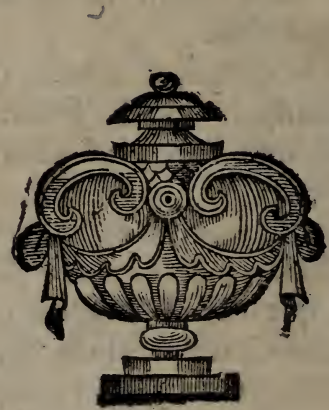




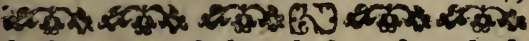

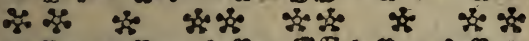

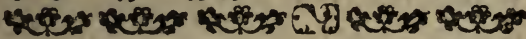

\section{CHAPITRE XII.}

Defcription d'une bonne Serre, \& des autres expediens par lefquels on peut garantir dis froid les Orangers \& les $\mathrm{C} i$ tronniers.

T E bâtiment que nous appelLlons Serre, pour y ferrer \& loger en feureté les Orangers \& les Citronniers durant l'hiver, doit avoir plufieurs conditions. Pour commencer par celle qui regarde fa fituation, elle doir être expofée le plus que l'on peat au Midi; de forte que le Soleil la regarde \& la frappe de fes raions depuis neuf ou dix heures du matin, jufqu'a ce qu'il foit prêt de fe coucher. L'expofition du Levant qui donne le Soleil depuis fon lever jufqu'à deux out trois heures aprés midi, n’elt

$\mathrm{N}$ 


\section{$146 \quad$ Defcription}

gueres moins favorable. On peut fe paffer de celle du Couchant faute d'autre, aiant encore le Soleil affez confiderablement, fçavoir depuis midi jufqu'au foir : mais pour celle du Nord, autant prefque vaudroitil de n'avoir point de Serre, que d'être reduit à $\mathrm{fe}$ contenter d'une qui s'y trouvât ficuée, puifqu'elle ne jouiit que tres-peu du Soleit. Il eft plûtôt a fouhaiter qu'outre le rempart d'un bon mur qu'on oppofera de ce côté, on la puiffe adoffer à quelque autre bâtiment, à uhe montagne feche, ou à quelque bois de haute futaie qui la metrent d'autant plus à l'abri des incommoditez gui lui peuvent venir de lì.

L'expofition étant choifie, il faut commencer par de bons fondemens. Il eft à propos qu'ils foient de trois pieds de profondeur fi l'on peut, à caufe qu'il elt plus facile quand les Orangers croiffent \& s'élevent, de tirer un ou deux pieds de terre de l'Orangerie pour l'abaiffer, qu'il ne feroit d'élever tout le bâtiment. 
d'une borine Serre, doc. 147 Ce fera encore mieux fi l'on donne d'abord à la Serre une hauteur affez confiderable, comme de quin-. ze à feize pieds; car 1 left à craindre que le fol étant plus bas que le rez de chauffée, il ne ferve d'égoût aux eaux de dehors, \& n'attire par ce moien une humidité qui peut être fort nuifible.

Quant aux murs, voici quelle en doit être la conftruction. Il faut une bonne muraille du côté du Nord, fans aucune ouverture. Elle peut être de moilon \& de mortier à chaux \& à fable, ou bien de plâtre, fi ces materiaux font communs. Ailleurs où l'on n'en a pas commodément, on peut faire une mu:raille de bauge ; c'ett-à-dire de terre detrempée, \& mêlée de foin \& de chaume pour lui donner plus de confiftance, ou bien une double cloifon de bois dont cn remplit l'entre-deux de terre ou de fable.

L'épaiffeur de ce mur de quoi gu'il foir, doit être du moins de trois pieds, Les deux pignons doiyent être de-même. Le côté ex= $\mathrm{N}$ ij 
pofé au Soleil veut être le plus ouvert qu'il fe peut. Il feroit bon que les fenêtres \& les portes qui l'occuperont entierement, ne fuffent feparées que par des piliers, foit de bois ou de pierre, afin que les ouvrant, les Orangers fe trouvaffent comme en pleint air, \&z fuffent mieux vûs du Soleil.

Les fenêtres peuvent avoir quatre, cinq ou fix pieds de large, \& la hauteur de toute la Serre, à la referve de l'appui, qui pour l'ordinaire eft de trois pieds ou trois pieds \& demi. La porte doir avoir la même hauteur, \& une largeut fuffifante pour le palfage des $\mathrm{O}$. rangers.

La menuiferie en doit être fi jufte, auffi-bien que celle des fenêtres, qu'elle ne lailfe pas le moindre jour. Comme il eft mal aifé d'avoir des ais auffi longs, on peut faire une porte brifée, dont le haut n'ouvre que pour entrer \& fortir les grands Orangers, o: qui fe démonte de quelque autre maniere.

Il feroir fort utile que ces portes 
d'une bonine Serre, ơ $c$.

fulfent doubles \& à deux battans; en forte que l'une s'ouvrit en dehors \& l'autre en dedans, pour ab_ battre la premiere fur foi quand on veut aller faire la vifite dans la Serre, fans que le froid s'y infinuë. On peut encore remplir l'entredeux de ces portes, de foin biern preffé, \& ajoûter même au dehors du fumier de cheval tout chaud, fi l'hiver eft extraordinairement rude.

Les chaffis doivent auffi être doubles ; l'un en dedans, de papier feulement, mais qui en foit colé aux deux côtez de chaque quarré ; \& en dehors, d'un autre de verre fi l'on veut en faire la dépenfe, ou bien encore de papier que l'on huilera comme lautre, tant pour J'éclaircir, que pour le rendre plus chaud \& le faire mienx refifter a la pluie. On peut y mêler par cette mêne raifon, de la cire vierge $\&$ de la terebentine, faifant fondre le tout enfenble avec l'huile; \& pour le plus feur, avoir des contrevents de bois, qui étant plus folides feront mieux à l'épreuve des 
isō

Defcription

injures du tems, faifant ouvrir les uns \& les autres d'une maniere qui ne dérobe point aux Orangers l'afpect des raions du Soleil, quand la faifon le permetrra

La Serre doit être bâtie au commencement de l'Eté, pour avoir bien le tems de fe fecher'; autrement elle eft fort fufceptible de gelée. Le plancher d'en haur doir être couvert de foin ou de paille, s'il ne fert à quelque logement habité ou à quelque gallerie, \& s'il n'eft ceintré fort materiellement, \& couvert encore de beaucoup de rerre; ce que neanmoins je n'afprouve pas rant qu'un plancher de bois, parce que la terre \& la pierre font toûjours plus humides. Il en eft de même du plancher d'enbas; il eft mienx quatil foit de bois que de plâtre, de falpêtre battu, ou de rerre endurcie; à moins qu'on ne voulût faire fervir la Serre dans le tems que les Oranger's font dehors, à quelque femblable ufage que ci-deffus ; à quoi elle n'êt gueres propre, étant dans une 
d'une bonne Serre, o c c. Ift expofition auffi chatude \& aërée qu'orr le peut juger : mais toûjours elle feroit plus fraîche pour cela, aiant le fol de ces dernieres façon's, gu'avec un plancher de bois.

duant à la longueur \& à la largeur de la Serre, chacun petit la regler fuivant fes facultez. Une Serre de quatre toifes de large $\&$. d'une longueur proportionnée, peut affez bien s'accommoder à la portée de toutes fortes de currieux un peu diftinguez, \& doit paffer pour fort belle. Il s'en peur faire de cinq a fix toifes de profondeur, \& même davantage, qui ne feront gueres moins bonnes, pourveu qu'elles foient également hautes \& feches, \& que le froid \& l'hunidité ne les puiffent penetrer ; cir c'eft la l'effentiel, \& l'on ne ŕçuroit trop prendie de foin pour bien munir une Serre contre ces deux inconveniens, puifque de là dépend la confervation des Orangers, Le confeil que l'on peut donner, eft de faire toûjours ce bâtiment de troiswou quatre toifes plus grand 
Isi

qu'on ne fe propofoit; parce que l'amour - pour la culture de ces Arbres, \& le defir d'en avoir beaucoup augmentant infeníblement, il fe trotiveroit en peu de tems trop petit ; outre qu'il fert à renfermer divers autres Arbuftes qu'on éleve en pots ou en caiffes, comme Jaf mins d'Efpagne, Myrtes, LauriersThims, Lauriers - Cerifes, Lentifques, \& même des Plantes potageres que l'on conferve pour l'hiver \& pour le Carême.

Quelque neceffaire que foit une Serre auffi bien conditionnée que celle que nous venons de décrire, peu de gens veulerit, ou peuvent faire la dépenfe d'une telle entreprife. Il eft plus ordinaire de voir convertir à cet ufage des lieux qui ont fervi de falle, d'écurie, de cellier, \& quelquefois de cave, ce quii eft le pire de tous; parce que les lieux bas \& creux comme ces derniers, te peuvent être que fort humides, \& ne font jamais échaufez des raions du Soleil.

Pour les autres, avec unapeu de 
d'une bonne Serre, odc. Is? reparations que l'on y fait, ils peuvent paffer \& fuffire. On doit particulierement faire un bon contremur, ou de maçonnerie ou de fumier, d'un pied d'épaiffeur, \& de route la haureur \& longueur des murailles fufpectes, foit en dedans foit en dehors, fuivant que les lieux le permettront. Si c'eft en dedans, ce ne fera pas un fort grand agrément pour l'cdorat ni pour la vûë, fi l'on ne difpofe les Orangers d'une maniere qui cache aux yeux prefque tout ce funier, corme je dirai dans la fuite qu'on le peut faire. Les rats \& fouris peuvent même y trouver un afile \& metrre au hazard ces Arbres en rongeant leur écorce \& leurs racines : mais il y a plufieurs moiens de les détiuire, foit avec de la pâte preparée pour cet effet, foit avec des fourifferes, ou enfin par le fecours dis chats pour qui l'on peut laiffer une ouverture aux deux portes ; en forte neanmoins qu'elles ne fe répondent pas l'une a l'autre, \& que celle de dedans foit bouchée d'un morceau 
ist Defription

de feutre ou de chapeau qui joigne bien, \& qui n'étant attaché que par le haut, ne laifle pas de donner aux Chats la liberté d'entrer quand ils fe prefentent.

Il n'eft pas impoffible quavec tous ces foins les Orangers ne foient pas encore en feureté du côté du froid; il peur être fi cuifant, \& fe gliffer d'une maniere fi imperceptible, que le dedans de la $S$ erre s'en reffente. Pour connoître quand il y penetre, on met auprés des fenêtres \& fur le bord des caiffes en divers endroits, de petirs linges moitillez, ou de l'eau dans quelque chofe; \& quand on voit que ce linge \& certe eau fe glacent, on doit fans differer tâcher a y rétablir la chaleur, ou par l'ufage du feu de charbon moderé, \& difperfé en plufieurs places dans des terrines; ou par le moicu de ces fourneaux de nouvelle invention dont on fe fert depuis quelques années pour rendre des appartemens auffi chauds qu'un poële, fans en avoir de l'inconmodité; ou enfin de quelquaurre maniere que ce foir. 
d'une bonne Serre, ơc. 15 Je fçai qu'il $y$ a des perfonnes qui n'approutvent pas ce premier expedient, c'eft-à-dire, le feu de charbon, \& qui font de grands raifonnemens pour en bannir l'ufage. Je ne m’arrêtrerai qu'à ce qu'ils alleguent; que ce feu étant placé en bas ne peut agir fur le haut de la tête, ni fur les côtez oppofez, ou que s'il eft ćlevé il ne peut agir lur les branches baffes, ainfi il ne fait que trés-peu de bien.. A quoi joppofe ce dont ils conviennent cux-mêtmes, que ce ne font pas les raions du Soleil frappans directement fur les feuiiltes des Orangers, qui leur font falutaires dans les ferres, parce qué rarement donnent-ils fur la plûpart de celles qui font dans le miliet de la tête, quelque bien expofée qu'elle foir; mais que tout l'avantage vient, de ce que lés raions du Soleil donnant dans la capacité de cette ferre, y détruifent \& en chaffent l'humidité. D'où il eft aifé de tirer contre eux une confequence femblable a l'égard du feu de charbon.

Il me refteroit à parler des moiens 


\section{Ij6 Defription}

de garantir du froid les Orangers en pleine terre, fi l'on n'en trouvoit une idée fuffifante dans ce que nous avons dit de la difpofition des ferres; entre autres dans cette double cloir fon que l'on peut faire au lieu de mur, \& dont on peut remplir l'entre-deux de fumier, élevant de certe maniere une effece de Dôme ou de Pavillon à chaque Oranger, fuivant les autres regles \& conditions qui ont été marquées pour les Serres.

A l'égard des Orangers en $E f p a-$ liers, pour les conferver, il y a plus de facilité qu'on ne penfe: Car comme on n'a à les mettre à l'abri que d'un côté, (à moins que le inur contre lequel ils feroient ne parût pas affez folide; auquel cas il faudroit faire un contre-mur de fumier comme ci-devant, pour vû qu'on fût le maître du côté exterieur, ) il et aifé de fabriquer des volets de planches bien jointes, ou des panneaux de paille bien fournis \& bien ferrez, avec lefquels on les couvrira. Ces Volets ou maniere de Contre-vents, 
20" une bonne Serre, ofc. is ou de Paillaffons, doivent joindre au mur par en haut, \& s'en éloignant par en bas, former comme une petite loge. Ils doivent être attachez de telle forte qu'avec des poulies \& des cordes on puiffe les élever \& abaiffer quand on voudra pour les faire profiter du Soleil. On peut ajoûter à cela du fumier chaud'au pied de l'Arbre, fans neanmoins que cela en touche le tronc; \& lorfque le froid augmente, redoubler la couverture avec des nattes, ou autres femblables chofes. On y fait encore moins de façon dans les Pais chauds; mais il feroit inutile d'en parler ici.

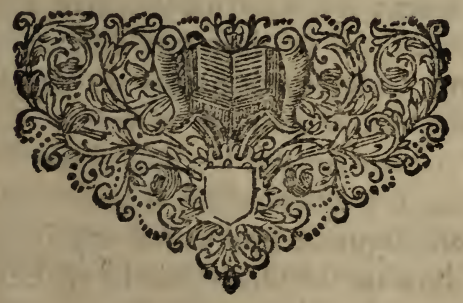


igs Enquel temps on met

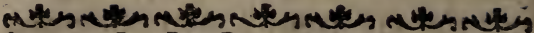

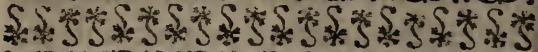

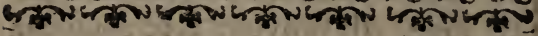

\section{CHAPITRE XIII.}

En quel temps on met les Orangers dans la Serre: Quand on les en tire; \& des foins qu'il en faut prendre dans ces deux conjonilures.

T E mois d'OAtobre eft la faifon Len laquelle on doit fe difpofer à ferrer les Orangers. Comme vers le milieu de ce mois, les nuits commencent ordinairement à être affez froides, on ne doit pas differer de fonger à les mettre hors du danger qu'ils en pourroient recevoir. On peut bien ne pas les renfermer encore, fi la faifon eft fort belle; mais il eft du moins bon de les approcher de la ferrefi l'Orangerie en eft éloignée, afin d'être en état au premier shangement de vent qui annoncera 
les Orangers dans la Serre, efrc. Ifg de la gelée, de les placer commodément \& promptement en lieu de feureté,

On doit auparavant avoir ménagé les labours \& les arrofemens fuivant les regles que j'ai marquées cidevant. Si quelque pluie douce peut furvenir enfuite, elle fert heureufement à laver \& nettoier les feuiilles de la pouffiere qu'elles peuvent avoir contractée dehors. Ce n'eft pas qu'il faille ferrer durant cette pluie; on verroit bien-tôt fi on le faifoir, les feúilles de l'Oranger devenir fales, à caufe de la poudre qui s'y arrêteroit dans la ferre, \& même fe roiiiller \& noircir. Il faut done attendre que le temps foit ferain \& tranquille, \& choifir pour cela quelque beau jour.

L'on f̧cait que pour tranfporter les caiffes mediocres, on fe fert de civieres, ou de gros bâtons qui prer : nent aux quatre pieds avec des cordes, ou qui embraffent le fond des caiffes des detıx côtez avec de bons crochers. Si les Orangers font gros, l'on a un petit chariot fort bas fur 
i6o En quel temps on met

deux rouletres, pour les y charger facilement. C'eft ce qu'on fait en levant une cailfe par l'un des côtez avec des leviers ou barres de bois; \& aiant placé deffous le perit chariot, on acheve de pouffer le refte à force des mêmes leviers; \& deux ou plufieurs hommies conduifent enfuite l'Oranger aì il faur.

Il faut prendie garde de ne pas placer ces Arbres fi prés du mur de la ferre que leurs branches y touchent; parce que dans le dégel, cela pourroit leur être fort nuifible. Il faut laiffer un efpace pour y pouvoir paffer, quand on veut vificer chaque Arbre \& l'arrofer, fi par hazard il étoir necelfaire de le faire, outre le grand \& ample arrofement qu'on leur doit donner aprés qu'on les a ferrez, \& mis en place,

Dans cette fituation on peut fuivant que la ferre eft grande, obferver diverfes difpofitions forr agreables, fe fervant pour cela des autres Arbuftes que l'on cultive, \& qui par la grande varieté de leur verd, mêlée du coloris des fleurs de la fai- 
Tes Orangers dans la Serre, $20.16 \mathrm{t}$ fon qu'on peut ayoir dans des vafes, pour les y ajoûter, formeront enfemble une décoration trés-finguliere. On peut par éxemple les ranger en allee oul loon puiffe fe promener à fon aife au milieu pour joüir de cet ornement: On les range auffi en cercle : ou bien l'on fait un enfoncement, ou une manicre d'amphiteatre, élevant les perits vafes fur des billots, \& même des grands Arbres, afin de cacher autant qu'on peut les murailles, comme on fait auffi tous ces billots par d'autres. Arbres ou caiffes plus baffes; enforte que tout le lieu paroiffe fort rempli \& touffu, quoiqu'on puiffe paffer par tout.

On ne ferme pas fi-tôt les fenêtres de la Serre aprés y avoir mis les. Orangers; il eft bon de les laiffer un peu endurcir à l'air, afin qu'ils foient enfuite moins fenfibles au froid, \& à la privation de la chalenr du Soleil qu' on leur doit retrancher. On s'applique cependant à bien nettoier les Orangers de toutes les ordures de Punaifes ou autres quan. 


\section{$\ulcorner$ En quel tempsion met}

n'a pas eû le temps d'en ôter, \& calfeutrer foigneufement les fenêtres $\&$ les portes; \& quand on voir que la gelée donne, on ferme alors les chaffis pour ne les plus ouvrir qu' aux jours qu'il fait un beau Soleil, fans mêlange de vent, depuis envi. ron dix heures, jufqu'à deux ou trois heures aprés midy.:

C'eft tout ce qu'il y faut faire jufqu'au mois d'Avril que nous avons vû qu'il falloit recomnencer de leur donner quelques arrofemens. On ouvre auffi dans ce remps les fenêtres de la Serre pour accoutumer infenfiblement les Orangers à leur premier train. On ne les fort que vers la my-May-aprés la pleine Lune d'Avril, qui fe trotlve ordinairement. a. quelques jours prés de là. On peut fortir un peu plus-tôt quand la faifon eft douce \&z pluvieufe, \& plustard fi elle eft feche, venteufe \& froide; autrement les gelées blanches qui fe font encare fentir quelquefois, pourroient caufer un trésgrand dommage aux Orangers.

Pour cette raifon, il vaut toûs. 
les Orangers dansla Serre, ofc. 16; jours mieux retarder quavancer, le peril n'en eft pas fi grand. On doir fiu tout fe preffer moins de fortir dans les licux bas, que dans les lieux élevez, parce que le grand air, \& un peude vent qui y regne, $y$ tentdent les gुelées moins dangerenfes \& plus rares, fur-tout dans une faifon déja autant avancée, où les Orangers marquent le defir qu'ils ont $d^{\prime} \hat{c}_{\vec{r}}$ tre mis en liberté par les jets nouveaux qu'ils commencent à pouffer.

S'il y a une place deftinée pour ces Arbres, on les y rangera, foir en Allées, ou en forme de Quinconce, dans une diftance raifonnable, afin que l'on puiffe aifement paffer tout autour, pour en prendre les foins réceffaires durant l'Eté. Que s'il n'y avoit point encore de lieut particulier, \& qu'on pût choifir aux expofitions; celles du Levant\& du Midy font les plus favorables au fortir de la Serre, jufqu'a la fin d'Aouft ; parce que ces expofitions couv rent les Orangers des vents dia

$\mathrm{O}$ ij 
$164 \quad$ Fn quel temps or met

Nord \& de Galerne qui font froids : \& depuis la fin d'Aouft ju'qu'à ce qu'on les remette dans la Serre, celle du Nord les défendra des vents du Mdy \& du Couchant qui fouflen en ce temps-la , \& qui leur font fort incommodes, comme nous l'avons déja touché ailleurs.

Le bel ordre \& la varieté ne font pas moins à fouhaiter dehors que dans les Serres; c'eft pourquoi il eft important de fe les propofer en plaçant les Orangers. Quand ils feront rangez on leur donnera à chacun le grand arrofement que j'ai dir; en fon lieu; \& l'on continuera' par les Labours, la Taille, \& tout le refte, dont il a été parlé jufqu'ici.

Puifque je ne fçache rien autre qui puiffe contribuer à avoir en tour temps des Orangers \& des Citronniers qui foient beaux \& bien fains; je devrois finir en cet endroit, le Traité que j'ai refolu d'en donier au Public. Mais je me fens engazé à parler encore d'un point, qui 
les Orangers dans la Serre, Ec c. $16 g$ quoique hors de ma Profeffion particuliere, me paroît digne de n'y être pas oublié. C'eft l'utilité que l'on retire des Orangers \& des Citronniers, \& l'ufage qu'on peut faire de leurs fleurs \& de leurs fruits. Je ne ferai qu'eflleurer cette matiere; \& je ne m'y arrêterai que fort $p$ i $u$, laiffant à ceux du reffort defquels. elle eft, à s'y étendre plus à fond.

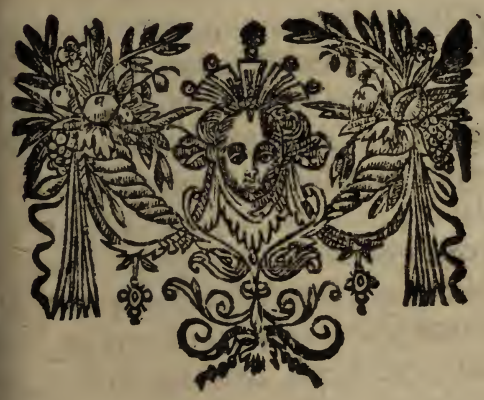

$O$ iij 
r66 De l'utilité quion regoit

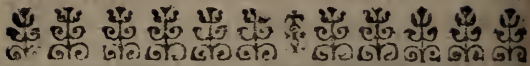

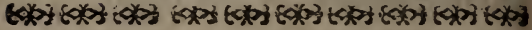

CHAPITRE XIV.

De l'utilité qu'on reçoit des Oran. gers \& Citronniers, dans lia. fage de leurs Fleurs o de leurs Fruits.

CE feroit une ingratitude extréme, ou plûtôt une malice affectée de vouloir nier que les Orangers \& les Citronniers ne foient trésavantageux; non-feulement pour le plaifir, mais auffi pour les befoins mêmes de la vie.

Pour parcourir fuccinctement ces avantages, l'on fçait en premier lieu, que l'eau de fleur d'Orange a plufieurs belles proprietez; entre autres, de chaffer les puanteurs des lieux infects, de ranimer les fens des perfonnes en défaillance, \& de faazer agreablement le goût \& l'odorat $t_{2}$ 
des Orangers, of c. 167 étant répandue fur les Tourtes, $\mathrm{Pa}$ tifferies, Confitures, \& azutres apprêts delicieux.

Le fruit de ces Arbres eft d'une utiliré encore plus étenduë. Il fe marrge crud; on le confit ; \& il fert pour faire des boiffons excellentes.

Les Orangers de la Chine, de Portugal, \& des Indes qui font douces, on aigres-douces, font les meilleures à manger. Les premieres ont un fuc vineux fort agreable. Ceux qui s'entendent en Medecine, tiennent qu'on en peut ufer devant out aprés. le repas ; parce qu'étant plus humides que froides, elles temperent aulfi, aprés la table, un eftomac trop chaud \& trop fec , \& favorifent ainf: la coction des viandes.

Les Oranges ordinaires de Portti gal font plus froides que ces premieres ; aufí rafraichiffent-elles davanrtage, \& s'oppofent plus à la corruption de nos humeurs.

Le jus des Bigarades \& des autres Oranges aigres, donne une pointemerveilleufe aux ragoûts, \& autres; chofes où il eft exprimé. On ne 
16S Delutilisé quion reçoit confeille pas d'ufer de telles Oranges aigres,aprés le repas : Elles empêchent, dit-on, par leur froideur la digeftion de l'eftomac; mais elles font fort propres à éteindre le feu de nôtre foie', \& à nous donner de l'appetit, $f i$ avant que nous metre à table, nous en prenons e fuc avec de l'eau, \& un peu de calfonnade, mais principalement lorfque les grandes chaleurs de l'Eté ou de l'Autom. ne nous épuifent.

Les Malades qui ufent des unes \&z des autres, s'en trouvent fi bien, qu'à les en croire fur l'experience qu'ils en ont faite, il n'y a point de meilleur remede que ces fruits pour éteindre la foif, rafuîchir l'eftomac, remperer le foie, provoquer les urines, combattre larde'r du cour, s'oppofer aux venins internes, en un mot pour guerir les Maladies qui font accompagnées d'une chaleur $\&$ d'une fechereffe infupportable.

Une Orange de la Chine, ou une vineufe de l'ortugal coupée en quatre quartiers, \& jettée dans un pot d'eau avec l'écorce, fait une boiffon 


\section{des Orangers, of $c$.}

qui a toutes ces qualitez. L'ćcorce feule des Oranges aigres exprimée dans le vin, le rend plus agreable, $\&$ le fait paffer plus promtement par les urines.

Quelle n'eft pas encore la vertu rafraîchiffante \&aaperitive des Orangeades, des Limonades, de l'Aigre de Cedre, \& des autres boiflons que l'on fait avec ces fruits ? Si l'on veur en fçavoir la maniere, on peur lire les Délices de la Campagne où on les trouve décrites. Les feiiilles mêmes du Cedrat y font propres, aiant par une proprieté finguliere les mêmes qualitez \& le même goût quele fruit de cet Arbre qui fe mange en Salade, à caufe de fa douceur, auff-bien que beaucoup d'aurres fortes de Citrons.

Quant aux Conficures que l'on fait de ces fritits, la varieté en eft fort grande. On confit des Oranges, ou entieres ou par quartiers comme des Citrons: On fait de la Corferve de Fleurs d'Oranges; de la Conferve d'Oranges mêmes \& de Cirrons ; des Bif́uits \& des Pain 
a $>0$ Del'utilité qu'on reçoit, êc.' de Citrons, 8 plufreurs autres chofes dontion apprend auff la maniere dans le nême Livre, sidan' l'Intruction pour les: Canfitures qu'on a mife au jour depuis peu.

Qưon ajoutce te plaifir qu'il y a de voir des Arbresschargez en toute faifon, de' Feürilles, de IFleurs, \& de Fruits : Et frlion refufe aprés cela de les cherir \& de les cutriver, pour ne s'attacher qu'à des Aubres fruitiers dont le profit eft plus commun, rebutez peut-être par les difficultez qu'il y a dans cette Culture; que l'on compare, avec nous ces difficultez à celles qui regardent ces autres Arbres, \& l'on en jugera fans doute plus fainement.

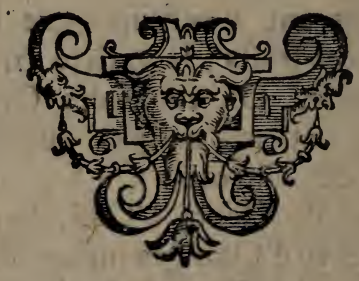




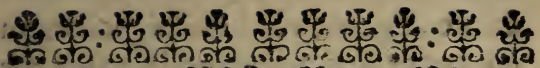

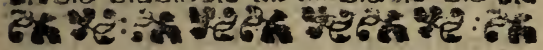

\section{CHAPITRE XV.}

Ia Culture des Orangers \& des Citronniers, comparée avec celle des autres Plantes.

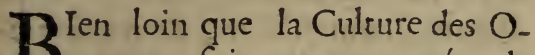
Brangers foit accompagnée de plus de difficultez, on peut dire qu'elle a de plus grands avantages que prefque toutt ce qu'il y a d'autres $A r-$ bres, Arbriffeaux, Arbuftes, \& Plants de chaque genre. Oferoiton en effet confier ceux-ci à autant de nourritures differentes, comme on peut faire les Orangers, élevez fi diverfement en differens endroits, fuivant les Terres \& les ingrediens qu'on a à fa commodité.

Les Amandiers par exemple, \& les Pefchers veulent abfolument des terres feches \& legeres, \& periffent 
172 La Culture des Orangers dans les terres fortes par la furabondance de gomme. Le Coignaffier au contraire ne s'accommode point des terres legeres \& feches, \& y jaunit. Les Pruniers, Grofeillers, \& Merifiers veulent des terres fortes; le Poirier \& la vigne aiment les terres legeres, \& ainfi de la plûpart des autres Plants.

Parmi les Fleurs on eft encore le plus fouvent affujetti au naturel de chacune. L'oillet veut une terre fraîche, nourriflante, \& mediocrement legere. Les terres fablonneufes \& moins fortes font plus propres pour les Tulippes, que celles qui le font davantage, à moins qu'on ne les amande \& foulage avec du terrot de fumier de Cheval bien confommé. L'Anemone veut une terre legere, fortifiée auffi par quelques engrais, mais tres-legers; ceux qui font chauds \& gras, comme la Poudretre \& le fumier de Pigeon, lui ćtant tres-pernicieux. L'Oreille d"Ours aime la fraîcheur $\&$ un peu plus de terre franche que l'Oeillet; $\alpha$ de mêne du refte des Fleurs; tan- 
of des Citronniers, ofoc. 173 dis que l'Oranger vient également bien dans quatre ou cinq fortes de rerres differentes, pourvû qu'on air foin de proportionner là-deffus les autres points de la Culture.

La facilité avec laquelle ils reprennent eft un autre avantage particulier. L'on fçait qu'il n'y a que tres-peu de Plants qui viennent de Bouture \& de Marcotte: prefque tout ce qu'il y a d'Arbres de bonne efpece, paffe par les degrez de Sauvageons \& de Greffes, qui font affez longs à donner du Fruit, quand on commence foi-même par là. Les Orangers \& les Citromniers peuvent bien être élevez de la même maniere quand on n'a pas d'autres moiens d'en avoir, ou qu'on veut exercer fa patience en contentant fa curiofité : Mais l'on a la commodité d'en trouver de tout élevez, \& la fatisfaction de les voir reprendre fort heureufement ; ce qui arriveroit mal.aifement de tout autre Plant qui nous feroit apporté d'auffi loin.

Le fort ordinaire des Vegetaux P iij 
$174 L_{a} C$ ulture des Orangers eft de ne durer que fort peu de temps dans leur perfection. Les Fleurs periffent \& fe fanent prefquauaffi-tôt qu’elles font épanoiiies. Les Plantes Potageres n'ont qu'une faifon fort courte. Les Arbres qui ont un peu plus de force tiennent une partie de l'année, mais ne la paffent pas: Ils fe dépoiiillent aux approches de l'Hyver, \& font obligez de fe repofer pour reprendre haleine. Mais les Orangers fe perpetuent d'année en année. Leur vigueur eft telle qu'ils font toûjours dans l'a. ction. Le Soleil \& les autres fecours va Ciel quils reçoivent en quatre ou cing mois qu'ils font dehors, leur fuffir pour refinter à la revolurions qui fe fait dans le refte de la nature, \& pour vivre beaucoup plus longtemps que ne font pas les autres Plants, principalement les Fruits à noiau.

Que fi l'on confidere les Maladies aufquelles ils font fujets, \& les. foins qu'il faut prendre d'y remedier; y a-t-il Arbre qui en foir éxempt, \& qui ne puiffe même être 
a) den Citranniers, of 6 its attaqué par des Ehnemis 'plis cruels's: par éxemple, les Fraifiers: dont les Tons coupencla racine, les Chenilles les feuilles ; \& le Chancre les decole à fieur de terre. Quel defordre, ne caufene pas quelquefois les Tygres parmi les Poiriers; la Gomme, les Fourmis, \& les Pucerons dans les Pefchers, \& ainfi des. autres.

Je ne repeterai pas ici que la Taille des Orangers \& des Citronniers eft plus heureufe \& plus facile que des Arbres Fruitiers ordinaires. J'ajoûterai feulement qu'il n'y a pour ainfi dire, qu'unè même façon pour les uns \& pour les auttres. Car enfin, on racourcit \& on retaille les racines des autres Arbres avant que de les planter, de la même maniere qu'on le faic aux Orangers qu'on encaiffe. L'ufage eft auffi quand on plante les premiers, de tenir les Terres plus hautes que la fuperficie voifine, furtout lorfque les trous ou tranchées font nouvellement faits, de peur que la terre venant à s'affaiffer, on 
I76 La Culture des Orangers, of c. $n$ 'ait enfuite des Arbres qui foient enfoncez trop avant. De forte que qui s'applique la Culture des Orangers, fe rend capable de celle de tous les autres Plants; \& que qui eft déja fçavant en celle-ci, $s^{\prime} a c$. quite aifement de la premiere, comme ne dépendant que des mêmes notions.

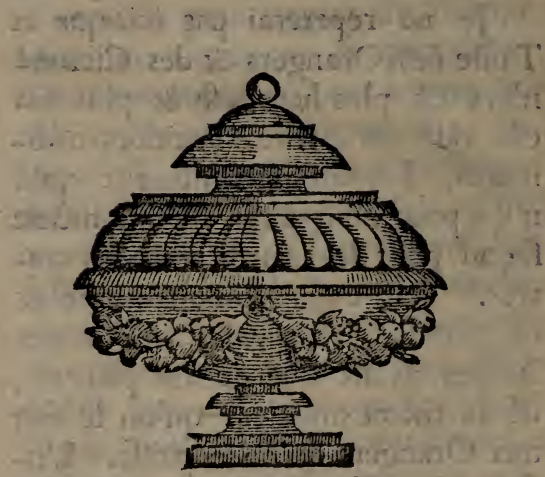




\section{CHAPITRE XVI. '}

Des Grenadiers, Genèts, Fafmins, Lauriers, \& autres Arbuftes qui fervent d'orne. ment aux fardins aprés les Orangers \& les Citronniers.

T'Ajoûterai ici quelque chofe des Jatres Plants dont on embellit ordinairement les Jardins. Je ime fuis étendu beaucoup fur les Orangers, parce que les Traitez qu'on avoit la-deffus n'avoient pas ce me femble affez éclairci une matiere fi curieufe \& fi divertiffante. Comme il y a plus d'Auteurs qui ont écrits des fleurs \& des autres plantes qui entrent dans les parterres, \& que la culture en étant plus conmune, elle eft en même-tems plus connuë, je n'aurai pas befoin d'être fi diffus à l'avenir, ni d'entrer dans d'auffi grands détails. Je remarqque: 


\section{Des Grenadiers, Genêts}

rai feulement ce qu'il y a d'eflentiel, \& ce que je fçai de particulier fur chrque chofe.

Les Arbuftes par lefquels je vais pourfuivre ont cette difference d'avec les Arbres dont nous avons parlé, qu'ils appartiennent plus proprement aux parterres; au lieu que les Orangers \& les Cirronniers font aufi mis au rang de Arbres fruitiers. Il n'y a que les Grenadiers qui psiffent avoir le même rapport, parce qu'il en eft qui porrent da fruir \& les autres non. Parmi ceux-là, les uns donnent leur fruit aigre, les autres doux \& des autres aigres-doux ; on diftingue les Grenades douces, en ce quelles ont la peau \& la couleur plus noirâtre que les aigres qui d'ordinaire fone plus colorés, plus vermeilles \& plus groffes. Le bois des douces eft encore plus épais \& plus en buiffon que celui des aigres qui femble plus dégagé. Les fleurs de ces Grenadiers font fimples ; ainfi c'eft pour leur fruit principalement qu'on les cultive. 
Fufmins, Lauriers, of c. 179
On éleve les Grenadiers avec beaucoup de facilité ; ils reprennent de bouture \& de marcotte; en les couchant en terre comme l'on fait la Vigne \& le liguier : il n'eft pas neceffaire de les greffer fi l'on ne veut. On le fait en fente \& en écuffon aux faifons ordinaires, \& l'on y remarque un goût plus agreable dans leur fruit, quand. on greffe un Grenadier doux fur un qui foit aigre. Pour avoir des Grenades plus groffes \& plus colorées, il faut les planter en Efpalier contre les murailles, \& les paliffer. II faut fe garder de les tondre: ils. veulent eftre taillez tous les ans. Les Grenadiers s'accommodent affez de toute expoiition : celle du Midi leur eft neanmoins plus favorable.

Les gelées de l'hiver font ce qu'il $\mathrm{y}$ a de plus à craindre pour ces Arbres. Pour les en garantir, on met quatre ou cinq pouces épais de grand fumier au pied, \& trois pieds de large. Ce fumier empêche les racines de reffentir la rim 
¿So Des Grenadiers, Genêts', gueur du froid, \& conferve en nếme-tems le bois : on peut y ajoûter des paillaffons. On en éleve dans des caiffes pour les mettre encore plus à l'abri en les ferrant avec les Orangers, mais il faut les placer féparement dans la Serre; aurrement leur figure dépoüillée dépare un peu le refte de la decoration.

Si les Grenadiers coulent \& ne confervent pas leur fruit, il faut croire que cela provient de trop de fechereffe dans la terre; c'eft pourquoi il faudra les arrofer, \& l'on verra que les fleurs noüeront.

Les Grenades aigres qui nous viennent d'ECpagne font meilleures que celles que nous cultivons pour l'ufage des malades; càr l'on fçair que ce fruit eft tres. falutaire pour plufieurs indifpolitions. La fleur \& l'écorce en font aftringentes, \& fervent l'une \& l'autre à nous foulager dans les maix qui nous font caufez par une trop grande humidité. Le dedans des grains de la Grenade eft inurile \& indigette; 
Fafmins, Lauriers, $\mathbb{F}_{6} . \quad 181$ il n'y a que la chair qui eft autour des grains qui rende un fuc agreable. Ceux qui voudront fçavoir les ufage des unes \& des autres, \& les proprietez qu'elles ont, le trouveront dans la feconde partie de l'Art de tailler les Arbres fruitiers dont nous avons fait mention; cette feconde partie traite de l'ufage des fruirs pour fe conferver en fanté, ou pour fe guerir lorfqu'on eft malade. Comme l'Aureur eft un Medecin, on peut bien s'en rapporter à luy, voiant qu'il en parle d'une maniere fi judicieufe.

Les Grenadiers à fleur, c'eft-àdire qui l'ont double, \& qui ne donnent point de fruit, fe gouvernent \& s'élévent comme les precedens. Leur fleur eft fi vermeille \& fi remplie, qu'elle lui fait meriter d'être mife au rang des plus belles plantes ; elle dure depuis le mois de Mai jufqu'au mois d'Août. On en fair des paliffades $\&$ des efpaliers, auffi - bien que des Grenadiers à fruit. Ils veulent une bonne terre, gralle \& hamide 
iriz Des Grenadiers, Genêts, \& du Soleil mediocrement.

Le Genêt blanc n'auroir pas ici fon rang, fi nous ne fuivions l'ordre de l'alphaber, pour ne point faire de jaloufie dans la grande contention quil y a entre certaines fleurs pour avoir la preference fur les autres. C'eft un Arbriffeau qui s'éléve fort haut \& fort proprement. Il pouffe plufieurs branches defquelles il s'éleve une grande quantité de petits brins delicats \& pointus qui s'étendent jufqu’à la hauteur d'un pied \& demi ; \& ces brins jettent de petites feüilles faites à peu prés comme celles de la Rhü̈, \& des fleurs en abondance. Elles font rouges par le fond, \& blanches à l'égard du refte, \& comme elles font atrachées de prés aux branches, elles femblent autant de perles deftinées pour leur ornement.

Pour cultiver cette forte de $\mathrm{Ge}$ nêt, il ne faut qu'une bonne Terre à potager \& du Soleil moderément. On en éleve de graine ; \& patce qu'elle a l'écorce dure, 
Fafmins, Lauriers, $\& c . \quad 1 \$_{3}$ on la concaffe legerement, \& on la niet un peu tremper avant que de la femer, de-même que les autres graines de cette nature.

Le Jarmin que nous appellons d'Efpagne n'en eft pas toûjours ; il en vient beaucoup plus de Provence \& de Gennes à caufe de la proximité. Les Jardiniers même d'Orleans en élevent beaucoup à prefent, \& on peut avoir ailleurs la même facilité, puifqu'ils fe greffent en fente fur du Jafmin commun, lequel tout le monde fçait faire venir de bouture \& de marcotte fort heureufement.

Les Jafmins d'Efpagne s'élevent d'ordinaire dans des pots ou caiffes pour avoir la commodité de les ferrer pendant l'hiver. Sil'on vouloit en mettre en pleine terre le long de quelque mur au Levant ous au Midi, on le gouverneroit comme de la vigne; \& aux approches du froid, il faudroir l'abatre doucement contre terre, \& le couvrir de paillaffons \& de grand fumier. On taille tous les ans les Jafmins 
184 Des Grenadiers, Genêts, au fortir de l'hiver, prés de la greffe, ne laiffant qu'un cil à chaque brin pour produire les nouveaux jets qui donneront les fleurs. On forme l'Arbre comme une perite tête d'ofier, lui lailfant un pied de hauteur en fa tige.

Les Jafimins en pors ou en caifles fuivent les Orangers dans la Serre de huit ou quinze jours felon la faifon, \& les precedent d'autant à la fortie. Ceux qui font en plein air fe trouveront bien, fi aux heures qu'il fait un beau Soleil pendant l'hiver on les découvre de leurs paillaffons ou nattes, pour les en faire joiiir comme on fair aux Arbres \& Arbultes qu'on ferre.

Les Jafmins communs n'ont pas befoin de tant de foins : ils viennenit en toutes expofitions.

L'odeur agreable de la fleur des $J$ afimins d'Efpagne ne le cede gueres à celle des Orangers; quelques-uns même l'aiment davantage, à caufe qu'elle a je ne fçai quoi de plus doux \& de plus flateur.

Il y a encore le Jalmin de Cata. logne, 
Fafmins, Lawicrs, of 185 . logne, d'A rabie, des Indes \& d'Amerique : on en trouve la Defcription \& la Culture dans un Traitć pour la Culture des Fleurs, imprimé chez le même Libraire que celui-ci, qui eft fort urile à ceux qui s’appliquent à cette aimabie occupation.

Les Lauriers fe diftinguent en Lauriers - Thims, Lauriers - Cerifes , Lauriers - Rofes \& Lauriers francs ; les Lauriers-R ofe font ceux qui font un effer le moins agreable dans la Serre, à caufe de leurs feiiilles pointuës \& grifatres. L'Eté leurs fleurs augmentent confiderablement leur ornement \& leur beauté. Il y en a de blanches \& d'incarnat. Tous ces Lauriers fe marcottent, ou provignent. Il faut le faire un peu auparavant la féve du mois d'Aouft, \& fendre pour cela le bois que l'on met en rerre à l'endroit d'un noud, jufqu'à la moirié de la groffeur de la branche, \& environ trois ou quatre doigrs de longueur fuivant gu'elle eft forte; en fix femaines le

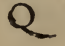




\section{Des Grenadiers, Genêts;}

chevelu eft fuffifant pour fevret la branche \& la tranfplanter féparément.

Les Lauriers francs fe fement de graines dans des caiffes comme les Orangers, \& fe replantent dés la premiere ou feconde année.

On prend à peu prés les mêmes foins pour les uns \& les autres que pour ces derniers ; \& comme ils font même moins agiffans quoiqu'ils confervent leur verd, on doit être encore plus circonfpect à les arrofer dans la Serre, que pour les Orangers; les frequens arrofemens leur gâtant les racines.

Les Mirthes marquent quelquefois le befoin quils en ont par des feüilles fanées; il y a le commun \& le double qui ont leurs. feüilles femblables : mais le dernier eft fi fecond qu'il fleurit prefque toute l'année. Ils fe provignent comme les Arburtes precedens, \& demandent la même culture.

Aprés eux viennent l'Althea-Erito 
Fafmins, Lauriers, ofc. 187 tex, l'Arbre de Judée, les Lilâs, tant l'ordinaire que celui de Perfe ; les Chevre-feuiilles, le Sureau, l'Alaterne, les Rofiers de toutes efpeces, le Frenle jaune, \& divers autres Arbuftes. Comme ils font tres-faciles à gouverner \& élever, je ne m'y arrêterai pas, renvoiant ceux qui pourroient n'en être pas infruits au Traité dont j'ai fait mention, \& à divers Auteurs quii ont écrit fur ces Matieres.

\section{F IN.}




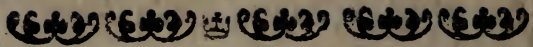

\section{TABLE}

DESPRINCIPALES matieres contenuës dans ce Livre.

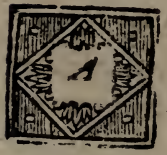

Runftes differens pour les Parterres, page 177. Arrofemens des Orangers \& Citronniers dans leur naiffance,

Arrofemens necellaires à ceux qui font grands,

A quoi on connoît le bəfoin qu'ils en ont,

Les retrancher dans la Serre, \& pendant l'hiver, Maniere de les faire, 106.108 $S$ 'il faut arrofer le matin ou le foir, 107

Avantages qu'on reçoit de la culture des Orangers \& Citron. 166 Buture, Maniere d'avoir des O. B rang.\& Cit.par cette voie, 14.15 En quel tems de la Lune on le fait, Iy CAijJes où l'on éleve les Orangers \& Citronniers, leur conftruction, 


\section{DES MATIERES.}

Choix des Orangers \& Citronniers qu'on achete,

32

Conditions qu'ils doivent avoir, 34.35 Citronniers, A quoi on les diftingure des Orangers,

Pourquoi on leur doit laiffer plus de bois qu'à ceux-ci,

127

Efpeces \& qualitez differentes des Cirrons,

IO. II

Cire pour la Taille des Orangers \& Citronniers,

133

Culture de ces Arbres comparée avec celle des autres,

171

Dmi-Rencaiffemens, Quand ils font necelfaires,

Deffein \& divifion de $1^{3}$ Aureur 8s

$\rightarrow$ Bourgeonnement des Orangers,

I. Quelle operation, \& comment elle fe fait, 118.119 .8132 EcufJon, Ce qu'on appelle ainfi dans les Greffes,

Encaißemens des Orangers, ce qu'on y doit obferver,

HEu de charbon, s'il peut fervir ou - nuire aux Orangers dans la Serre,

Iss

Figure propreaux Orang. \& Cit.iry Fleurs d'Orange, 


\section{$T A B L E$}

Fleurs de Limoniers \& Citron. 12 j Quelles on doit laiffer pour noïer, tà même, \& 126

Froid, moien pour connoître quand il penetre dans les Serres,

Comment en garantir les Orangers en Efpalier, \& en pleine terre, 156 Enêt d'Épagne, $\quad{ }_{182}$ IG Graines d'Orang. \& Citron. II Greffes qui conviennent à ces $\mathrm{Ar}$ bres,

Greffe en approche, là-même. Greffe à éculfon à ceil dormant, 23 En quel tems greffer, $22 . \& 28$ Grinadiers, leurs efpeces, \& la ma-. niere de les gouverner,

$1>8$

T Afmin: d'Elpagne \& autres, com-

J ment les connoître \& les élever,

Infectes contraires aux Orangers, 136. \& fuiv.

T Abours neceffaires atrx Oran1 gers \& Citronniers,90. Juiv. Lawizers. Rofes, \& autres, $18 \mathrm{~s}$ M Arcottes d'Orang. \& Citron. I comment elles fe font, 16.17 Quel tems de la Lune y eft propre, I\& Marc de vigne, s'il ent bon ou nui- 
DES MATIERES.

fible aux Orangers \& Citron. 43 Mirthes, leur culture, $\quad 186$ Ranges, leurs efpeces differentes \& leurs qualitez, 9. \& 10 Leur maturité,

$O$ cangers en pleine terre

Orangers en buiffon,

Orangers en Efpalier,

128

Orangers à haute tige,

55

Maniere de planter ceux qui font apportez de dehors,

II2

II 3

II 4

36

D Epinieres d Orangers \& Citron-

niers,

12

Comment on en peut élever de pepins,

12

Quels pepins profitent davantage, 19. 20

Pincement des Orangers, quelle operation c'eft, \& fon utilité, 117.123 En quel tems on la fait, 119.120 Pouffe des Orangers, là-même. $\mathrm{D}$ Avalement neceffaire aux $\mathrm{O}$ IL rangers malades, $\quad 128$ Rencaißemens des Orangers \& $\mathrm{Ci}$ tronniers,

75.76

Ce qu'on y doit obferver, 79 . \& 128 Rondeur propre aux têtes d'Orangers, 


\section{TABLE DES MATIERES.}

$S$ Auvageons d'Orang. \& Cittron.

$S$ comment on les gouverne, 13 Sur lefquels on peut greffer en changeant d'efpece,
Serres pour les Orangers, leur conftruction,

Quels autres bâtimens on y peut fubftituer,

Is 2

En quel tems on y doit renfermer ces Arbres, \& ce qu'il faut obferver alors,

Quand on les en doit fortir, $\quad 162$ Séve, de quoi elle fe forme, $\quad 97$ T Aille des Orang. \& Citron. In 1 Pourquoi on taille, $112 . \& 122$ Ce qu'on y doit obferver, $\quad 114$ Quel en eft le tems, $\quad 120.134$ Combien elle eft utile \& heureufe, 121 Terres propres aux Orangers \& $\mathrm{Ci}-$ tronniers, 42 \& fuiv. Tranport de ces Arbres des Païs. trangers, queis foins il demande, 33 Supercherie qu'on y fait à certe occafion,

TT Afes, leur ufge pour eleve 34 des Orangers, $\sigma_{2}$

Fin de la Table des Matieres. 


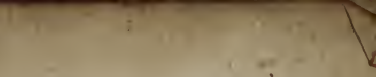






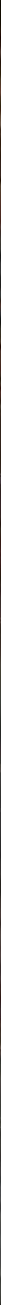




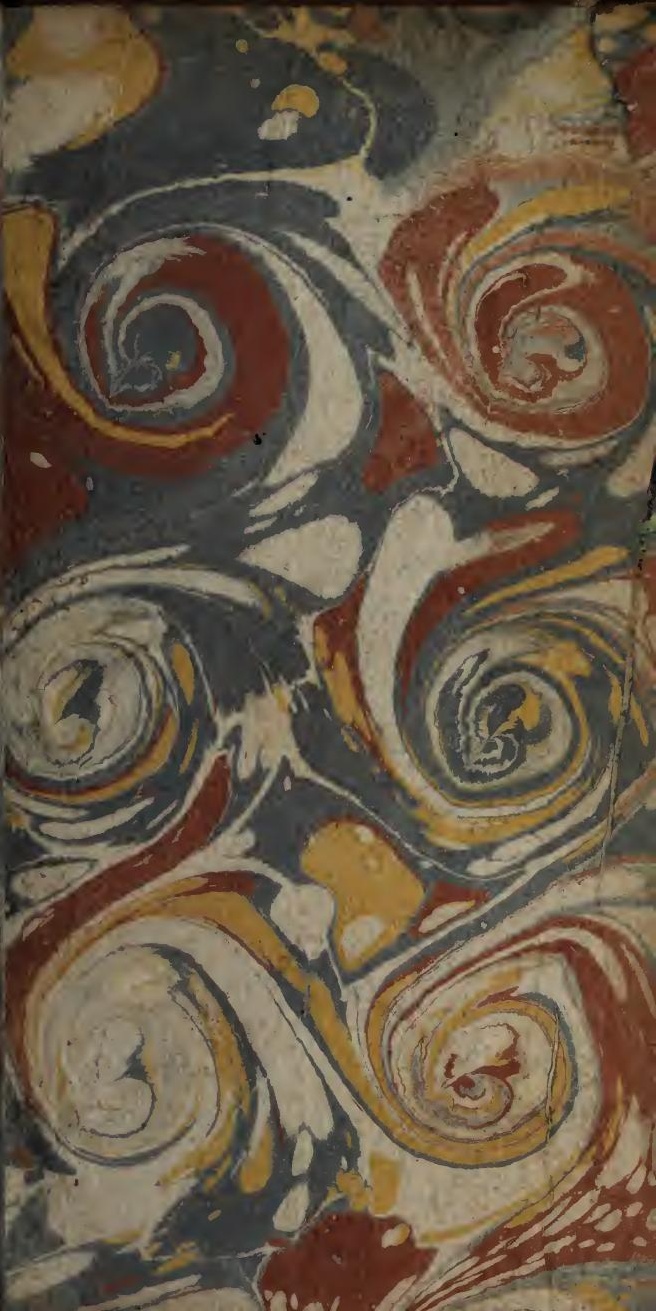


